\title{
Accounts
}

\section{Thirty Six Years of Research on the Selective Reduction and Hydroboration}

\author{
Jin Soon Cha \\ Department of Chemistry, Yeungnam University, Gyongsan 712-749, Korea. *E-mail: jscha@yu.ac.kr \\ Received February 24, 2011, Accepted March 9, 2011
}

\begin{abstract}
From 1975 to 2011, for thirty six years, the author and his collaborators have developed a variety of reducing and hydroborating agents, and applied them to organic synthesis, which involves the 1,2-reduction of $\alpha, \beta$ unsaturated carbonyl compounds, stereoselective reduction of cycloalkanones, regioselective ring-opening of epoxides, partial reduction of carboxylic acid derivatives to aldehydes, regioselective addition to carbon-carbon multiple bonds, etc. by utilizing metal hydrides and the newly-devised the Meerwein-Ponndorf-Verley (MPV) type reagents. Such developments provide a new synthetic methodology making possible valuable selective reductions and hydroborations, not practical previously.
\end{abstract}

Key Words : Reducing and hydroborating agents, Organic functional groups, Aluminum and boron reagents, MPV type reagent, Selective reduction and hydroboration

\section{Introduction}

Thirty four years ago, there appeared in the January 1977 issue of the Journal of the Korean Chemical Society a publication, "Selective Reduction with Lithium Borohydride. Reaction of Lithium Borohydride with Selected Organic Compounds Containing Representative Functional Groups," which reports the first systematic study of lithium borohydride on its reducing characteristics in the reduction of organic functional groups. ${ }^{1}$ Since then, some two hundred papers on the development of metal hydride systems and their applications for the reduction of organic functionalities and for the hydroboration of carbon-carbon multiple bonds have been published in the journals, by the author and his coworkers. It appears desirable to overview the research developments which have been carried out from the year of 1975 until his retirement in 2011, for thirty six years, because reduction or hydroboration is usually one of the major reaction steps of choice for organic synthesis.

In 1979, Professor Brown and Krishnamurthy published a review ${ }^{2}$ titled "Forty Years of Hydride Reduction", which reports the research developments from the original observation on the hydride reduction in $1979 .{ }^{3}$ Accordingly, a part of this account (i.e., the area of reduction) seems to get joined

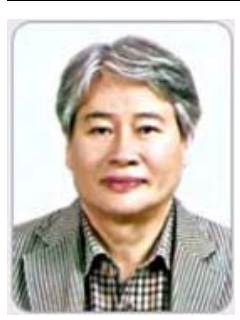

Professor Jin Soon Cha was born in Myungchun, Hamkyungbukdo, Korea on the 11th of June, 1946. He received his Ph.D from Sogang University in 1979 under the guidance of Professor Nung Min Yoon. He became an assistant Professor at Yeungnam University in 1980 and promoted to a full Professor of Chemistry in 1988. He worked with Professor Herbert C. Brown (Nobel Laureate in Chemistry for 1979) as a research associate for three years (19821984, 1989-1990) at Purdue University, and served as a visiting profes- on the review, and has covered the developments for the next thirty six years.

This account has attempted to focus on the selective transformation of organic functional groups via reduction and hydroboration, such as 1,2-reduction of $\alpha, \beta$-unsaturated carbonyl compounds, stereoselective reduction of cycloalkanones, regioselective ring-opening of epoxides, partial reduction of carboxylic acid derivatives to aldehydes, regioselective addition to carbon-carbon multiple bonds, etc., in order to provide useful informations where chemists can choose a proper reducing or hydroborating system readily for their own purpose.

The author has paid attention mainly to the developments published in the journals by the author and his collaborators. So, almost the related references are omitted. If necessary, see the references cited therein.

\section{Development of Various Hydride Reagents and Their Application in Organic Synthesis}

For defining the reducing characteristics of each new reagent, its reactivity was determined towards a group of 5060 representative organic compounds containing common functional groups of interest in reductions. The reactions

sor at Hokkaido University (Professor A. Suzuki, 1986, Nobel Laureate in Chemistry for 2010) and Wales University (Professor A. Pelter, 1996). He also served as Vice President of General Affairs (2003) and President (2007) of the Korean Chemical Society. He is scheduled to retire from Yeungnam University at the end of August, 2011. His major research interest centers on the development of new reducing and hydroborating systems utilizing aluminum and boron metals and the application to the selective transformation of organic functional groups. He has contributed two hundred and eight research articles to the Journals. 
were carried out under standard conditions (usually THF solvent, $0{ }^{\circ} \mathrm{C}$ ). Normally, four equivalents of hydride per mole of the functional group was employed. The solutions were permitted to stand for varying intervals of time, and then aliquots were analyzed for residual hydride. In this way it is able to define the approximate rate and stoichiometry of the reaction. Such an exploratory study conducted under standard reaction conditions gave us an insight into the possible areas of application for the new reagent. this was usually followed by detailed exploration of the new reagent for the specific transformation(s).

Lithium Borohydride. The addition of an equivalent quantity of lithium chloride to an one molar sodium borohydride suspended in THF and refluxing the mixture for 3-4 days results in the formation of a precipitate of sodium chloride and the in situ formation of lithium borohydride. ${ }^{1}$ The reduction characteristics of supernatant clear THF solution of lithium borohydride at $0{ }^{\circ} \mathrm{C}$ are summarized as follows:

$$
\begin{aligned}
\text { aldehyde } & \rightarrow \text { alcohol (fast) } \\
\text { ketone } & \rightarrow \text { alcohol (fast) } \\
\text { acid chloride } & \rightarrow \text { alcohol (fast) } \\
\text { lactone } & \rightarrow \text { glycol (slowly) } \\
\text { epoxide } & \rightarrow \text { alcohol (slowly) } \\
\text { ester } & \rightarrow \text { alcohol (slowly) } \\
\text { carboxylic acid } & \rightarrow \text { no reduction } \\
\text { amide } & \rightarrow \text { no reaction } \\
\text { nitrile } & \rightarrow \text { no reaction } \\
\text { nitro compound } & \rightarrow \text { reaction } \\
\text { sulfur compound } & \rightarrow \text { no reaction }
\end{aligned}
$$

The reagent, however, at room temperature can reduce carboxylic acids to alcohols slowly, ${ }^{4}$ and in the presence of triethylborane reduces epoxides at a dramatically accelerated rate. ${ }^{5}$ The stereoselectivity in the reduction of alicyclic ketones is also increased by addition of tri-s-butylborane to the solution of lithium borohydride: the ratio of the thermodynamically less stable isomer increases much more than the case of lithium borohydride alone. ${ }^{6}$

Borane-lithium Chloride System. The addition of an equivalent quantity of lithium chloride to an one molar solution of borane in THF equilibrates with lithium chloroborohydride as in the Eq. (1).

$$
\mathrm{BH}_{3}+\mathrm{LiCl} \rightleftharpoons \mathrm{LiBH}_{3} \mathrm{Cl}
$$

The reducing characteristics of the system in THF show remarkable contrast to that of borane itself. The selectivity as well as the rate enhancement is realized in the reduction of carbonyl compounds, acid chloride and epoxides even in the presence of 0.1 equivalent of lithium chloride. Especially noteworthy is the reduction of epoxides such as 1,2-butylene oxide, styrene oxide and cyclohexene oxide: the reduction is completed less than $2 \mathrm{~h}$ at $0{ }^{\circ} \mathrm{C}$, a much faster rate compared to that with borane itself which requires 3-4 days for completion $^{7}$ (Eq. 2). The chemoselectivity between equimolar mixture of two structurally different carbonyl compounds is also remarkably enhanced ${ }^{8}$ (Eq. 3). Such a selectivity and rate enhancement are believed to the combination result exerted from borane and chloroborohydride species in the reaction mixture, namely the borane coordination to oxygen and the hydride attack by the chloroborohydride on the borane adduct.

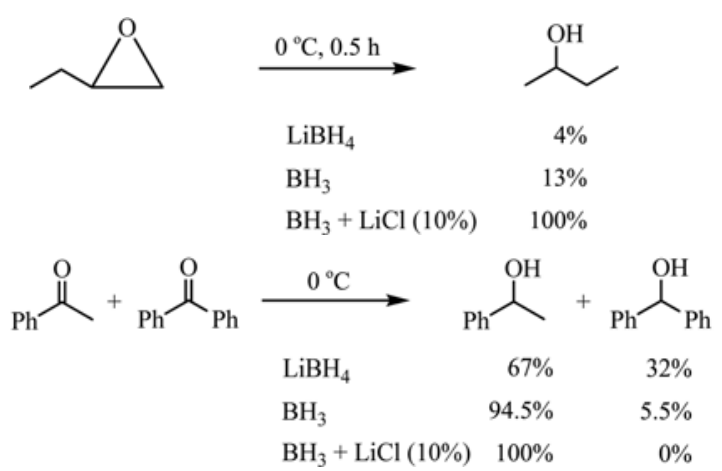

Di-s-butoxyborane. Generally, primary, straight-chain dialkoxyboranes undergo slow redistribution to give a mixture of borane and trialkoxyborane. However, di-s-butoxyborane, prepared from the reaction of borane -methyl sulfide (BMS) and two equivalents of $s$-butyl alcohol (Eq. 4) is quite stable at least for 5 days at room temperature (this period is our primary concern for the reduction of organic compounds). ${ }^{9}$

$$
2 s-\mathrm{BuOH}+\mathrm{BH}_{3} \cdot \mathrm{SM}_{2} \longrightarrow(s-\mathrm{BuO})_{2} \mathrm{BH}+2 \mathrm{H}_{2} \uparrow
$$

The general reducing characteristics of the reagent are also explored systematically in THF at room temperature. The reagent is extremely mild, showing only the reactivity toward simple aldehydes: almost all other reducible organic functional groups including alcohol function are essentially inert. However, the addition of a small quantity of lithium tetra-sbotoxyborate enhances the rate of reduction of aldehydes, ketones, anhydrides, acid chlorides, lactones, and epoxides. This catalytic effect is assumed due to in situ formation of lithium trialkoxyborohydride via disproportionation as in Eq. (5).

$$
\begin{aligned}
& \mathrm{Li}(\mathrm{RO})_{4} \mathrm{~B}+(\mathrm{RO})_{2} \mathrm{BH} \rightleftharpoons(\mathrm{RO})_{3} \mathrm{~B}+\mathrm{Li}(\mathrm{RO})_{3} \mathrm{BH} \\
& \mathrm{Li}(\mathrm{RO})_{3} \mathrm{BH}+\mathrm{R}^{\prime} 2 \mathrm{CO} \longrightarrow \mathrm{Li}\left(\mathrm{R}^{\prime} \mathrm{O}\right)(\mathrm{RO})_{3} \mathrm{~B} \\
& \mathrm{Li}\left(\mathrm{R}^{\prime} \mathrm{O}\right)(\mathrm{RO})_{3} \mathrm{~B}+(\mathrm{RO})_{2} \mathrm{BH} \rightleftharpoons(\mathrm{RO})_{3} \mathrm{~B}+\mathrm{Li}(\mathrm{RO})_{3} \mathrm{BH}
\end{aligned}
$$

2,2'-Biphenoxyborane. As catecholborane (1,3,2-benzodioxaborole), 2,2'-biphenoxyborane (1,3,2-biphenyldioxaborepin) can be readily prepared by the reaction of 2,2'biphenol and borane in THF at $-10{ }^{\circ} \mathrm{C}$ (Eq. 6) and this dialkoxyborane is very stable, similar to that of catecholborane. In order to utilize this reagent as a hydroborating and

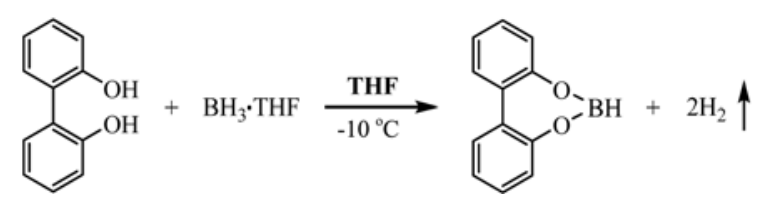

reducing agent, we examined its reducing characteristics toward representative organic functional groups under standardized conditions..$^{10}$ The reducing power appears to be 
much stronger than that of other dialkoxyboranes, such as catecholborane and di-s-butoxyborane. The reagent reduces aldehydes, ketones, quinones, lactones, tertiary amides and sulfoxides readily. Carboxylic acids, anhydrides, esters and nitriles are also reduced slowly. However, the reactions of acid chlorides, epoxides, primary amides, nitro compounds and disulfides with reagent proceed on sluggishly.

Thexylhaloboranes. Thexylhaloborane-methyl sulfide (ThxBHX.SMe $\mathbf{S}_{2}, \mathrm{X}=\mathrm{Cl}, \mathrm{Br}, \mathrm{I}$ ) is conveniently prepared by a simple addition of 2,3-dimethyl-2-butene to the corresponding monohaloborane-methyl sulfide in methylene chloride (Eq. 7).

$$
\rangle\left\langle\left\langle\mathrm{BH}_{2} \mathrm{X} \cdot \mathrm{SMe}_{2} \frac{\mathrm{CH}_{2} \mathrm{Cl}_{2}}{-10 \rightarrow 25^{\circ} \mathrm{C}}\right\rangle \underset{(\mathrm{X}=\mathrm{Cl}, \mathrm{Br}, \mathrm{I})}{-\mathrm{BHX}_{2}}\right.
$$

Originally, thexylchloroborane-methyl sulfide (ThxBHCl-

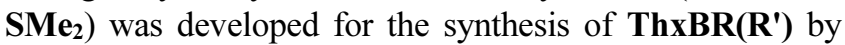
stepwise hydroboration with different alkenes through hydridation of chlorine atom, which is then applied to the synthesis of unsymmetrical ketones. Soon after, the reagent is found to be an excellent reducing agent for the direct conversion of carboxylic acids to the corresponding aldehydes. $^{11,12}$ The slow addition of $10 \%$ excess reagent $(2.2$ equiv) to one equivalent of compound in methylene chloride at $0{ }^{\circ} \mathrm{C}$ for the hydrogen evolution stage, followed by reduction at room temperature, is optimum for the reduction to aldehyde. Generally, the yields of aromatic series are lower than those in the aliphatic series. Examining the results for the aromatic series more closely, a significant influence of substituents upon the yield appears to exist. However, in the case of aliphatic compounds, it appears that the yields of aldehydes are almost quantitative, with no observable dependence on the structure of the acid. Even the aliphatic dicarboxylic acids are reduced to the corresponding dialdehydes in essentially quantitative yields ${ }^{12,13}$ (Eq. 8).

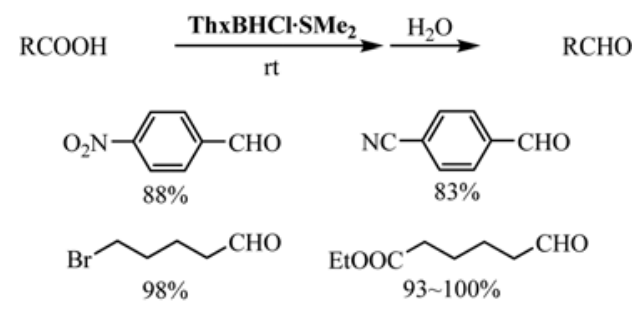

The reduction of aliphatic carboxylic acids is much faster than the reduction of aromatic carboxylic acids. The former reduction is complete within $15 \mathrm{~min}$, whereas, the latter requires some $24 \mathrm{~h}$, both at room temperature. The remarkable difference in the rate of reduction of aliphatic and aromatic carboxylic acids suggests the possibility of achieving the selective reduction of aliphatic carboxylic acids in the presence of aromatic carboxylic acids under preparative conditions. Indeed, it is possible to achieve up to $92-93 \%$ reduction of aliphatic carboxylic acids in mixtures with benzoic acid, with only minor reduction of the benzoic acid (Eq. 9).

$$
\begin{gathered}
\mathrm{CH}_{3}\left(\mathrm{CH}_{2}\right)_{3} \mathrm{CH}_{2} \mathrm{COOH}+\mathrm{PhCOOH} \underset{\mathrm{rt}}{\longrightarrow} \\
\mathrm{CH}_{3}\left(\mathrm{CH}_{2}\right)_{3} \mathrm{CH}_{2} \mathrm{CHO}+ \\
92 \%
\end{gathered}
$$

The approximate rate and stoichiometry of the reaction of excess ThxBHCl-SMe 2 with 56 selected organic compounds containing representative functional groups under standard conditions (methylene chloride, $0{ }^{\circ} \mathrm{C}$ ) are investigated, and the selectivity of the reagent is also compared to those of borane and thexylborane $(\mathbf{T h x B H})$ both in $\mathbf{T H F}{ }^{13}$ The results are summarized as follows:

$$
\begin{aligned}
\text { aldehyde } & \rightarrow \text { alcohol (fast) } \\
\text { ketone } & \rightarrow \text { alcohol (fast) } \\
\text { carboxylic acid } & \rightarrow \text { aldehyde } \\
\text { acid chloride } & \rightarrow \text { alcohol (very slow) } \\
\text { ester } & \rightarrow \text { no reaction } \\
\text { epoxide } & \rightarrow \text { no reaction } \\
\text { amide } & \rightarrow \text { reaction (slow) } \\
\text { nitrile } & \rightarrow \text { amine (slow) } \\
\text { nitro compound } & \rightarrow \text { reaction (slow) } \\
\text { sulfoxide } & \rightarrow \text { sulfide (very fast) } \\
\text { other sulfur compound } & \rightarrow \text { no reaction } \\
\text { alkene } & \rightarrow \text { organoborane }
\end{aligned}
$$

Generally, the reagent appears to be very mild reducing agent: it can reduce only carbonyl compounds, carboxylic acids and sulfoxides effectively. It is interesting to note that this reagent shows a high reactivity toward sulfoxides among various sulfur compounds examined. ${ }^{14}$ In fact, the reagent reduces various sulfoxides to the corresponding sulfides in almost quantitative yields in less than $10 \mathrm{~min}$ at $0{ }^{\circ} \mathrm{C}$ (Eq. 10). Furthermore, the reagent reduces sulfoxides selectively in the presence of other readily reducible compounds, such as acid chlorides, esters, epoxides and amides. For example, in the reaction of equimolar mixture of di- $n$-butyl sulfoxide and caproyl chloride, only the sulfoxide is reduced to di- $n$ butyl sulfide ( $98 \%$ yield) and almost the starting acid chloride is recovered unattacked (Eq. 11).

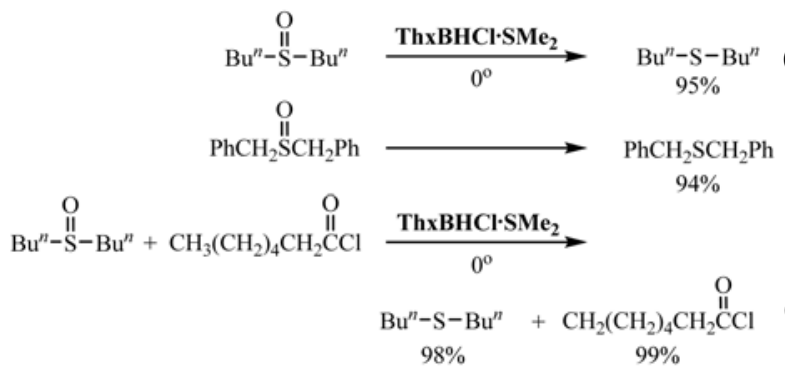

Similarly, the general reducing characteristics of thexylbromoborane-methyl sulfide (ThxBHBr$\cdot \mathbf{S M e})^{15}$ are also examined and the results are summarized as follows:

$$
\begin{aligned}
\text { aldehyde } & \rightarrow \text { alcohol (fast) } \\
\text { ketone } & \rightarrow \text { alcohol (fast) } \\
\text { carboxylic acid } & \rightarrow \text { aldehyde } \\
\text { acid chloride } & \rightarrow \text { alcohol (very slow) } \\
\text { ester } & \rightarrow \text { no reaction }
\end{aligned}
$$




$$
\begin{aligned}
\text { epoxide } & \rightarrow \text { no reaction } \\
\text { amide } & \rightarrow \text { reaction (slow) } \\
\text { nitrile } & \rightarrow \text { amine (slow) } \\
\text { nitro compound } & \rightarrow \text { reaction (slow) } \\
\text { sulfoxide } & \rightarrow \text { sulfide (very fast) } \\
\text { other sulfur compound } & \rightarrow \text { no reaction } \\
\text { alkene } & \rightarrow \text { no reaction }
\end{aligned}
$$

Generally, the reactivity of $\mathbf{T h x B H B r} \cdot \mathrm{SMe}_{2}$ toward organic functional groups are milder than those of ThxBHCl-SMe, but the reducing characteristics of the reagent are quite

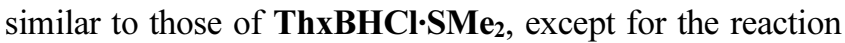
of olefins and nitriles: simple olefins are resistant to hydroboration with the reagent, whereas the chloro-derivative readily hydroborates double bonds. This mildness of the reagent leads to the conversion of even $\alpha, \beta$-unsaturated carboxylic acids to the corresponding olefinic aldehydes ${ }^{16,17}$ (Eq. 12).

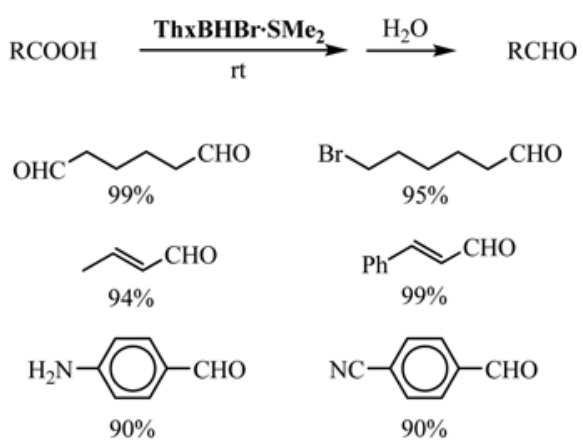

ThxBHBr:SMe $\mathrm{S}_{2}$ can also reduce nitriles to the corresponding aldehydes: the yields from aliphatic nitrile are satisfactory, but from aromatic series vary with the substituents on the benzene ring $^{18}$ (Eq. 13).

$$
\text { R-C } \equiv \mathrm{N}
$$

The most interesting feature of $\mathbf{T h x B H B r} \cdot \mathbf{S M e}_{2}$ is the ability to convert sodium and lithium carboxylates to the corresponding aldehydes at room temperature in high yields. ${ }^{17,19}$ This facile reduction is due to the simple substitution for the bromo group of the reagent by a carboxylate to form thexyl(acyloxy)borane $\mathbf{1}$, the acyloxy group of which is readily reduced to aldehyde by another one equivalent of ThxBHBr$\cdot \mathrm{SMe}_{2}$ (Eq. 14 and 15).

This substitution reaction occurs readily in methylene chloride with precipitation of the metal bromide even under the heterogeneous conditions.

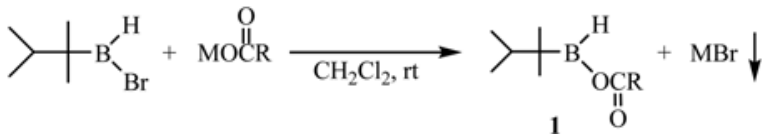

$$
\begin{aligned}
& \underset{\mathrm{rt}}{\stackrel{\mathrm{ThxBHBr} \cdot \mathrm{SMe}_{2}}{\longrightarrow}} \stackrel{\mathrm{H}_{2} \mathrm{O}}{\longrightarrow} \quad \mathrm{RCHO}
\end{aligned}
$$

This system reduces both sodium and lithium salts of most aliphatic carboxylic acids, including diacids, to aldehydes in approximately $3 \mathrm{~h}$ at room temperature in yields of $85-99 \%$. Just as in the reduction of $\alpha, \beta$-unsaturated carboxylic acids by this reagent, the reduction of their salts gives the corresponding aldehydes in good yields, without attack on the double bond. The yields of aldehydes in the reduction of aromatic series are significantly lower and vary with the substituents (Eq. 16).

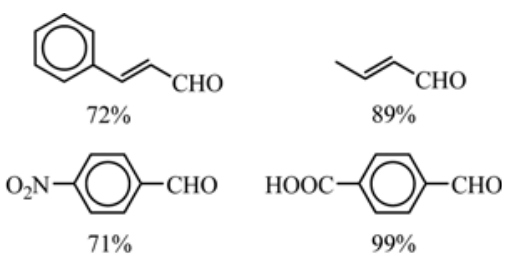

The reagent $\mathbf{T h x B H X} \cdot \mathbf{S M e}_{2}$ appears to be an excellent reducing agent for synthesizing aldehydes by reduction as described above. However, the convenient isolation of the aldehyde products from the reaction mixture provided another important problem to be solved. The byproduct, thexylboronic acid, is relatively difficult to remove from the reaction mixture. On the basis of the results of a study of the chemical and physical characteristics of thexylboronic acid, ${ }^{20}$

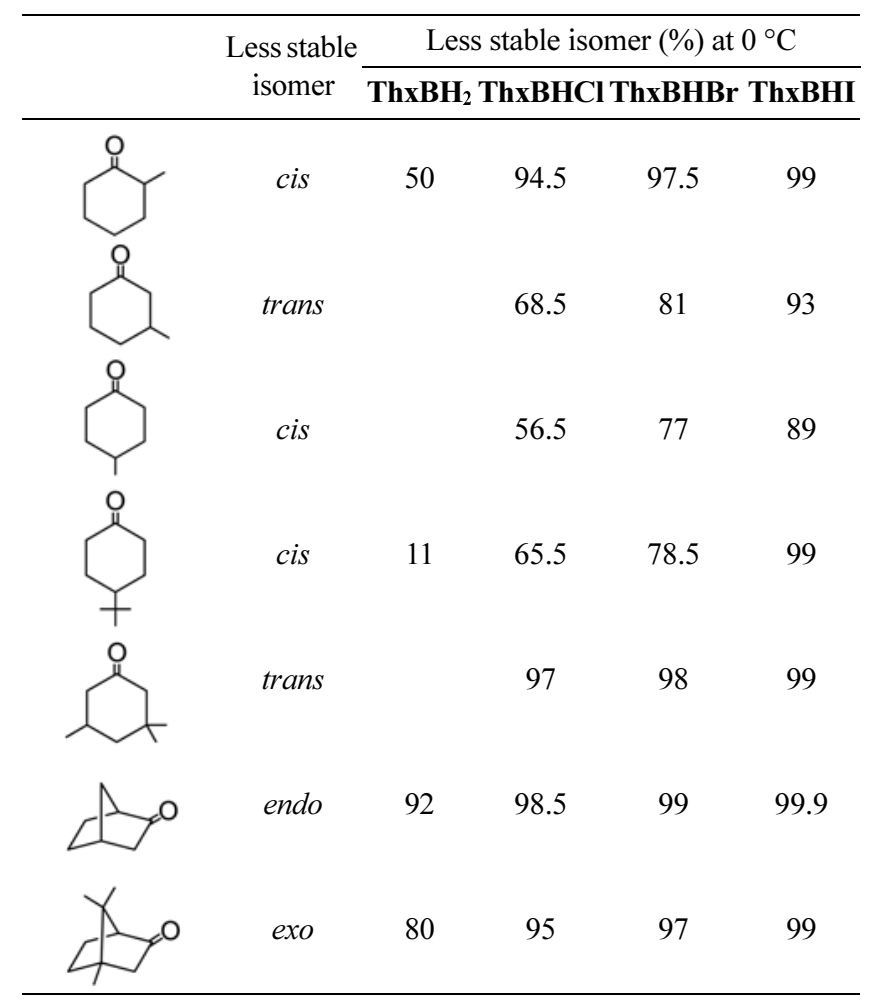


we found that the classical procedure, the separation of aldehydes as the sodium bisulfite adduct from the reaction mixture, followed by the regeneration of aldehydes from the adducts with formaldehyde, provides a highly convenient, general, and practical method. ${ }^{12}$

The halogen substituent in $\mathbf{T h x B H X} \cdot \mathbf{S M e}_{2},(\mathrm{X}=\mathrm{Cl}, \mathrm{Br}, \mathrm{I})$ plays an important role in the stereoselective reduction of typical cyclic ketones as anticipated. ${ }^{21}$ The stereoselectivity increases dramatically with increasing steric size of the substituent. For example, in the reduction of 4-tert-butylcyclohexanone, thexylborane affords only $11 \%$ cis-4-tert-butylcyclohexanol, the less stable isomer. However, the substitution of a chlorine atom for hydrogen in thexylborane exerts a tremendous stereoselectivity enhancement (to 66\%). Furthermore, the stereoselectivity increases consistently with increasing size of the halogen substituent, approaching 99\%. Finally, the iodo derivative, ThxBHI-SMe $\mathbf{H}_{2}$ achieves highly selective reduction, comparable to the results previously achieved at $0{ }^{\circ} \mathrm{C}$ with trialkyl- and alkylalkoxyborohydrides.

Isopinocampheylhaloboranes. Isopinocampheylhaloboranes-methyl sulfide (IpcBHX·SMe $2, X=\mathrm{Cl}, \mathrm{Br}, \mathrm{I}$ ) can be prepared by the hydroboration of $\alpha$-pinene with the corresponding $\mathbf{H}_{2} \mathbf{B X} \cdot \mathbf{S M e}_{2}(\mathrm{X}=\mathrm{Cl}, \mathrm{Br}, \mathrm{I})$ in methylene chloride ${ }^{22,23}$ (Eq. 17)

$$
\underset{\mathbf{H}_{2} \mathbf{B X} \cdot \mathrm{SMe}_{2}}{\stackrel{\mathrm{CH}_{2} \mathrm{Cl}_{2}}{-10 \sim 2{ }^{\circ} \mathrm{C}}} \underbrace{.}_{(\mathrm{X}=\mathrm{Cl}, \mathrm{Br}, \mathrm{I})}
$$

The halogen substituent in IpcBHX.SMe 2 plays an exactly same role in the stereoselective reduction of cyclic ketones: the stereoselectivity increases consistently with

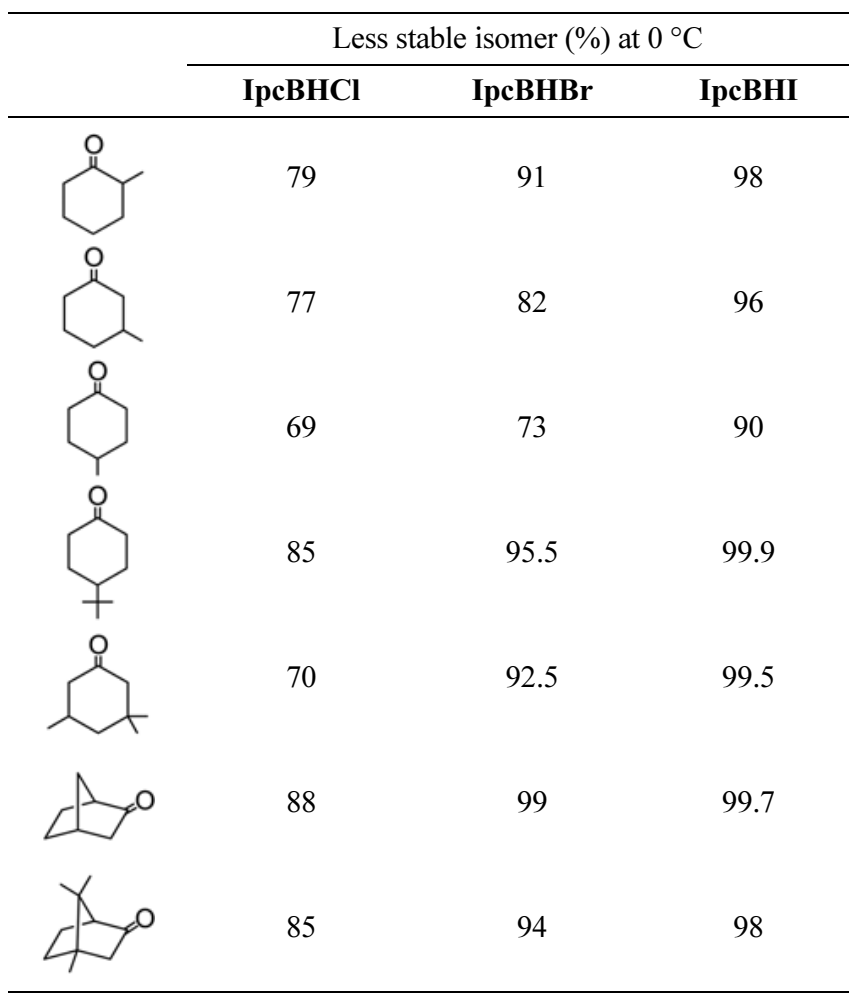

increasing steric size of halogen substituent, approaching essentially $100 \%$ as listed below:

Thexylalkoxyboranes. Thexylborane $\left(\mathbf{T h x B H}_{2}\right)$ reacts with primary and secondary alcohols, such as ethyl alcohol, isopropyl alcohol, isobutyl alcohol, $s$-butyl alcohol and phenol, readily to evolve one equivalent hydrogen within 0.5 $\mathrm{h}$ at $-25^{\circ} \mathrm{C}$ and no further reaction is apparent even in the presence of excess alcohols, whereas the reaction of $t$-butyl alcohol needs an elevated temperature to 0 or $25{ }^{\circ} \mathrm{C}$ to complete the quantitative hydrogen evolution ${ }^{25}$ to produce the corresponding thexylalkoxyboranes (ThxBHOR) (Eq. 18).

$$
\begin{aligned}
& \left.\searrow-\mathrm{BH}_{2}+\mathrm{ROH} \frac{\mathrm{THF}}{-25^{\circ} \mathrm{C} \text { or } 0{ }^{\circ} \mathrm{C}}\right\rangle-\mathrm{BHOR}+\mathrm{H}_{2} \uparrow \\
& (\mathrm{R}=i-\mathrm{Pr}, i-\mathrm{Bu}, s-\mathrm{Bu}, t-\mathrm{Bu}, \mathrm{Ph})
\end{aligned}
$$

The reducing characteristics of all the derivatives prepared above (Eq. 18) toward representative organic functional groups are examined systematically under practical conditions (THF, $25^{\circ} \mathrm{C}$, the quantitative amount of reagent to compound), ${ }^{24,25}$ and the reducing properties of the $s$-butoxy derivative $^{24}$ are summarized as a representative as follows:

$$
\begin{aligned}
\text { ketone } & \rightarrow \text { alcohol (very slow) } \\
\text { carboxylic acid } & \rightarrow \text { aldehyde (slow) } \\
\text { acid chloride } & \rightarrow \text { aldehyde (slow) } \\
\text { ester } & \rightarrow \text { alcohol (very slow) } \\
\text { amide } & \rightarrow \text { no reaction } \\
\text { epoxide } & \rightarrow \text { no reaction } \\
\text { nitrile } & \rightarrow \text { no reaction } \\
\text { nitro compound } & \rightarrow \text { no reaction } \\
\text { disulfide } & \rightarrow \text { no reaction } \\
\text { aldehyde } & \rightarrow \text { alcohol (slow) } \\
\text { sulfoxide } & \rightarrow \text { sulfide (slow) }
\end{aligned}
$$

In general, the reactivity of ThxBHOR is much milder than that of $\mathbf{T h X B H X} \cdot \mathbf{S M e}_{2}$, but the reagents can achieve the conversion of carboxylic acids to the corresponding aldehydes successfully as ThxBHX.SMe does $^{26}{ }^{26}$ Especially, the yield of aldehydes by $\mathbf{T h x B H O}^{i} \mathbf{P r}$ and $\mathbf{T h x B H O}^{s} \mathbf{B u}$ are comparable to those obtained by and ThXBHX.SMe $(\mathrm{X}=\mathrm{Cl}, \mathrm{Br})($ Eq. 19). In addition to that, these reagents can convert acid chlorides to aldehydes. Among these, the yields obtained by $\mathbf{T h x B H O}{ }^{i} \mathbf{P r}$ and $\mathbf{T h x B H O}^{s} \mathbf{B u}$ are quite satisfactory (Eq. 20).

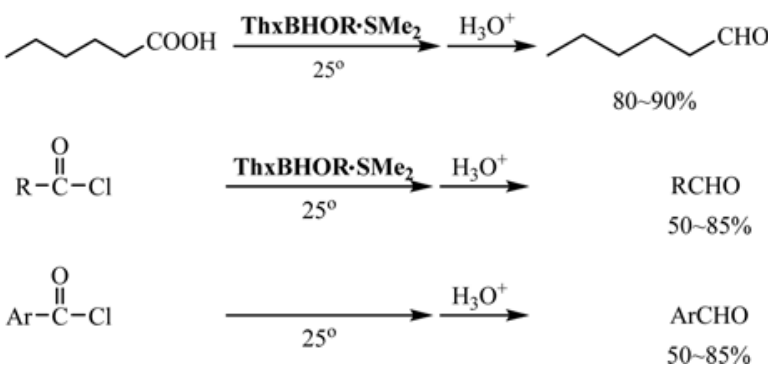

Metal Trialkoxyborohydrides. The higher potassium trialkoxyborohydrides, such as triisopropoxy-, tri-s-butoxy-, tri-t-butoxy-, tricyclopentoxy-, tri(2-methylcyclohexoxy-), 
and triphenoxyborohydrides can be prepared cleanly from the corresponding trialkoxyboranes and excess potassium hydride in THF, but the reaction fails in the case of unhindered trialkoxyborohydrides, such as trimethoxy-, and triethoxyborohydrides, where rapid disproportionation of the product occurs ${ }^{27}$ (Eq. 21).

$$
\mathrm{KH}+(\mathrm{RO})_{3} \mathrm{~B} \longrightarrow \mathrm{K}(\mathrm{RO})_{3} \mathrm{BH}
$$

The stereoselectivity of the stable potassium trialkoxyborohydrides in the reduction of representative cyclic ketones has also been examined. ${ }^{27}$ Among those higher derivatives, potassium triisopropoxyborohydride (KIPPBH) and potassium tri-s-butoxyborohydride show a high stereoselectivity, whereas the other derivatives show a much lower selectivity.

The reduction characteristics of potassium triisopropoxyborohydride, KIPBH, in THF have been explored systematically. ${ }^{28}$ The reagent behaves as an extremely mild reducing agent, similar to sodium borohydride and lithium tri-tertbutoxyaluminohydride. With the exception of aldehydes, ketones, and disulfides, almost all other organic functional groups are inert toward this reagent. This is unexpected because hydride transfer should be more difficult from a strong Lewis acid, such as $\mathrm{BH}_{3}$, than from a weaker Lewis acid, such as $(\mathbf{R O})_{3} \mathbf{B}$, weakened by back bonding. It seems that back bonding does not play an important role in the transition state so that the inductive effect of the isopropoxy groups predominates. The reduction characteristics of KIPBH at $0{ }^{\circ} \mathrm{C}$ are summarized as following:

$$
\begin{aligned}
\text { aldehyde } & \rightarrow \text { alcohol (fast) } \\
\text { ketone } & \rightarrow \text { alcohol (fast) } \\
\text { acid chloride } & \rightarrow \text { reaction (slowly) } \\
\text { carboxylic acid } & \rightarrow \text { no reduction } \\
\text { ester } & \rightarrow \text { no reaction } \\
\text { epoxide } & \rightarrow \text { no reaction } \\
\text { amide } & \rightarrow \text { no reaction } \\
\text { nitro compound } & \rightarrow \text { no reaction } \\
\text { disulfide } & \rightarrow \text { thiol (fast) } \\
\text { other sulfur compound } & \rightarrow \text { no reaction }
\end{aligned}
$$

Even though KIPBH is extremely mild reducing agent as described above, the reagent reduces disulfides to the corresponding thiols in essentially quantitative yields at a different reaction rate between aromatic and aliphatic disulfides: the reduction of aromatic disulfide is much faster than aliphatic one. Consequently, the former reduction is conveniently carried out at $0{ }^{\circ} \mathrm{C}(15 \mathrm{~min})$, whereas, it is convenient to carry out the latter at $25^{\circ} \mathrm{C}(5 \mathrm{~h})$. The remarkable difference in the rate of aromatic and aliphatic disulfides suggested the possibility of establishing the practicality of a procedure under preparative conditions for the selective reduction of aromatic disulfides in the presence of an aliphatic disulfide. Indeed, we achieved to $99 \%$ reduction

$$
\begin{array}{rrrr} 
& \multicolumn{2}{c}{0{ }^{\circ} \mathrm{C}} & \\
\cline { 2 - 3 } \longrightarrow & 2 \mathrm{PhSH} & +n \text {-BuSH } \\
& 1.5 \mathrm{KIPBH} & 95 \% & 2.5 \% \\
& 2.0 \mathrm{KIPBH} & 99 \% & 7 \%
\end{array}
$$

diphenyl disulfide, with only minor reduction of di- $n$-butyl disulfide ${ }^{29}$ (Eq. 22).

Similarly, attempts have been made to prepare stable lithium trialkoxyborohydrides. ${ }^{30}$ Preliminary experiments revealed that the reaction of trialkoxyboranes with excess lithium hydride did not proceed to the formation of lithium derivatives. Finally, it was realized that the reaction of stable potassium trialkoxyborohydrides with lithium chloride forms the white precipitate of potassium chloride immediately, indicating the formation of the corresponding lithium derivatives. However, unfortunately, with the exception of triisopropoxyborohydride, other lithium derivatives, containing $\mathrm{R}=s$ - Bu, $t$-Bu and 2-methylcyclohexyl, with increasing steric requirements, are dissociated into the redistribution products (Eq. 23).

$$
\mathrm{K}(i-\mathrm{PrO})_{3} \mathrm{BH}+\mathrm{LiCl} \longrightarrow \mathrm{Li}(i-\mathrm{PrO})_{3} \mathrm{BH}+\mathrm{KCl} \downarrow
$$

The reducing power of lithium triisopropoxyborohydride is much stronger than that of the potassium derivative, however, is still mild. However, the general reduction pattern is quite similar to that of the potassium derivative, as summarized above. ${ }^{30}$

The stereoselectivity of lithium triisopropoxyborohydride toward cyclic ketones is much different from that of the potassium derivative, KIPBH. Thus, the reagent shows much less degree of stereoselectivity than KIPBH in the case of reduction toward monocyclic ketones. However, the reagent achieves a same or higher degree of selectivity than KIPBH in the reduction of rigid bicyclic ketones. ${ }^{30}$

Potassium 9-alkoxy-9-boratabicyclo[3.3.1]nonanes. Our original experience in attempting to synthesize potassium dialkylmonoalkoxyborohydride, $\mathbf{K R}_{\mathbf{2}} \mathbf{R}^{\prime} \mathbf{O B H}$, had been discouraging because of rapid disproportionation of the products. The stabilizing effect of excess potassium hydride and of 9-BBN as a dialkylboryl group encouraged us to examine the potassium 9-alkoxy-9-boratabicyclo[3.3.1]nonane (K9-OR-9-BBNH).

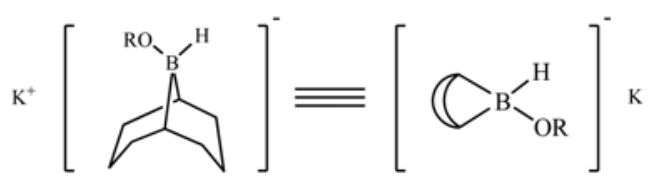

A representative series of $B$-alkoxy-9-BBN esters with increasing steric requirements of the $\mathrm{R}$ group were prepared and reacted with sufficient potassium hydride (Eq. 24). The reactivity and stability of the products appear to vary strongly with the steric requirements of the alkoxy groups. For

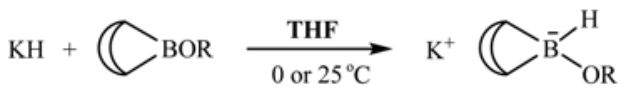

$\mathrm{R}=\mathrm{Me}$ and $n$ - $\mathrm{Bu}$, the products proved to be unstable toward redistribution. On the other hand, the more hindered alkoxy derivatives, $\mathrm{R}=i$-Pr, sec- $\mathrm{Bu}, t-\mathrm{Bu}, t-\mathrm{Am}$, Thx, and $\mathrm{Et}_{3} \mathrm{C}$, are very stable under nitrogen in $\mathbf{T H F}$ at room temperature with or without added potassium hydride. ${ }^{31 \mathrm{a}}$ 
All of these stable reagents reduce monocyclic and bicyclic ketones to the corresponding alcohols with remarkable stereoselectivity at 0 and $-25^{\circ} \mathrm{C}$, producing the thermodynamically less stable isomers exclusively. Especially noteworthy is the thexyl derivative, potassium 9-(2,3-dimethyl2-butoxy)-9-BBNH. This compound reveals the most favorable stereoselectivity of the compounds examined at 0 ${ }^{\circ} \mathrm{C} .{ }^{31 \mathrm{~b}}$

Less stable isomer $(\%)$ at $0{ }^{\circ} \mathrm{C}$<smiles>CC1CCCCC1=O</smiles><smiles>CC1CCCC(=O)C1</smiles><smiles>CC1CCC(=O)CC1</smiles><smiles>CC(C)(C)C1CCC(=O)CC1</smiles><smiles>CC1CC(=O)CC(C)(C)C1</smiles><smiles>C1C2CC(O2)C2CC1O2</smiles>

Potassium 9-Alkyl-9-boratabicyclo[3.3.1]nonanes. In similar to the synthesis of potassium 9-alkoxy-9-boratabicyclo[3.3.1] nonane (K9-OR-9-BBNH), potassium 9-alkyl9-boratabicyclo[3.3.1] nonanes (K9-R-9-BBNH) can be readily prepared by a simple addition of potassium hydride to 9-alkyl-9-BBN with various steric requirements of the $\mathrm{R}$ group, which are prepared by hydroborating the corresponding olefins with 9-BBN ( $\mathrm{R}=$ sec-amyl, neohexyl, thexyl, $n$ octyl, and cyclohexyl), and by treating 9-methoxy-9-BBN with the corresponding alkyllithium $(\mathrm{R}=n$-butyl, $t$-butyl and phenyl), and by hydroborating propargyl bromide with two equivalent 9-BBN followed by ring closure $(\mathrm{R}=$ cyclopropyl) (Eq. 25). All these (25) prepared derivatives in THF are very stable toward disproportionation either at $0{ }^{\circ} \mathrm{C}$ or room

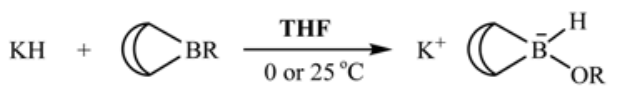

$$
\begin{aligned}
& \mathrm{R}=n-\mathrm{Bu}, t-\mathrm{Bu}, s-\mathrm{Am}, \text { neohexyl, } \\
& \text { Thx, n-octyl, cyclohexyl, } \mathrm{Ph}
\end{aligned}
$$

temperature..$^{32,33}$

All these derivatives thus prepared are examined their stereoselectivity toward representative cyclc ketone reductions at $0{ }^{\circ} \mathrm{C}$ and $-25^{\circ} \mathrm{C}$. Generally, the degree of stereoselectivity exibits a close correlation with the bulkiness of alkyl substituent in the reagent. However, it should be pointed out that the selectivity achieved at $0{ }^{\circ} \mathrm{C}$ with K9-tBu-9-BBNH is exceptionally high, compared to the results with lithium trisiamylborohydride ( $\left.\mathbf{L i S i a}_{3} \mathbf{B H}\right)$ at that temperature. This reagent has $\alpha$-methyl substituted tertiary alkyl group on boron, which is more effective than those have $\beta$ or -methyl substituted bulkier alkyl groups on boron.

\begin{tabular}{ccccccc}
\multicolumn{5}{c}{ Less stable isomer (\%) at $0{ }^{\circ} \mathrm{C}$} \\
\cline { 2 - 7 } & & $t$-Bu & $s$-Am neohexyl cyclohexyl & $\mathrm{Ph}$ \\
97.5 & 99.5 & 99.5 & 98 & 99.5 & 90.5 \\
\hline & & & & & & \\
\hline
\end{tabular}

The general reducing characteristics of potassium 9-secamyl-9-BBNH (K9-s-Am-9-BBNH) as a representative for the series are explored systematically at $0{ }^{\circ} \mathrm{C}$ in $\mathbf{T H F}$, and the results are summarized as follows: ${ }^{34}$

$$
\begin{aligned}
\text { aldehyde } & \rightarrow \text { alcohol (fast) } \\
\text { ketone } & \rightarrow \text { alcohol (fast) } \\
\text { carboxylic acid } & \rightarrow \text { no reduction } \\
\text { anhydride } & \rightarrow \text { alcohol (slow) } \\
\text { acid chloride } & \rightarrow \text { alcohol (fast) } \\
\text { epoxide } & \rightarrow \text { alcohol (fast) } \\
\text { ester } & \rightarrow \text { alcohol (slow) } \\
\text { amide } & \rightarrow \text { no reaction } \\
\text { nitrileno } & \rightarrow \text { reaction for aliphatic } \\
& \text { slow reaction for aromatic } \\
\text { nitro compound } & \rightarrow \text { reaction } \\
\text { disulfide } & \rightarrow \text { thiol (fast) } \\
\text { other sulfur compound } & \rightarrow \text { no reaction }
\end{aligned}
$$


The reagent, K9-s-Am-9-BBNH shows a very interesting feature in the reduction of nitriles under standardized reaction conditions as summarized above: the reaction of typical aliphatic nitrile, caprylonitrile, appears to be essentially inert to this reagent in 5 days, but the representative aromatic nitrile, benzonitrile, uses the first hydride at a moderate rate and the subsequent second hydride relatively very slowly. In fact, the reagent achieves almost quantitative transformation of a variety of aromatic nitriles into the corresponding aldehydes at room temperature, whereas aliphatic nitriles are essentially inert (Eq. 26). Such a remarkable feature in the rate of reaction provides the possibility of achieving the selective reduction of aromatic nitrile to aldehyde in the presence of aliphatic nitrile under practical conditions. Thus, only the aromatic nitrile is reduced selectively in an equimolar mixture of aromatic and aliphatic nitriles, ${ }^{35}$ as in Eq. (27). Such a chemoselectivity between nitriles is classified as the first example in the literature.

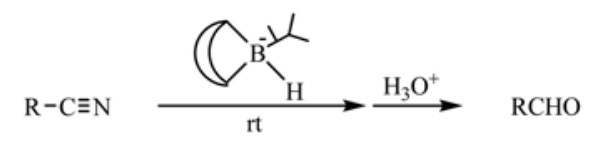

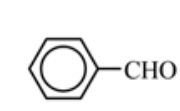

$98 \%$
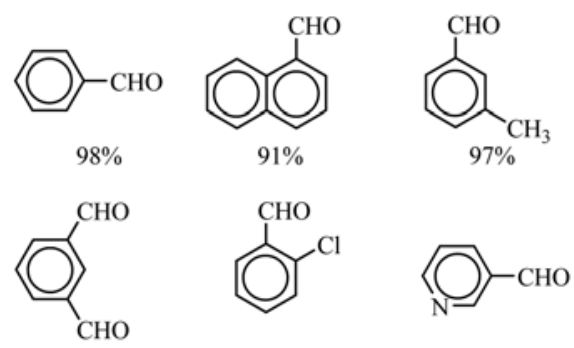

$97 \%$

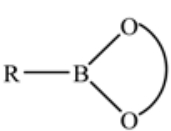

$\left.\begin{array}{c}\mathrm{HO} \\ \mathrm{HO}\end{array}\right)=$
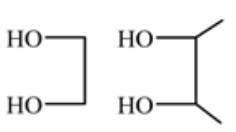

a

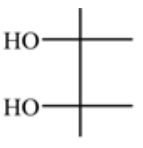

b<smiles>OCCCO</smiles>

d

$$
\begin{aligned}
1, \mathrm{R} & =\mathrm{Me} \\
2, \mathrm{R} & =n-\mathrm{Hex} \\
3, \mathrm{R} & =3-\mathrm{Hex} \\
4, \mathrm{R} & =t-\mathrm{Bu} \\
5, \mathrm{R} & =\mathrm{Thx}
\end{aligned}
$$

$\mathrm{Ph}-\mathrm{C} \equiv \mathrm{N}+\mathrm{CH}_{3}\left(\mathrm{CH}_{2}\right)_{5} \mathrm{CH}_{2} \mathrm{C} \equiv \mathrm{N}$

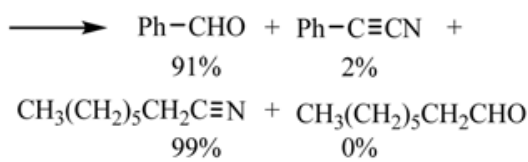

Potassium Dialkoxymonoalkylborohydrides. Generally, the products from simple boronic esters, $\mathbf{K R B}(\mathbf{O R})_{2} \mathbf{H}$, undergo rapid redistribution. However, the use of cyclic esters such as 2-alkyl-1,3,2-dioxaborolanes (the use of diol of $\mathbf{a}, \mathbf{b}, \mathbf{c}$ ) and 2-alkyl-1,3,2-dioxaborinanes (the use of diol d) is promising. The reactivity of cyclic esters containing $R$ group with various steric requirements $(\mathbf{1}, \mathbf{2}, \mathbf{3}, \mathbf{4}, \mathbf{5})$ toward excess potassium hydride and the stability of the dialkoxymonoalkylborohydrides are studied. ${ }^{36}$ In general, the stability varies with the steric bulkiness of the alkyl groups. Thus, when the alkyl group possesses low steric requirements, the corresponding products formed are unstable regardless of the steric bulkiness of the dialkoxy groups. However, in cases where the alkyl group of the cyclic boronic esters possessed moderate steric bulkiness, the corresponding products are quite stable. Thus, $\mathbf{1} \mathbf{a}^{\prime}, \mathbf{1} \mathbf{c}^{\prime}, \mathbf{2} \mathbf{a}^{\prime}, \mathbf{2} \mathbf{b}^{\prime}, \mathbf{3} \mathbf{a}^{\prime}, \mathbf{3} \mathbf{b}^{\prime}, \mathbf{4} \mathbf{a}^{\prime}$, $\mathbf{4} d^{\prime}, \mathbf{5} \mathbf{a}^{\prime}, \mathbf{5} \mathbf{b}^{\prime}$, and $\mathbf{5} \mathbf{d}^{\prime}$ appear to be quite stable over excess potassium hydride at room temperature.

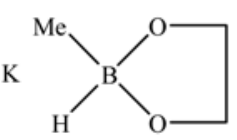

$1 a^{\prime}$

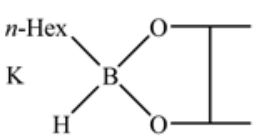

2b'

K

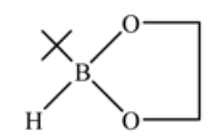

$4 a^{\prime}$

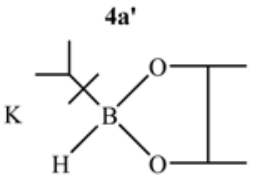

5b'
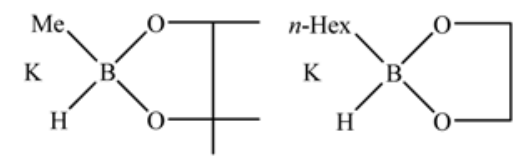

$1 c^{\prime}$<smiles></smiles>

3a'

K<smiles>CC(C)(C)B1OCCCO1</smiles>

4d'

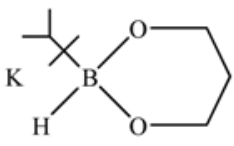

5d'

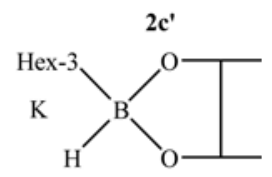

3b'<smiles>[Y]C(C)(C)B1OCCO1</smiles>

$5 a^{\prime}$
Among these stable derivatives, a systematic exploration of the reducing characteristics of potassium 2-thexyl-1,3,2dioxaborinane hydride (KTDBNH, 5d') in THF at $0{ }^{\circ} \mathrm{C}$ is carried out as a representative reagent, ${ }^{37}$ and the results are summarized as follows:

$$
\begin{aligned}
\text { aldehyde } & \rightarrow \text { alcohol (fast) } \\
\text { ketone } & \rightarrow \text { alcohol (fast) } \\
\text { carboxylic acid } & \rightarrow \text { alcohol (slow) } \\
\text { acid chloride } & \rightarrow \text { alcohol (fast) } \\
\text { ester } & \rightarrow \text { alcohol (fast) } \\
\text { amide } & \rightarrow \text { amine (slow) } \\
\text { nitrile } & \rightarrow \text { amine (slow) } \\
\text { nitro compound } & \rightarrow \text { reaction } \\
\text { disulfide } & \rightarrow \text { thiol (fast) } \\
\text { other sulfur compound } & \rightarrow \text { reaction }
\end{aligned}
$$

Lithium (2,3-Dimethyl-2-butyl)-t-butoxyborohydride. The solution of lithium (2,3-dimetyl-2-butyl)-t-butoxyborohydride $\left(\mathbf{L i T h x}^{t} \mathbf{B u O B H}_{2}\right)$ in THF can be easily prepared by a consecutive reaction of thexylborane (2,3-dimethyl-2-

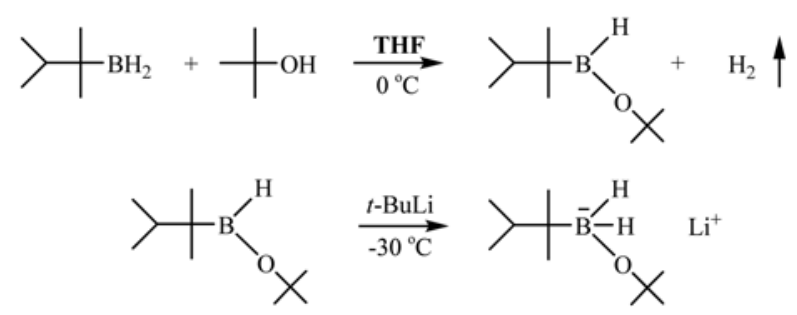


butylborane, $\mathbf{T h x B H _ { 2 }}$ ) with tert-butyl alcohol, followed by treatment with tert-butyllithium at $-30{ }^{\circ} \mathrm{C}^{38 \mathrm{a}}$ (Eq. 28).

The general reducing characteristics of the reagent toward selected organic compounds containing representative functional groups under practical conditions (THF, the limiting amount of the reagent to compound, $0{ }^{\circ} \mathrm{C}$ ) are investigated ${ }^{38}$ and the results are summarized as follows:

$$
\begin{aligned}
\text { aldehyde } & \rightarrow \text { alcohol (very fast) } \\
\text { ketone } & \rightarrow \text { alcohol (very fast) } \\
\text { carboxylic acid } & \rightarrow \text { no reduction } \\
\text { acid chloride } & \rightarrow \text { alcohol (very fast) } \\
\text { epoxide } & \rightarrow \text { alcohol (very fast) } \\
\text { ester } & \rightarrow \text { alcohol (fast) } \\
\text { nitrile } & \rightarrow \text { amine (fast) } \\
\text { amide } & \rightarrow \text { no reaction } \\
\text { disulfide } & \rightarrow \text { thiol (very fast) }
\end{aligned}
$$

The reagent, $\mathbf{L i T h x}^{t} \mathbf{B u O B H}$, reveals an excellent stereoselectivity in the reduction of representative cyclic ketones to provide the corresponding thermodynamically less stable alcohol epimes, ${ }^{38 \mathrm{~b}}$ comparable to those obtained previously by $\mathbf{L i S i a}_{3} \mathbf{B H}$ and K9-t-Bu-9-BBNH, even considerably superior over Lis-Bu $\mathbf{B}_{3} \mathbf{B H}$ and K9-OThx-9-BBNH (the comparison data obtained by the various reagents showing a remarkable stereoselectivity are listed at the following section, vide, infra).

Lithium di(3-methyl-2-butyl)alkoxyborohydrides. A class of reducing agents, lithium di(3-methyl-2-butyl)alkoxyborohydrides ( $\left.\mathbf{L i S i a}_{2} \mathbf{B}(\mathbf{O R}) \mathbf{H}\right)$, possessing various steric requirements $(\mathrm{R}=\mathrm{Et}, i-\mathrm{Pr}, t-\mathrm{Bu})$, can be readily prepared by adding a solution of tert-butyllithium in pentane to a solution of di(3-methyl-2-butyl)alkoxyborane ( $\left.\mathbf{S i a}_{2} \mathbf{B O R}\right)$ in $\mathbf{T H F}$ at $25^{\circ} \mathrm{C}^{39}$ (Eq. 29). The solution of Sia $\mathbf{B O R}$ is also readily prepared by reacting a solution of disiamylborane $\left(\mathbf{S i a}_{2} \mathbf{B H}\right)$ in THF with the corresponding alcohols at $0{ }^{\circ} \mathrm{C}$ (Eq. 30).

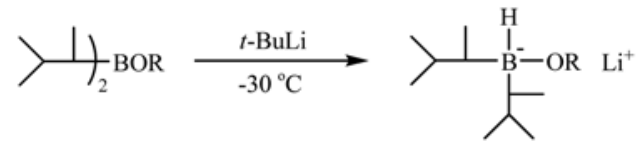

$$
\begin{aligned}
& \searrow)_{2} \mathrm{BH}_{2}+\mathrm{ROH} \underset{0^{\circ} \mathrm{C}}{\stackrel{\mathrm{THF}}{\longrightarrow}} \searrow \mathrm{f}_{2} \mathrm{BOR}+\mathrm{H}_{2} \uparrow \\
& \mathrm{R}=\mathrm{Et}, \mathrm{Sia}_{2} \mathrm{BOEt} \\
& =i-\mathrm{Pr}, \mathrm{Sia}_{2} \mathrm{BO}^{i} \mathrm{Pr} \\
& =t-\mathrm{Bu}, \mathrm{Sia}_{2} \mathrm{BO}^{t} \mathrm{Bu}
\end{aligned}
$$

The degree of stereoselectivity toward representative cyclic ketones exhibits a close correlation with a bulkiness of alkoxy substituent in the reagent. Especially, the $t$-butoxy derivative reveals an excellent selectivity at 0 and $-20{ }^{\circ} \mathrm{C}$ to afford the thermodynamically less stable alcohol epimes, comparable to the results previously achieved by $\mathbf{L i S i a} 3 \mathbf{B H}, \mathbf{K 9 - t}-\mathbf{B u}-\mathbf{9 -}$ BBNH, and lithium (2,3-dimethyl-2-butyl)- $t$-butoxyborohydride $\left(\mathbf{L i T h x} \mathbf{x}^{t} \mathbf{B u O B H} \mathbf{O B}_{\mathbf{2}}\right)^{39}$ as indicated by the following comparative study.

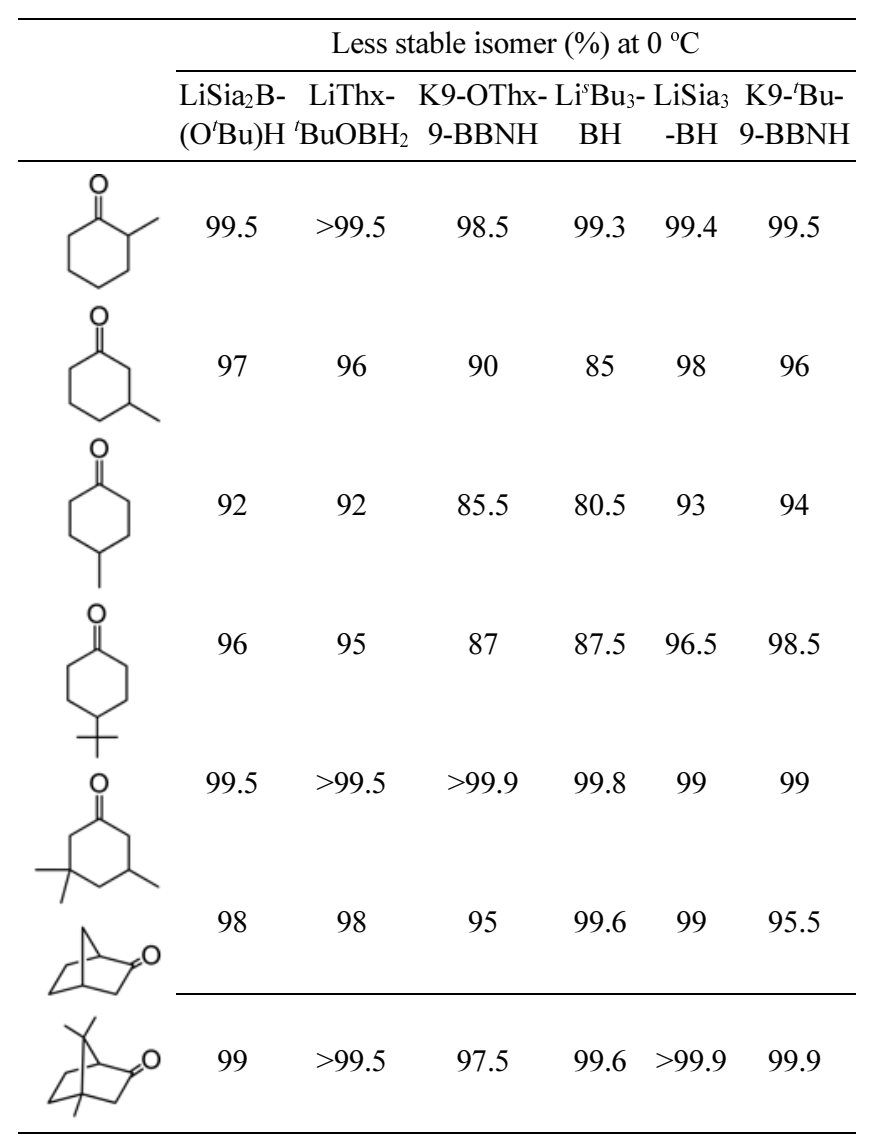

Sodium Aluminum Hydride. Even though sodium aluminum hydride (SAH) possesses some advantages over the lithium derivative, lithium aluminum hydride (LAH), because of the much mildness in reactivity toward organic functional groups and much easiness to handle, the use of SAH in organic synthesis has been restricted because of the high price to purchase due to the lack of mass production commercially. In fact, the systematic studies on the reducing characteristics and properties of SAH have fully revealed its usefulness in organic synthesis. In general, the reducing action of SAH is very similar to that observed previously for LAH: SAH reduces almost every organic functional group as readily as LAH does. Although SAH shows a much lower reactivity than $\mathbf{L A H}$ toward some functionalities at 0 ${ }^{\circ} \mathrm{C}$, such as carboxylic acids, anhydrides, epoxides, amides and nitro compounds, it can reach the final reduction stages readily at room temperature. ${ }^{38}$ Such a slow reaction, on the other hand, adds an advantage to SAH to a possible selective reduction between some organic functional groups, for example, the transformation of tertiary amides to aldehydes. As a consequence, SAH can replace LAH effectively in most organic reductions. The general reducing characteristics toward the representative organic functional groups are summarized as follows: ${ }^{40}$

$$
\begin{aligned}
\text { aldehyde } & \rightarrow \text { alcohol (very fast) } \\
\text { ketone } & \rightarrow \text { alcohol (very fast) } \\
\text { carboxylic acid } & \rightarrow \text { alcohol (very fast) }
\end{aligned}
$$




$$
\begin{aligned}
\text { anhydride } & \rightarrow \text { alcohol (very fast) } \\
\text { ester } & \rightarrow \text { alcohol (very fast) } \\
\text { acid chloride } & \rightarrow \text { alcohol (very fast) } \\
\text { amide } & \rightarrow \text { amine (fast) } \\
\text { aromatic nitrile } & \rightarrow \text { amine (fast) } \\
\text { epoxide } & \rightarrow \text { alcohol (slow) } \\
\text { nitro compound } & \rightarrow \text { reaction (slow) } \\
\text { sulfur compound } & \rightarrow \text { slow or no reaction }
\end{aligned}
$$

In addition to such a standard study using excess amount of SAH, a possibility for quantitative reductions of representative organic compounds in the absence of excess reagent has been examined..$^{41}$ All carbonyl compounds tested are cleanly reduced to alcohols with the stoichiometric amount of SAH. In the case of cinnamaldehyde, the nature of the product depends on the amount of hydride utilized: thus, only cinnamyl alcohol is obtained with a quarter equivalent of SAH, while a quantitative reduction to the saturated alcohol is realized when a half equivalent of the reagent is utilized. The reduction of tertiary amides with a half equivalent of SAH gives a mixture of the corresponding tertiary amine and alcohol whereas the use of the quarter equivalent results in formation of the corresponding aldehydes in good yields. With a half equivalent of SAH, benzonitrile is reduced to benzylamine in quantitative yield at $0{ }^{\circ} \mathrm{C}$ and room temperature while the theoretical amount of hydride affords benzaldehyde in a yield of $85 \%$ at room temperature in $1 \mathrm{hr}$. as in Eq. (31).

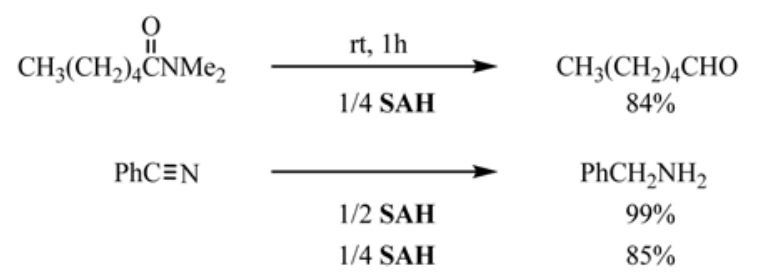

Sodium tri-tert-butoxyaluminohydride. Like lithium aluminum hydride (LAH), sodium aluminum hydride (SAH) reacts with only three equivalent of tert-butyl alcohol with the evolution of three equivalent of hydrogen at $0^{\circ} \mathrm{C}$ or room temperature, even in the presence of excess alcohol, to form stable sodium tri-tert-butoxyaluminohydride (STBA $)^{42}$ (Eq. 32).

$$
\mathrm{NaAlH}_{4}+3 t-\mathrm{BuOH} \longrightarrow \mathrm{Na}(t-\mathrm{BuO})_{3} \mathrm{AlH}+3 \mathrm{H}_{2} \uparrow
$$

The conversion of acid chlorides to aldehydes is one of the most useful transformations in organic synthesis. Especially lithium tri-tert-butoxyaluminohydride (LTBA) has been used widely for such purposes because of its simplicity and mildness. However, the reagent cannot achieve a very general reduction of both aliphatic and aromatic acid chlorides. STBA in diglyme (dissolved up to $0.52 \mathrm{M}$ at $0{ }^{\circ} \mathrm{C}$ ) reduces acid chlorides dissolved in THF at $-78^{\circ} \mathrm{C}$ to the corresponding aldehydes in high yields, which are far superior to those by LTBA $^{42}$ (Scheme 1).

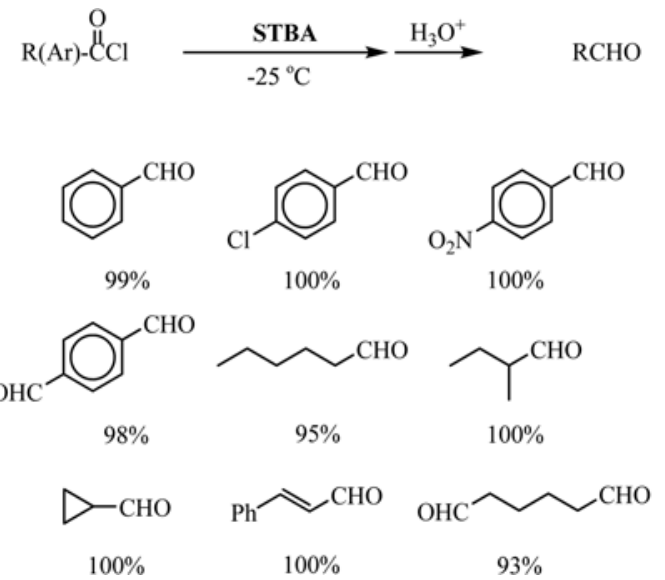

Potassium Diisobutylalkoxyaluminum Hydrides. The solution of potassium diisobutylalkoxyaluminum hydrides in THF with various alkoxy group of different steric environments can be prepared one of two methods. Thus, the reaction of excess potassium hydride with diisobutylalkoxyalanes $\left(i-\mathrm{Bu}_{2} \mathrm{AlOR}, \mathrm{R}=\mathrm{Et}, i-\mathrm{Pr}, t-\mathrm{Bu}, s-\mathrm{Bu}, \mathrm{PhCH}_{2}\right)$, which is prepared from the corresponding alcohols and DIBAH (Eq. 33 and 34). Alternatively, these reagents can be prepared from the reaction of potassium diisobutylaluminum hydride with the corresponding alcohols at $140^{\circ} \mathrm{C}$, which is prepared from the reaction of DIBAH with excess potassium hydride at room temperature (Eq. 35 and 36). ${ }^{43}$

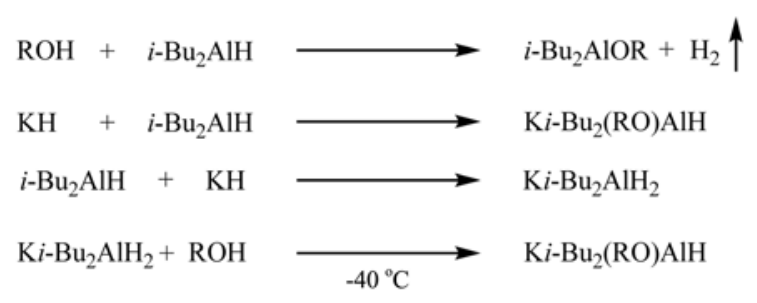

The reactivity of this series of agents toward representative carbonyl compounds are examined. ${ }^{43}$ Generally, all these derivatives appear to be extremely mild reducing agents. The reactions of aldehydes and ketones are very slow at room temperature, so requires a drastic condition under reflux in THF to be completed. However, the relative reactivity of these reagents is in the order of $\mathrm{R}=\mathrm{OEt}>\mathrm{O}^{i} \mathrm{Pr}>$ $\mathrm{O}^{t} \mathrm{Bu}$. Apparently, such a reactivity order arises from the size of the alkoxy substituent.

Interestingly, the reaction of enals and enones with two equivalent of these reagents in refluxing THF proceeds cleanly in a 1,2-sense to give the corresponding allylic alcohols $^{43}$ (Eq. 37).

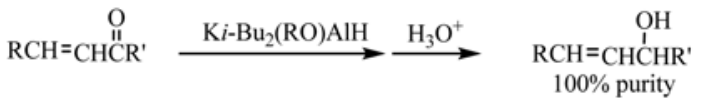

$$
\begin{aligned}
& \widehat{100 \%}_{\mathrm{OH}}^{\longrightarrow}-\mathrm{OH}
\end{aligned}
$$

The stereoselectivity toward cyclic ketones achieved by these reagents in refluxing THF are somewhat extraordinary. 
Thus, the reagents convert cyclic ketones to thermodynamically more stable alcohol epimers preferentially. ${ }^{43}$ This is in contrast to the case of trisubstituted borohydrides: usually, the trisubstituted borohydrides afford the thermodynamically less stable alcohol epimers.

Metal Cyanoaluninum Hydrides. The solution of sodium cyanoaluminim hydride (SCAH) is prepared by reacting $\mathrm{AlH}_{3}$ in THF with $\mathrm{NaCN}$ as a solid. The solid $\mathrm{NaCN}$ is slowly disappeared as cyanide ion adds to $\mathrm{AlH}_{3}$ in THF. The formation of SCAH is completed in $3 \mathrm{~h}$ at room temperature (Eq. 38). The solution of the lithium derivative (LCAH) is prepared by reacting SCAH in THF with $\mathrm{LiCl}$ at room temperature via metal exchange reaction. $\mathrm{As} \mathrm{NaCl}$ precipitates out from the reaction mixture, a solution of LCAH in THF forms (Eq. 39).

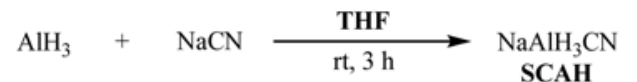

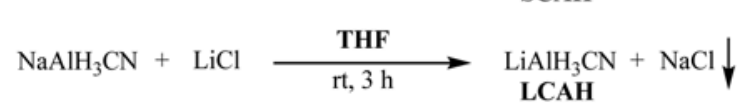

The general reducing characteristics of both $\mathbf{S C A H}^{44}$ and LCAH ${ }^{45}$ are examined in THF at $0{ }^{\circ} \mathrm{C}$ under practical conditions (the limiting amount of the reagents utilized) and are compared each other. ${ }^{45}$ In general, the reducing behavior of LCAH is resembles that of SCAH closely, but the reactivity of LCAH toward functional groups appears to be stronger than that of SCAH. And the reducing power of each reagent is much weaker than that of its parent metal aluminum hydride. However, reducing characteristics of both derivatives are significantly different from those of the parent lithium and sodium aluminum hydrides, apparently due to the presence of cyano substituent. The cyano substituent, a strong electron-withdrawing group, diminishes the reducing power of the parent metal aluminum hydrides and hence effects the alteration of their reducing characteristics. The reducing properties of SCAH are summarized as a representative as follows:

$$
\begin{aligned}
\text { aldehyde } & \rightarrow \text { alcohol (fast) } \\
\text { ketone } & \rightarrow \text { alcohol (fast) } \\
\text { carboxylic acid } & \rightarrow \text { alcohol (slow) } \\
\text { acid chloride } & \rightarrow \text { alcohol (very fast) } \\
\text { ester } & \rightarrow \text { alcohol (fast) } \\
\text { epoxide } & \rightarrow \text { alcohol (slow) } \\
\text { amide } & \rightarrow \text { amine (slow) } \\
\text { nitrile } & \rightarrow \text { amine (slow) } \\
\text { disulfide } & \rightarrow \text { thiol (very fast) } \\
\text { sulfur compound } & \rightarrow \text { reaction or no reaction }
\end{aligned}
$$

Aluminum Hydride-triethylamine Complex. Aluminum hydride, a very interesting and valuable reducing agent, has been widely used in numerous applications in organic synthesis. Brown and Yoon already reported a systematic study on the reducing properties of aluminum hydride in THF, comparing its reducing characteristics to that of lithium aluminum hydride in the 1960 's. $^{46}$ Even though aluminum hydride has found numerous applications in organic syn- thesis, the lack of availability commercially or a simple procedure for making it has caused it to be used less than its valuable reducing properties suggest.

The usual laboratory procedure for the synthesis of aluminum hydride solution in THF involves treatment of a standardized solution of lithium aluminum hydride (LAH) in THF with a theoretical quantity of $100 \%$ sulfuric acid. Even though this procedure provides a pure aluminum hydride solution in THF, there has been some resistance to the use of $100 \%$ sulfuric acid with LAH. Furthermore, the aluminum hydride solution in THF possesses a significant problem: such solutions undergo slow THF cleavage at room temperature. Therefore, the aluminum hydride solution should be maintained at $0{ }^{\circ} \mathrm{C}$, both for storage and reaction.

Consequently, there has been a need for development of a simple, convenient procedure for the preparation of solutions of aluminum hydride in THF and preparation of stable aluminum hydride reagent, easy to ship and use. Aluminum hydride-triethylamine appears to meet this requirement.

It appears that the reaction of $\mathbf{L A H}$ with methanesulfonic acid or hydrogen chloride could replace $100 \%$ sulfuric acid in the synthesis of aluminum hydride to avoid such difficulty. One problem is the solubility of lithium salts. Finally, we found that the reaction of sodium aluminum hydride (SAH) in THF and hydrogen chloride in diethyl ether appears to be the most convenient procedure for the synthesis of a pure aluminum hydride solution (Eq. 40).

$$
\mathrm{NaAlH}_{4}+\mathrm{HCl}\left(\text { in } \mathrm{Et}_{2} \mathrm{O}\right) \stackrel{\text { THF }}{\longrightarrow} \mathrm{AlH}_{3}+\mathrm{NaCl}+\mathrm{H}_{2} \uparrow
$$

We utilized the aluminum hydride solution in THF (after distillating out diethyl ether), thus prepared above, for the preparation of a pure aluminum hydride-triethylamine (AHTEA) solution in THF (Eq. 41).

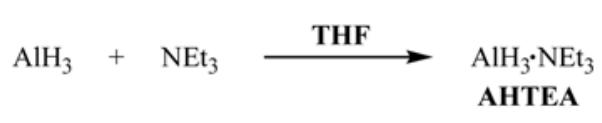

The reducing power of AHTEA complex in THF toward 59 selected organic compounds containing representative functional groups under practical conditions (THF, room temperature, the quantitative amount of reagent to compound) has been investigated ${ }^{47}$ The reducing characteristics of the complex appear essentially identical to those of aluminum hydride in THF. However, in this way, we have established that quantitative reduction of various organic functionalities can be readily achieved using the calculated quantity of AHTEA to avoid the use of reagent. This permits ready use of the aluminum hydride reagent in organic synthesis with high convenience and efficiency, with the possibility of an improved selectivity than that of aluminum hydride itself in THF.

Bis(dialkylamino)aluminum Hydride. The addition of two moles of dialkylamine, such as diethylamine, pyrrolidine and $N$-methylpiperazine, to the solution of one mole of aluminum hydride in THF provides the corresponding bis(dialkylamino)aluminum hydride (Eq. 42). 


$$
\begin{aligned}
& \mathrm{AlH}_{3}+\quad 2 \mathrm{R}_{2} \mathrm{NH} \frac{\mathrm{THF}}{0{ }^{\circ} \mathrm{C} \text { or } 25{ }^{\circ} \mathrm{C}} \quad\left(\mathrm{R}_{2} \mathrm{~N}\right)_{2} \mathrm{AlH}+2 \mathrm{H}_{2} \uparrow \\
& \mathrm{R}=\mathrm{Et}, \mathbf{B E A H} \\
&=\overbrace{}^{\mathrm{N}}, \text { DPAH } \\
&=\mathrm{Me}-\mathrm{N}^{\mathrm{NH}}, \mathbf{B M P A}
\end{aligned}
$$

The reducing characteristics of these $\mathbf{B E A H} \mathbf{H}^{48}$ and $\mathbf{D P A} \mathbf{H}^{49}$ toward representative organic functional groups under standardized conditions $\left(0{ }^{\circ} \mathrm{C}\right.$, THF $)$ are examined systematically. The results clearly reveal that the reducing power of DPAH, an alicyclic secondary-amino derivative, is stronger than that of BEAH, an aliphatic secondary-amino derivative, but weaker than that of parent aluminum hydride. However, the reducing action of DPAH is quite similar to that of BEAH. As a representative result, the reducing characteristics of DPAH are summarized as follows:

$$
\begin{aligned}
\text { aldehyde } & \rightarrow \text { alcohol (fast) } \\
\text { ketone } & \rightarrow \text { alcohol (fast) } \\
\text { carboxylic acid } & \rightarrow \text { alcohol (slow) } \\
\text { anhydride } & \rightarrow \text { reaction (slow) } \\
\text { acid chloride } & \rightarrow \text { alcohol (fast) } \\
\text { ester } & \rightarrow \text { alcohol (fast) } \\
\text { epoxide } & \rightarrow \text { alcohol (fast) } \\
\text { amide } & \rightarrow \text { reaction } \\
\text { nitrile } & \rightarrow \text { amine (fast) } \\
\text { disulfide } & \rightarrow \text { thiol (fast) } \\
\text { sulfone } & \rightarrow \text { no reaction } \\
\text { nitro compound } & \rightarrow \text { reaction }
\end{aligned}
$$

As revealed in the systematic study on the reducing characteristics of dialkylamino-substituted aluminum hydride, there seems no possibility for formation of aldehydes from carboxylic acids at $0{ }^{\circ} \mathrm{C}$ because of the slow reduction to alcohol. However, at the elevated temperature in refluxing THF all the derivatives provide the corresponding aldehydes in good yields (50-98\%). ${ }^{50}$ Especially, BMPA gives the most favorable results (Eq. 43).

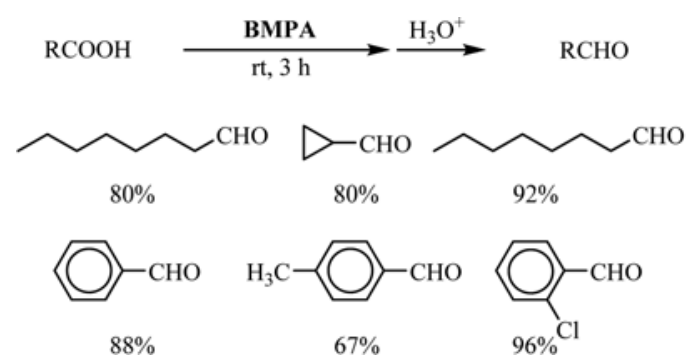

Cyclic Dialkyldiaminoaluminum Hydrides. The cyclic diaminoaluminum hydrides can be successfully prepared by a simple reaction of aluminum hydride $\left(\mathrm{AlH}_{3}\right)$ with $N, N^{\prime}$ dialkylethylenediamine $(\mathbf{R}=\mathbf{M e}, \mathbf{E t})$ in $\mathbf{T H F}$ at $0{ }^{\circ} \mathrm{C}^{51}$ (Eq. 44).

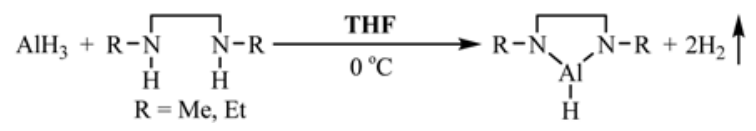

Both the reagents reduce aromatic carboxylic acids to aldehydes in 2-3 days at room temperature in yields of 70$90 \%$, showing no significant bias in yields in the substituents on the benzene ring. However, the yields aliphatic acids with both reagents are not satisfactory under the reaction conditions, yielding only in the range of $30-50 \%$, along with the reduction products of the corresponding alcohols, ${ }^{51}$ as in Eq. (45).

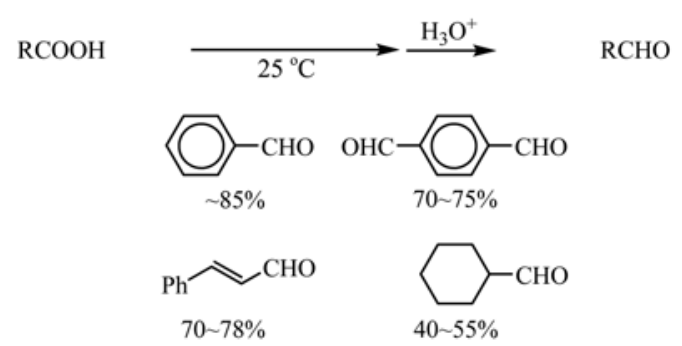

Generally, in aspect of the efficiency for the aldehyde synthesis from carboxylic acids, the $N$-methyl reagent is better than the $N$-ethyl reagent. The reductions by the former proceed under the much milder reaction conditions than those by the latter: the latter reagent requires drastic reaction conditions of a refluxing in THF and a large excess amount of reagent up to four equivalents to obtain satisfactory results.

Diisobutylaluminum Hydride-methyl Sulfide Complex. Diisobutylaluminum hydride (DIBAH), being widely used as a common reducing agent in organic synthesis, ${ }^{52}$ forms a stable complex with methyl sulfide to give a solution of diisobutylaluminum hydride-methyl sulfide complex in toluene (Eq. 46). DIBAH is very viscous liquid, but the 1:1

$(i-\mathrm{Bu})_{2} \mathrm{AlH}+\mathrm{SMe}_{2} \longrightarrow(i-\mathrm{Bu})_{2} \mathrm{AlH} \cdot \mathrm{SMe}_{2}$

complex becomes non-viscous and a toluene solution is quite stable toward air. The similarities and differences in the reducing characteristics of DIBAH and DIBAH·SMe 2 toward common organic functional groups are fully studied systematically. ${ }^{53}$ The reactivity toward representative organic compounds are summarized as follows:

$$
\begin{aligned}
\text { aldehyde } & \rightarrow \text { alcohol (fast) } \\
\text { ketone } & \rightarrow \text { alcohol (fast) } \\
\text { carboxylic acid } & \rightarrow \text { alcohol (slow) } \\
\text { anhydride } & \rightarrow \text { alcohol (slow) } \\
\text { acid chloride } & \rightarrow \text { alcohol (fast) } \\
\text { ester } & \rightarrow \text { alcohol (slow) } \\
\text { epoxide } & \rightarrow \text { alcohol (slow) } \\
\text { amide } & \rightarrow \text { amine (slow) } \\
\text { nitrile } & \rightarrow \text { amine (very slow) } \\
\text { nitro compound } & \rightarrow \text { reaction } \\
\text { disulfide } & \rightarrow \text { thiol (slow) } \\
\text { other sulfur compound } & \rightarrow \text { no reaction }
\end{aligned}
$$

In general, the reducing pattern of this complex is quite similar to that observed previously for DIBAH itself. However, the complex shows a relatively low reactivity than DIBAH alone. Such a low reactivity as well as its stability 
provides additional advantages to the usefulness of DIBAH. One example is an ability for the transformation of nitriles into the corresponding aldehydes. DIBAH.SMe 2 in toluene at $0{ }^{\circ} \mathrm{C}$ reduces both aromatic and aliphatic nitriles to aldehydes in yields better than those by DIBAH itself ${ }^{54}$ (Eq. 47).

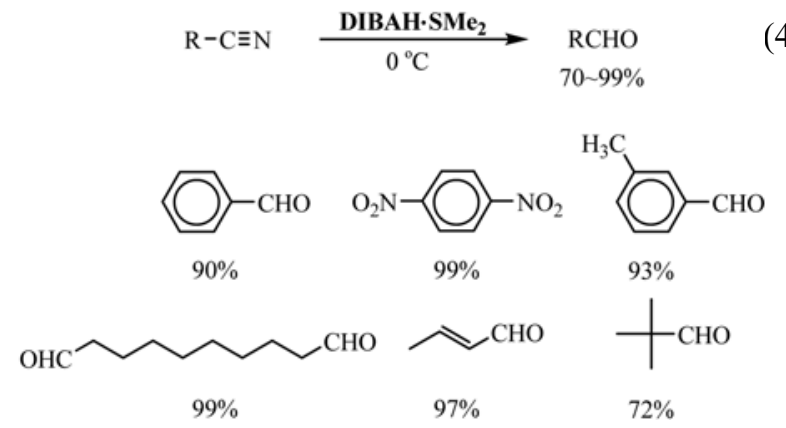

Catecholalane. In similar to the synthesis of catecholborane, catecholalane (1,3,2-benzodioxaaluminole), CA, can be conveniently prepared by the reaction of catechol with an equivalent of aluminum hydride in THF at $0{ }^{\circ} \mathrm{C}$ as in Eq. (48).

$$
\mathrm{OCH}_{\mathrm{OH}}^{\mathrm{OH}} \frac{\mathrm{AlH}_{3}}{{ }^{\circ} \mathrm{C}} \longrightarrow \mathrm{O}_{\mathrm{O}}^{\mathrm{O}} \mathrm{AlH}+2 \mathrm{H}_{2} \uparrow
$$

The reducing properties are quite different from those of the parent aluminum hydride. The reagent readily reduces both aromatic and aliphatic nitriles to aldehydes at $25^{\circ} \mathrm{C}$, but aluminum hydride reduces them only to amines. The yields of aldehydes both from aromatic and aliphatic nitriles are in the range of $92-100 \% .{ }^{55}$ There is no observable dependence on the structure of the nitrile. Even the $\alpha, \beta$-unsaturated nitrile, cinnamonitrile, is reduced to the corresponding enal in an essentially quantitative yield (Eq. 49).

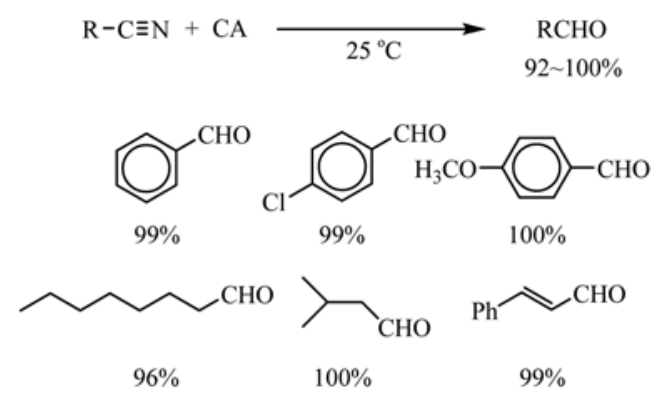

The reducing characteristics of $\mathbf{C A}$ toward representative organic functional groups ${ }^{56}$ are summarized as follows:

$$
\begin{aligned}
\text { aldehyde } & \rightarrow \text { alcohol (very fast) } \\
\text { ketone } & \rightarrow \text { alcohol (very fast) } \\
\text { carboxylic acid } & \rightarrow \text { alcohol (very slow) } \\
\text { ester } & \rightarrow \text { alcohol (slow) } \\
\text { acid chloride } & \rightarrow \text { alcohol (very fast) } \\
\text { epoxide } & \rightarrow \text { alcohol (slow) } \\
\text { amide } & \rightarrow \text { amine (slow) } \\
\text { nitrile } & \rightarrow \text { aldehyde or amine (slow) } \\
\text { sulfur compound } & \rightarrow \text { slow reaction or no reaction }
\end{aligned}
$$

Lithium Tris(Dialkylamino)aluminum Hydrides. The reaction in THF of lithium aluminum hydride (LAH) with representative dialkylamines of various steric and electronic environments was examined in detail to establish the generality of this synthesis of the corresponding lithium dialkylaminoaluminum hydrides, $\mathbf{L i}\left(\mathbf{R}_{\mathbf{2}} \mathbf{N}\right) \mathbf{n} \mathbf{A l H}_{\mathbf{4}}-\mathbf{n}(\mathrm{n}=2,3) .{ }^{57}$ In cases involving less hindered dialkylamines, such as diethylamine, di- $n$-butylamine and di- $n$-hexylamine, the reaction is very fast and gives the corresponding trisubstituted derivatives cleanly at $0{ }^{\circ} \mathrm{C}$ or room temperature. However, a moderately hindered one, such as diisobutylamine, reacts with LAH slowly to afford the corresponding disubstituted derivative at room temperature. In this case a trisubstituted derivative can also be obtained under reflux. The reaction of more hindered dialkylamines, such as diisopropylamine and dicyclohexylamine, is sluggish even at $50{ }^{\circ} \mathrm{C}$ and gives the corresponding disubstituted derivatives cleanly. Cyclic secondary amines, such as pyrrolidine, piperidine, morphorine and $N$-methylpiperazine, undergo the reaction rapidly to yield the corresponding trisubstituted derivatives even at $0{ }^{\circ} \mathrm{C}$. Finally, the reaction with diphenylamine gives the corresponding disubstituted derivative cleanly as Eq. (50).

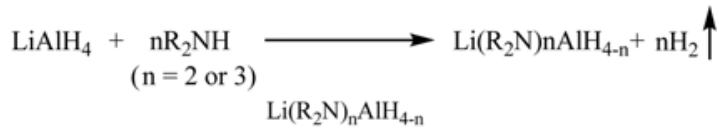

$$
\begin{aligned}
& \text { 1. } \mathrm{R}=\mathrm{Et}, \mathrm{n}=3 \text { LTDEA } \\
& \text { 2. } \mathrm{R}=n-\mathrm{Bu}, \mathrm{n}=3 \text { LTDBA } \\
& 3 . \mathrm{R}=n-\mathrm{Hex}, \mathrm{n}=3 \text {, LTDHA } \\
& \text { 4. } \mathrm{R}=i-\operatorname{Pr}, \mathrm{n}=2 \text {, LBDIPA } \\
& \text { 5. } \mathrm{R}=i-\mathrm{Bu}, \mathrm{n}=2 \text {, LBDIBA } \\
& \text { 6. } \mathrm{R}=i-\mathrm{Bu}, \mathrm{n}=3 \text {, LTDIBA } \\
& \text { 7. } \mathrm{R}=c \text {-Hex, } \mathrm{n}=2 \text {, LBDCHA } \\
& \text { 8. } \mathrm{R}_{2} \mathrm{~N}={ }_{\mathrm{N}}, \mathrm{n}=3 \text {, LTPRA } \\
& \text { 9. } \mathrm{R}_{2} \mathrm{~N}=\complement^{\mathrm{N}}, \mathrm{n}=3 \text {, LTPDA } \\
& \text { 10. } \mathrm{R}_{2} \mathrm{~N}=\mathrm{O}^{\mathrm{N}}, \mathrm{n}=3 \text {, LTMPA } \\
& \text { 11. } \mathrm{R}_{2} \mathrm{~N}=\mathrm{Me}^{-\mathrm{N}} \mathrm{NH}, \mathrm{n}=3 \text {, LTMPPA } \\
& \text { 12. } \mathrm{R}=\mathrm{Ph}, \mathrm{n}=2 \text {, LBDPA }
\end{aligned}
$$

Among the dialkylaminoaluminum hydrides thus prepared above, LTDEA ${ }^{58}$ LTDBA $^{59}$ LTDHA $^{60}$ and LTPDA $^{61}$ are chosen and examined in detail for their general reducing characteristics under the standardized conditions (THF, 0 ${ }^{\circ} \mathrm{C}$ ), and finally their reducing properties are compared each other. Generally, the reducing power of these derivatives is much weaker than that of the parent LAH and appears in this order: LTDEA > LTDBA > LTDHA > LTPDA, as expected. Especially noteworthy is that all these derivatives show promising possibilities for selective conversion of some particular organic functional groups (see below). In this text the general reducing characteristics of LTDEA and LTPDA toward representative organic functional groups are summarized as follows:

$$
\begin{aligned}
\text { LTDEA } & \text { LTPDA } \\
\text { aldehyde } \rightarrow \text { alcohol (fast) } & \text { alcohol (slow) } \\
\text { ketone } \rightarrow \text { alcohol (fast) } & \text { alcohol (slow) } \\
\text { carboxylic acid } \rightarrow \text { alcohol (slow) } & \text { alcohol (slow) } \\
\text { acid chloride } \rightarrow \text { alcohol (moderate) } & \text { alcohol (slow) } \\
\text { ester } \rightarrow \text { alcohol (moderate) } & \text { alcohol (slow) }
\end{aligned}
$$




$$
\begin{array}{rlrl}
\text { epoxide } & \rightarrow \text { alcohol (fast) } & & \text { epoxide (fast) } \\
\text { amide } & \rightarrow \text { amine (slow) } & \text { amide (slow) } \\
\text { nirtile } & \rightarrow \text { amine (slow) } & \text { amine(very slow) } \\
\text { nitro compound } & \rightarrow \text { reaction } & \text { reaction } \\
\text { disulfide } & \rightarrow \text { thiol with no } \mathrm{H}_{2} \text { (fast)thiol with } \mathrm{H}_{2} \text { (fast) } \\
\text { other sulfur compound } & \rightarrow \text { no reaction } & \text { no reaction }
\end{array}
$$

As mentioned above, these lithium dialkylaminoaluminum hydrides appear to be very milder reducing agents than that of the parent LAH and hence exhibit some very promising reducing capabilities in the reduction of organic functional groups, such as an aldehyde synthesis from carboxylic acid derivatives and a thiol formation from disulfides.

Firstly, LTDEA reduces aliphatic esters to aldehydes in yields of $55-80 \%$. $\alpha, \beta$-Unsaturated esters, such as ethyl crotonate and ethyl cinnamate undergo the reaction to afford the corresponding olefinic aldehydes in yields of $60-80 \%$. The reduction of aromatic esters provides the corresponding aldehydes in $65-99 \%$. The chloro and nitro groups on the benzene ring are readily accommodated as in Eq. (51). ${ }^{62,63}$

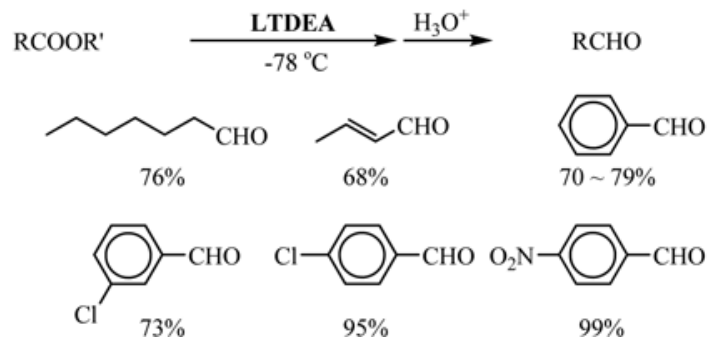

Secondly, more interestingly, LTDEA reduces both aliphatic and aromatic primary carboxamides to the corresponding aldehydes. These results are rather unexpected because every method for the transformation of carboxamides into aldehydes appeared in the literature has involved the reduction of $N, N^{\prime}$-disubstituted tertiary amides. Two equivalent of the reagent reduces primary amides slowly, requiring 6-12 h at room temperature, with concurrent evolution of less than one equivalent hydrogen. The yields from aliphatic series are $50-85 \%$; the yields from aromatics are $70-90 \%{ }^{63,64}$ (Eq. 52). Similarly, excess LTPDA can also reduce primary carboxamides to aldehydes more slowly, requiring 12-24 h at room temperature. ${ }^{63,65}$

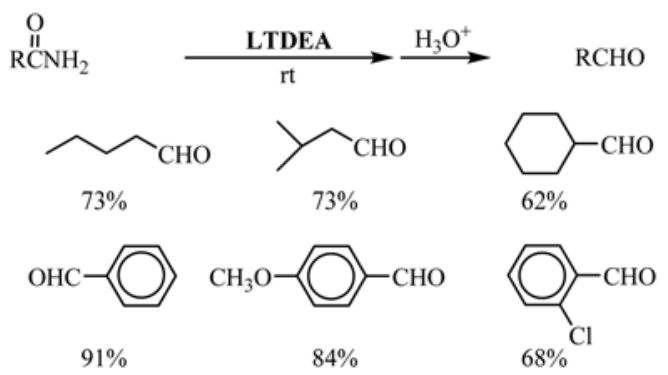

The aldehyde yields from aliphatic primary carboxamides with LTPDA are varying with the structure, showing 20$85 \%$. However, the yields from aromatic series are $80-95 \%$ as in Eq. (53).

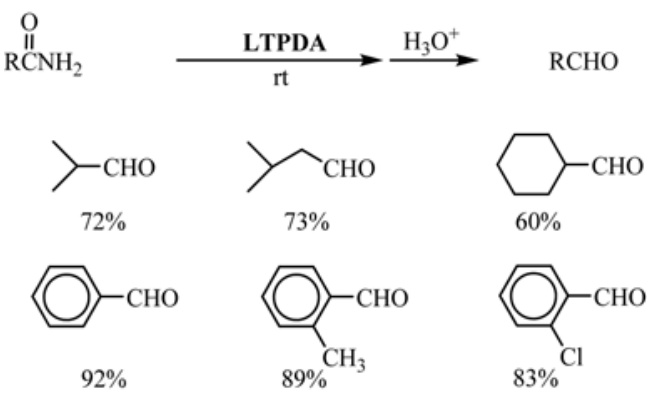

Thirdly, both LTDEA and LTPDA also reduce tertiary $N, N^{\prime}$-dimethylcarboxamides to aldehydes in good yields ${ }^{63}$ (Eq. 54). The reduction of aromatic series affords the corresponding aldehydes in more than $90 \%$ both at 0 and $25^{\circ} \mathrm{C}$. However, the yields from aliphatics are somewhat lower (around 80\%).

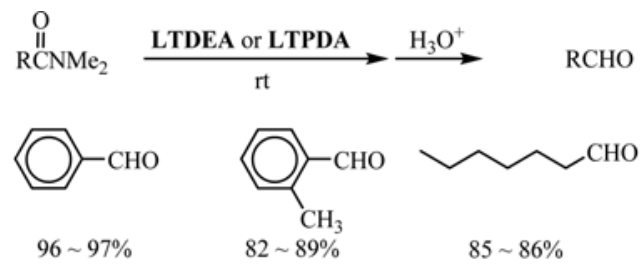

Fourthly, the reagents, LTDEA, LTDBA and LTDHA, are also applied to the partial reduction of nitriles both at 0 and $25^{\circ} \mathrm{C} .{ }^{63,66}$ In general, in the reduction of aromatic nitriles, the yields of aldehydes are in the order of LTDEA $<$ LTDBA < LTDHA. LTDEA seems to be too reactive to stop at the aldehyde stage. LTDBA is good enough to convert aromatic nitriles into aldehydes. However, LTDHA ${ }^{67}$ reduces various aromatic nitriles, except for nitrobenzonitrile, to aldehydes in essentially quantitative yields (Eq. 55), superior to potassium 9-sec-amyl-9-BBNH (K9-s-Am9-BBNH). ${ }^{33}$ The reduction of aliphatic nitriles with these
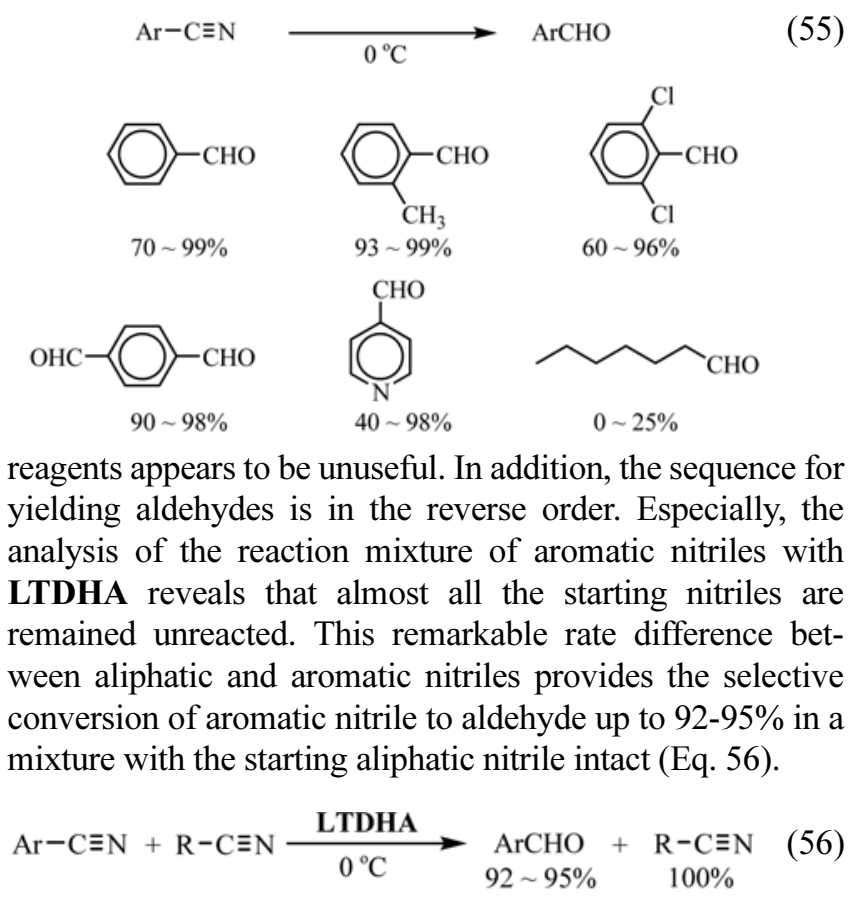
Fifthly, the reagents, LTDEA, LTDBA and LTDHA, readily reduce both aliphatic and aromatic disulfides to the corresponding thiols without any evolution of hydrogen even at room temperature. ${ }^{68}$ Because, usually the reaction of disulfides with metal hydrides evolves hydrogen as the reduction proceeds, these unique reactions provide a practical conversion of disulfides to thiols with only the calculated amount of reagent utilized in a safe manner where the system is free from the dangerous hydrogen evolution (Eq. 57). The rate of reduction is in the order of LTDEA > LTDBA > LTDHA. The reaction with LTDEA is completed readily at $0{ }^{\circ} \mathrm{C}$ or room temperature.

$$
\mathrm{R}-\mathrm{S}-\mathrm{S}-\mathrm{R}+\mathrm{LiAlH}\left(\mathrm{NR}_{2}\right)_{3} \longrightarrow 2 \mathrm{RSH}+\mathrm{noH}_{2} \uparrow
$$

Sodium Tris(Dialkylamino)aluminum Hydrides. Like lithium aluminum hydride (LAH), sodium aluminum hydride (SAH) reacts readily with three equivalents of dialkylamine $(\mathrm{R}=\mathrm{Et}, \mathrm{Bu}, \mathrm{Hex})$ with the evolution of three equivalents of hydrogen at $0{ }^{\circ} \mathrm{C}$, even in the presence of excess amines, to form stable sodium tri(dialkylamino)aluminum hydride $\left(\mathbf{N a}\left(\mathbf{R}_{\mathbf{2}} \mathbf{N}\right)_{\mathbf{3}} \mathbf{A l H}\right)$ as in Eq. (58).

$$
\begin{aligned}
& \mathrm{NaAlH}_{4}+3 \mathrm{R}_{2} \mathrm{NH} \underset{0 \sim 25^{\circ} \mathrm{C}}{\stackrel{\text { THF }}{\longrightarrow}} \mathrm{Na}\left(\mathrm{NR}_{2}\right)_{3} \mathrm{AlH}+3 \mathrm{H}_{2} \uparrow \\
& \mathrm{R}=\text { Et, STDEA } \\
& \text { Bu, STDBA } \\
& \text { Hex, STDHA }
\end{aligned}
$$

The general reducing characteristics of STDEA toward representative organic functional groups under standardized conditions (THF, $0{ }^{\circ} \mathrm{C}$ ) are examined ${ }^{69}$ and the results are summarized as follows:

$$
\begin{aligned}
\text { aldehyde } & \rightarrow \text { alcohol (fast) } \\
\text { ketone } & \rightarrow \text { alcohol (fast) } \\
\text { carboxylic acid } & \rightarrow \text { alcohol (very slow) } \\
\text { acid chloride } & \rightarrow \text { alcohol (slow) } \\
\text { ester } & \rightarrow \text { alcohol (slow) } \\
\text { epoxide } & \rightarrow \text { alcohol (fast) } \\
\text { amide } & \rightarrow \text { amine (very slow) } \\
\text { nitrile } & \rightarrow \text { amine (very slow) } \\
\text { nitro compound } & \rightarrow \text { reaction } \\
\text { disulfide } & \rightarrow \text { thiol (slow) } \\
\text { other sulfur compound } & \rightarrow \text { no reaction }
\end{aligned}
$$

Like lithium tri(diethylamino)aluminum hydride (LTDEA), the introduction of dialkylamino group into $\mathbf{S A H}$ diminishes its reactivity to a great extent. In general, the reactivity of STDEA toward organic functional groups are lower than that of the lithium derivative, but the reagent shows exactly same trends in those reactions as LTDEA. This phenomenon occurs to all other dialkylamino-derivatives. Such a lower reactivity of the sodium derivatives provides an additional advantage over the lithium derivatives in the selective reduction of organic functionalities.

Firstly, STDEA reduces aliphatic esters to aldehydes in yields of $60-95 \%$ at $-78{ }^{\circ} \mathrm{C}$, and aromatic esters to aldehydes in $85-98 \%$ yields. ${ }^{70}$ Like the case of LTDEA, $\alpha, \beta$-unsaturated esters, such as ethyl crotonate and ethyl cinnamate, undergo the reduction to afford the corresponding olefinic aldehydes in yields of $60-70 \%$. Generally, the yields of aldehydes by STDEA are higher than those of LTDEA as in Eq. (59).

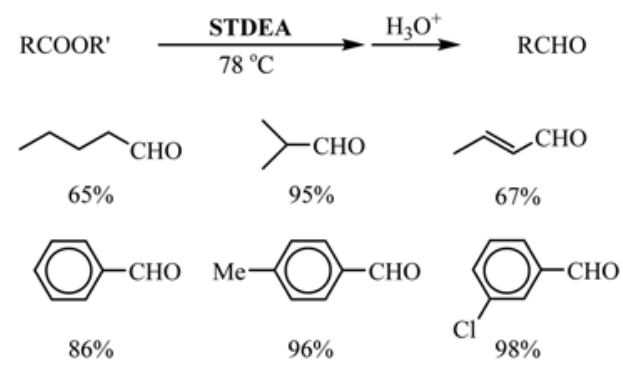

Secondly, all the reagents examined, STDEA, STDBA and STDHA, reduce both aliphatic and aromatic primary carboxamides to the corresponding aldehydes in satisfactory yields with a concurrent evolution of hydrogen slowly in an amount of less than one equivalent ${ }^{71}$ (Eq. 60). Tertiary $N, N^{\prime}$ dimethylcarboxamides are also reduced to the corresponding aldehydes with these reagents. ${ }^{69}$

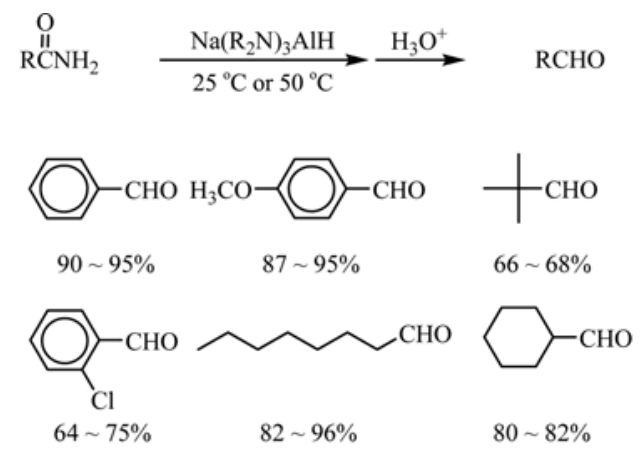

Thirdly, all the reagents, STDEA, STSBA and STDHA, are powerful enough to convert aromatic nitriles to aldehydes: the yields of aldehydes are much higher than those of the lithium derivatives. ${ }^{72}$ Especially, STDHA, like LTDHA, efficiently converts aromatic aldehydes to aldehydes in higher than $90 \%$ at room temperature. (Eq. 61). Similarly, all the sodium derivatives show very low reactivity toward aliphatic nitriles. Reduction of aromatic nitriles to the corresponding aldehydes chemoselectively in the presence of aliphatic nitriles leads to $93-99 \%$ conversion of aromatic nitriles with only minimal reduction of the aliphatic nitriles into aldehydes using a limiting amount of reagent (Eq. 62).

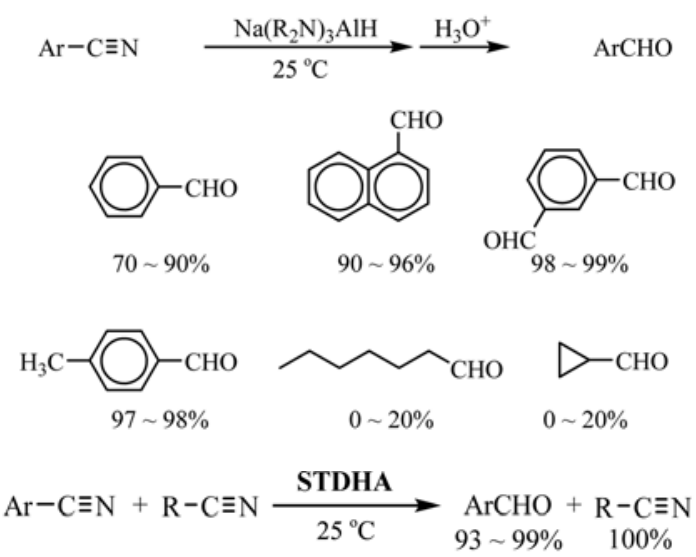


The use of SAH instead of LAH for preparation of other reducing agents, such as alkoxy- or dialkylamino-derivatives, and alane reagents, is desirable, because its lower cost and its relative mildness. Although the sodium derivatives show a lower reactivity than the lithium derivatives toward most functionalities, the reduction patterns appear to be exactly same. Such a relatively lower reactivity, on the other hand, adds an advantage to the sodium derivatives to achieve a higher selectivity in the reduction of organic functionalities. As a consequence, the sodium derivatives can replace the lithium derivatives efficiently, with a higher selectivity, in most organic reductions.

Lithium $N, N^{\prime}$-Dimethylethylenediaminoaluminum Hydride. This reagent in THF can be prepared by a simple addition of equimolar solution of $N, N^{\prime}$-dimethylethylenediamine in THF to a solution of $\mathbf{L A H}$ at $-78^{\circ} \mathrm{C}$ (Eq. 63).<smiles>[R]NCCN[R]</smiles>

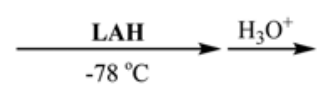

The reagent shows a very unique selectivity. Thus, in a similar to the behavior of K9-s-Am-9-BBNH ${ }^{35}$ toward nitriles, the reagent converts various aromatic nitriles into the corresponding aldehydes at $0{ }^{\circ} \mathrm{C}$, but does not show any reactivity toward aliphatic nitriles. The yields of aldehydes from a variety of aromatic nitriles are nearly quantitative ${ }^{73}$ (Eq. 64).

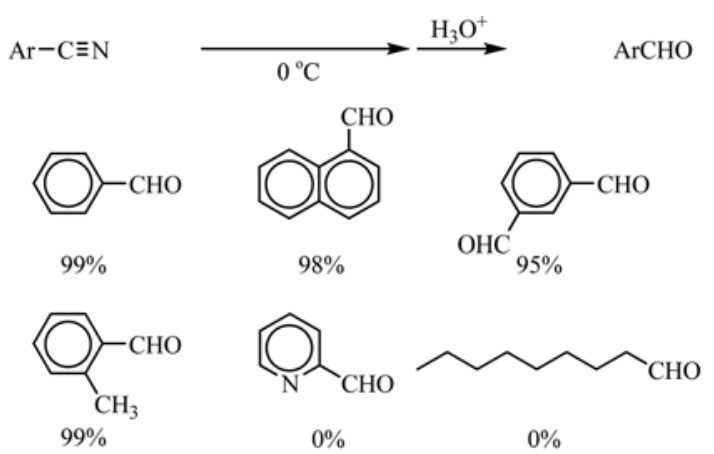

Such a remarkable rate difference in the reduction of aromatic and aliphatic nitriles affords the chemoselective conversion of aromatic nitrile in the presence of aliphatic one intact: for example, the reagent converts only $p$-tolunitrile selectively to $p$-tolualdehyde in the reduction of an equimolar mixture of $p$-tolunitrile and decanenitrile at $0{ }^{\circ} \mathrm{C}$ (Eq. 65).

$$
\begin{array}{r}
\mathrm{H}_{3} \mathrm{C}-\mathrm{C} \equiv \mathrm{N}+\mathrm{CH}_{3}\left(\mathrm{CH}_{2}\right)_{8} \mathrm{CH}_{2} \mathrm{C} \equiv \mathrm{N} \underset{{ }_{0}^{\circ} \mathrm{C}}{\longrightarrow}-\mathrm{CHO}+\mathrm{CH}_{3}\left(\mathrm{CH}_{2}\right)_{8} \mathrm{CH}_{2} \mathrm{C} \equiv \mathrm{N} \\
{ }_{99 \%} \mathrm{C}-{ }_{100 \%}-\mathrm{CH}
\end{array}
$$

The reagent can also convert carboxylic esters to the corresponding aldehydes in good yields at $0{ }^{\circ} \mathrm{C}$. The aldehyde yields from aromatic esters are in $80-95 \%$ and from aliphatic ones are $75-80 \%{ }^{74}$ (Eq. 66).

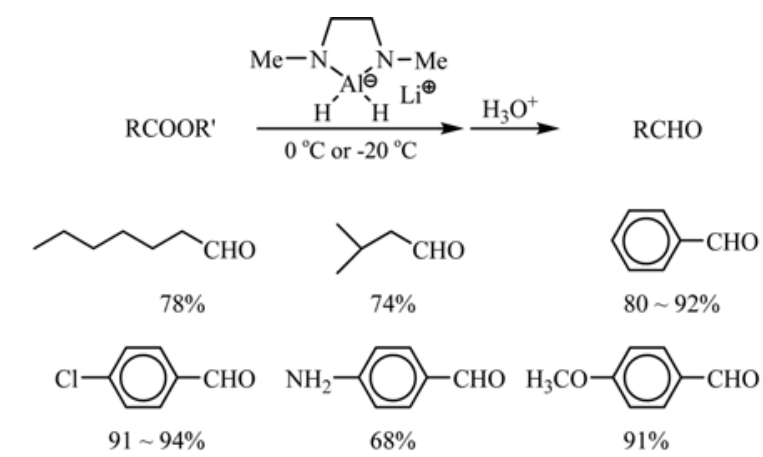

Lithium Tri(2-methyl-2-propanethioxy)aluminum Hydride. The reagent, lithium tri(2-methyl-2-propanethioxy)aluminum hydride (lithium tris(tert-butylthiolato)hydridoaluminate, LTBSA) is prepared from the reaction of one mole of LAH with three moles of 2-methyl-2-propanethiol in THF at room temperature (Eq. 67).

$$
\mathrm{LiAlH}_{4}+3 t \text {-BuSH } \underset{\mathrm{rt}}{\stackrel{\text { THF }}{\longrightarrow}} \mathrm{Li}(t-\mathrm{Bus})_{3} \mathrm{AlH}+3 \mathrm{H}_{2} \uparrow
$$

The general reducing characteristics toward organic functional groups under practical conditions $\left(0{ }^{\circ} \mathrm{C}\right.$, THF, $10 \%$ excess reagent utilized) are examined ${ }^{75}$ and the results are summarized as follows:

$$
\begin{aligned}
\text { aldehyde } & \rightarrow \text { alcohol (fast) } \\
\text { ketone } & \rightarrow \text { alcohol (slow) } \\
\text { carboxylic acid } & \rightarrow \text { alcohol (slow) } \\
\text { acid chloride } & \rightarrow \text { alcohol (fast) } \\
\text { ester } & \rightarrow \text { alcohol (slow) } \\
\text { epoxide } & \rightarrow \text { no reaction } \\
\text { amide } & \rightarrow \text { no reaction } \\
\text { nitrile } & \rightarrow \text { no reaction } \\
\text { nitro compound } & \rightarrow \text { no reaction } \\
\text { disulfide } & \rightarrow \text { thiol (slow) } \\
\text { other sulfur compound } & \rightarrow \text { no reaction }
\end{aligned}
$$

The introduction of tert-butylthio group into $\mathbf{L A H}$ diminishes the reaction power tremendously and modifies the reducing pattern of the parent $\mathbf{L A H}$, which subsequently induces unique reducing characteristics of the reagent. For example, the reagent reduces $\alpha, \beta$-unsaturated aldehydes, such as crotonaldehyde and cinnamaldehyde, cleanly to the corresponding allylic alcohols: the selectivity appears perfect. However, $\alpha, \beta$-unsaturated ketones are absolutely inert to this reagent (Eq. 68). Generally, LTBSA shows a relatively milder reducing power than that of lithium tri(tert-butoxy)aluminum hydride (LTBA). However, the reducing characteristics of LTBSA appear to be quite different from those of LTBA. It is noteworthy to note that such a difference originates only from one atom exchange between oxygen and sulfur, which serves as a bridge for connecting $t$ butyl group to aluminum.

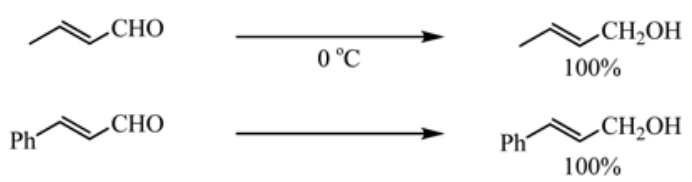




\section{Other Methods for Synthesis of Aldehydes from Carboxylic Acid and Its Derivatives by Stepwise Procedures}

Stepwise Reduction Procedure for Conversion of RCOOH to RCHO. One of the promising methods to obtain aldehydes is the reduction of a reactive intermediate, which is in situ formed by treating the starting carboxylic acd or its derivative with an appropriate reagent. As described above in the direct conversion of carboxylic acids to aldehydes with thexylhalo- and thexylalkoxyboranes, acyloxythexylalkoxy- (6) and acyloxythexylhaloboranes (7) seem to be reactive intermediates for reduction to the aldehyde stage. However, the reagents for preparing the intermediates should be synthesized by users themselves under the present situation. Consequently, the commercially available 9-borabicyclo[3.3.1]nonane (9-BBN, 8) seems to be one of candidates of choice for preparing such a reactive intermediate. The reaction of carboxylic acids with 9-BBN<smiles>CC(=O)OC(C)(C)C(C)(C)C(C)C</smiles>

6<smiles>C#CC1CCCCC1</smiles>

(8) provides readily the corresponding acyloxy-9-BBN (9) with evolution of one equivalent of hydrogen (Eq. 69).

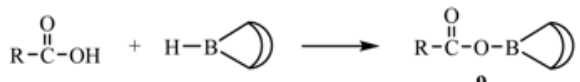

The addition of excess 9-BBN to the solution of 9 in THF can not attack the acyloxy group of $\mathbf{9}$ efficiently. However, the formation of lithium 9-acyloxy-9-boratabicyclo[3.3.1]nonane (Li acyloxy-9-BBNH, 10) by treatment of 9 with tert-butyllithium, which are much stronger in hydride-donating ability than 9-BBN (Eq. 70), accelerates the reduction of the acyloxy group intermolecularly or/and intramolecularly at room temperature. The yields of aldehydes obtained are not general, providing the variable yields of aldehydes with the structure of acyloxy group, even though the yields are high in some cases $(40-85 \%){ }^{76}$

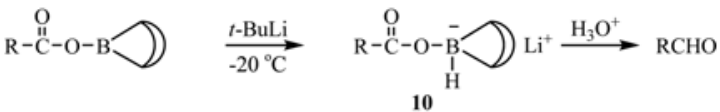

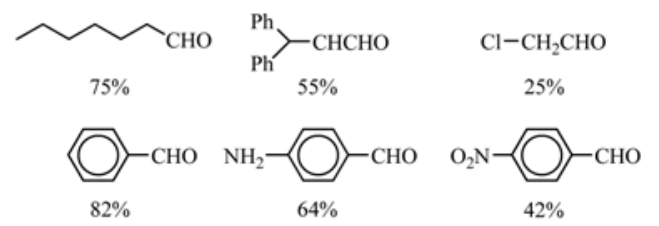

However, the addition of one equivalent of 9-BBN to the solution of 10 (Eq. 71), which serves as a bridge to transfer the hydride of $\mathbf{1 0}$ to the acyloxy group as in Scheme 1, achieves a nice conversion of the various acyloxy moieties of both aliphatic and aromatic carboxylic acids to the aldehyde stage, showing the very high yields of aldehydes $(80-99 \%)^{76,78}$

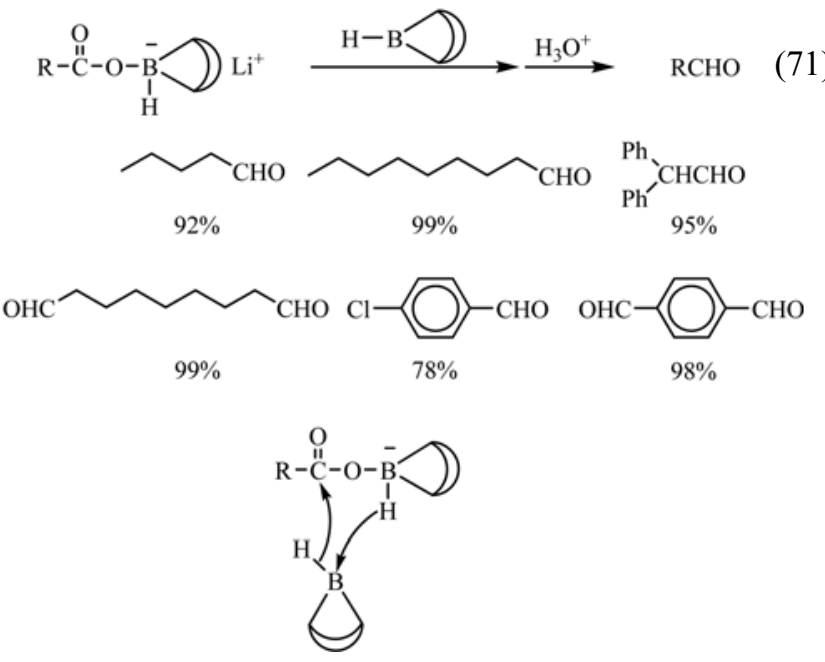

Scheme 1

Alternatively, the addition of lithium 9-boratabicyclo[3.3.1]nonane (Li 9-BBNH) itself to the solution of 9 instead of addition of 9-BBN to the solution of $\mathbf{1 0}$ equally achieves a nice conversion of the various acyloxy moieties of 9 to the aldehyde stage, showing very high yields (80$99 \%)^{77,78}$ (Eq. 72). The yields of aldehydes are exactly same as those obtained by the former method, which indicates strongly that the mechanism depicted in Scheme 1 is correct.

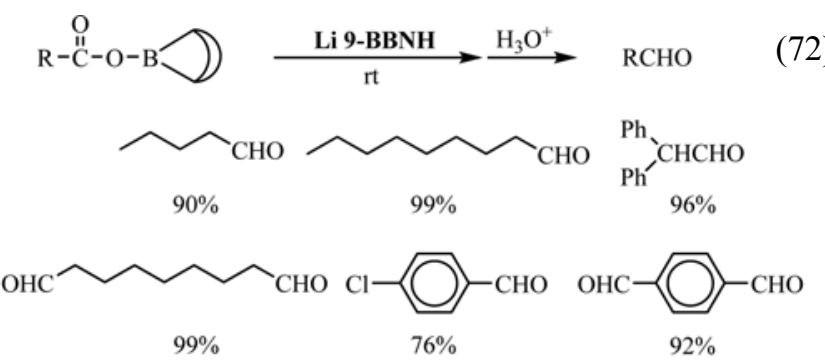

When the solution of $\mathbf{9}$ is treated with lithium aluminum hydride (LAH) at room temperature, the acyloxy group is completed reduced to the alcohol stage. However, in the presence of two equivalents of pyridine the reduction stops at the aldehyde stage (Eq. 73). This system reduces aromatic acyloxy groups to the aldehyde stage in yields of $80-95 \%$. On the other hand, the yields from aliphatic series are much

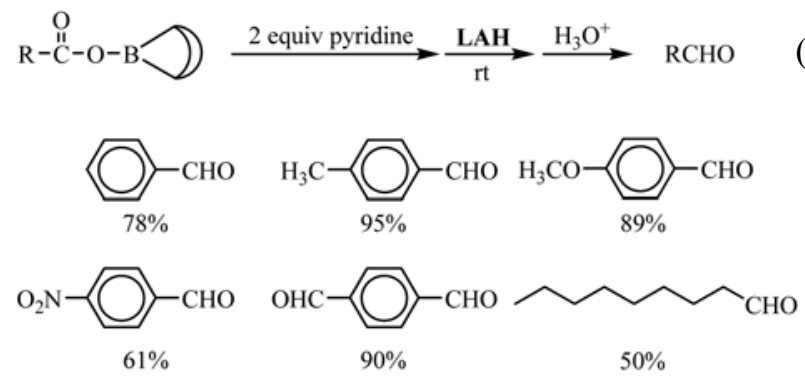


lower than those from aromatic series, showing approximately $50 \%$ yields. ${ }^{79}$

Similarly, the acyloxy group of acyloxy-9-BBN (9) in the presence of two equivalent of pyridine is readily converted to the corresponding aldehydes by reduction with lithium tri(diethylamino)aluminum hydride (LTDEA) (Eq. 74). However, in cases where no pyridine is added to the reaction mixture, the yields of aldehydes are significantly decreased. Such a dramatic enhancement of the yield of aldehyde seems to arise from the phenomenon where pyridine coordinates to the boron atom of acyloxy-9-BBN (9), which results in the inhibition of hydride transfer from LTDEA to this boron atom (when the hydride is transferred from LTDEA to form the acyloxy-9-BBNH (10), the aldehyde yields decrease significantly ${ }^{76}$ : Eq. 70). Accordingly, all the hydride can attack the acyloxy group of 9 to afford the aldehyde products in very high yields, ${ }^{63,80}$ as in Scheme 2.

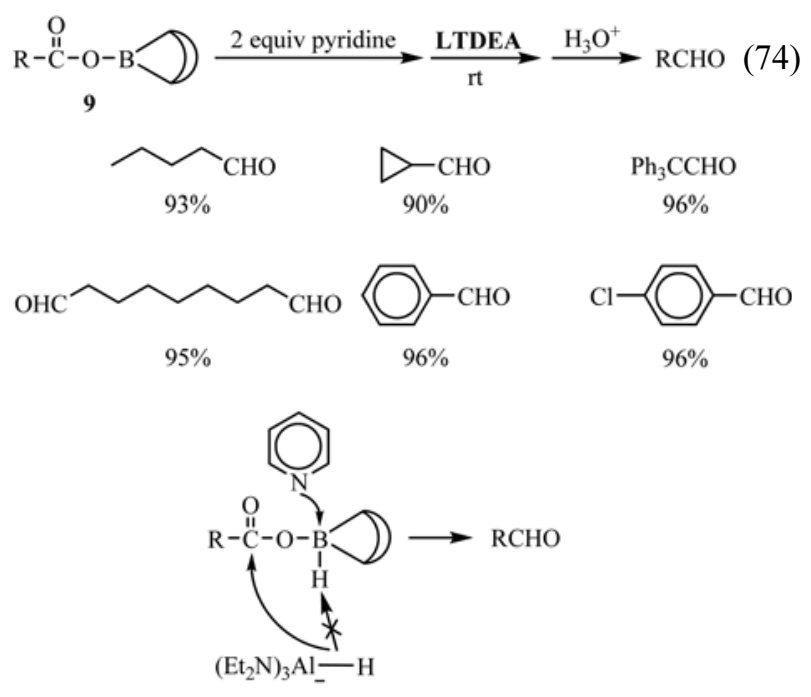

Scheme 2

Stepwise Reduction-oxidation Procedure for Conversion of RCOOH to RCHO. About thirty years ago, Professor Brown and coworkers reported that trialkyl borates are oxidized by pyridinium chlorochromate (PCC) to aldehydes and ketones, which provides another convenient procedure for the conversion of primary alcohols into the corresponding aldehydes in essentially quantitative yields. This method involves the reaction of alcohols with boranemethyl sulfide (BMS), followed by oxidation of the resultant trialkyl borate with $\mathbf{P C C}^{81}$ (Eq. 75). However, the reaction conditions are rather drastic for both the borate formation and oxidation steps (heating at $100{ }^{\circ} \mathrm{C}$ ).

$$
\begin{gathered}
3 \mathrm{RCH}_{2} \mathrm{OH}+\mathrm{BH}_{3} \underset{\mathrm{rt} \rightarrow 100^{\circ} \mathrm{C}}{\longrightarrow} \mathrm{B}\left(\mathrm{OCH}_{2} \mathrm{R}\right)_{3}+3 \mathrm{H}_{2} \uparrow \\
\mathrm{B}\left(\mathrm{OCH}_{2} \mathrm{R}\right)_{3} \underset{100^{\circ} \mathrm{C}, 1 \mathrm{~h}}{\longrightarrow} 3 \mathrm{RCHO}
\end{gathered}
$$

Alternatively, the use of aluminum hydride instead of borane provides another convenient procedure under much milder conditions (for both steps at $0{ }^{\circ} \mathrm{C}$ or room temper- ature). This method involves the reaction of alcohols with aluminum hydride $\left(\mathrm{AlH}_{3}\right)$, followed by oxidation of the resultant trialkoxyaluminum (11) with PCC (Eq. 76), to yield the corresponding aldehydes in higher than $96 \%{ }^{82}$

$$
\begin{aligned}
& 3 \mathrm{RCH}_{2} \mathrm{OH}+\mathrm{AlH}_{3} \underset{0{ }^{\circ} \mathrm{C} \rightarrow \mathrm{rt}}{\longrightarrow} \underset{\mathbf{1 1}}{\mathrm{Al}\left(\mathrm{OCH}_{2} \mathrm{R}\right)_{3}+3 \mathrm{H}_{2} \uparrow} \\
& \underset{11}{\mathrm{Al}\left(\mathrm{OCH}_{2} \mathrm{R}\right)_{3}} \stackrel{\mathrm{PCC}}{\mathrm{rt}, 1 \mathrm{~h}} \underset{\substack{3 \mathrm{RCHO} \\
>96 \%}}{3}
\end{aligned}
$$

This procedure for the conversion of alkoxyaluminum with PCC to aldehydes can be applied to synthesis of aldehydes, which involves the complete reduction of carboxylic acids with aluminum hydride or LAH to alkoxyaluminum species (12), followed by oxidation with $\mathbf{P C C} \mathbf{C}^{83}$ or pyridinium dichromate (PDC), ${ }^{84}$ as in Eq. (77). Both procedures achieve a clean, convenient conversion of both aliphatic and aromatic carboxylic acids to the corresponding aldehydes in essentially quantitative yields.

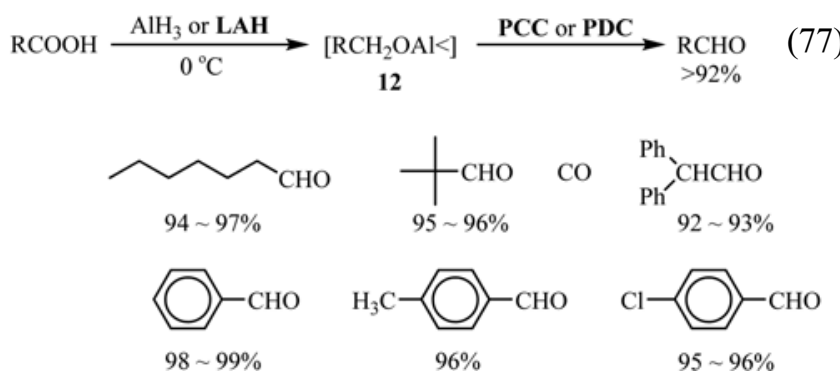

Carboxylic acids can also be converted to aldehydes by stepwise treatment with sodium borohydride and dimethyl sulfate. This method involves the reaction of carboxylic acids with sodium borohydride to form acyloxyborohydride (13), followed by treatment of $\mathbf{1 3}$ with dimethyl sulfate to form acyloxyborane (14), a reactive intermediate..$^{85}$ The initial reaction product in such reduction has been identified as the corresponding trialkoxyboroxine (15), as in Eq. (78). In similar to other cases utilizing aluminum reagents, the yields of aldehydes obtained from the reaction of both aliphatic and aromatic carboxylic acids are essentially quantitative.

$$
\begin{aligned}
& \mathrm{RCOOH} \underset{0{ }^{\circ} \mathrm{C}}{\stackrel{\mathrm{NaBH}_{4}}{\longrightarrow}} \mathrm{RCOOHBH} \mathrm{Na}_{3}+\mathrm{H}_{2} \uparrow \stackrel{\left(\mathrm{CH}_{3}\right)_{2} \mathrm{SO}_{4}}{\longrightarrow} \mathrm{RCOOBH}_{2}+\mathrm{CH}_{4} \uparrow
\end{aligned}
$$

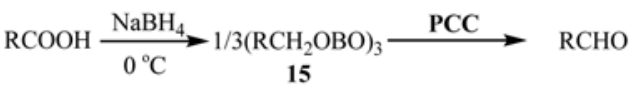

$$
\begin{aligned}
& \bigcirc-\mathrm{CHO} \\
& \mathrm{Cl}-\mathrm{CHO} \\
& \mathrm{O}_{2} \mathrm{~N}-\mathrm{CHO} \\
& \overbrace{\mathrm{CHO}} \\
& \underset{95 \%}{\mathrm{CHO}} \\
& \mathrm{Ph}_{94 \%} \mathrm{CHO}
\end{aligned}
$$

Stepwise Reduction Procedure for Conversion of $\mathbf{R C O O}^{-} \mathbf{M}^{+}$to RCHO. If a sodium or lithium carboxylate and 9-borabicyclo[3.3.1]nonane (9-BBN) forms an ate complex, metal 9-boratabicyclo[3.3.1]nonane (M 9-BBNH, 
$\mathbf{M}=\mathrm{Na}, \mathrm{Li}$ ), which is the same compound (10) formed by treatment of acyloxy-9-BBN (9) with tert-butyllithium (Eq. 69 and 70). Actually, this system is in equilibrium, in which the acyloxy group of the ate complex thus formed is readily transformed into the corresponding aldehyde stage in the presence of excess 9-BBN ${ }^{86,87}$ (Eq. 79). The reduction just

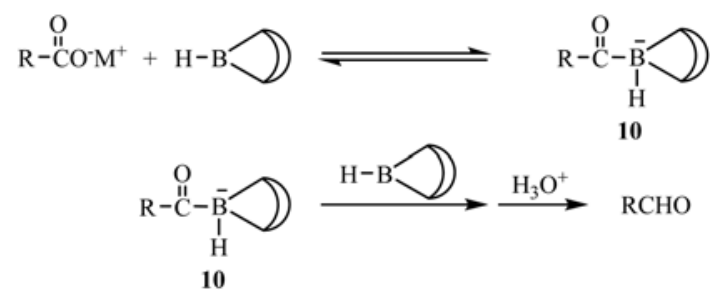

follows the consecutive hydride transfer pathway depicted in Scheme 2. The yields of aldehydes from both sodium and lithium carboxylates are very high.

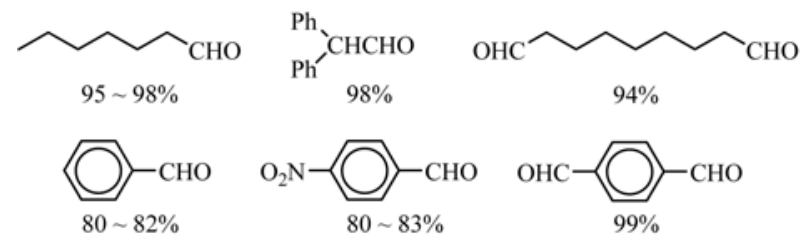

Stepwise Reduction-oxidation Procedure for Conversion of $\mathbf{R C O O}^{-} \mathbf{M}^{+}$to RCHO. The key step in the conversion of carboxylic acids to aldehydes by stepwise treatment with sodium borohydride and dimethyl sulfate is the in situ formation of acyloxyborane (14) and finally boroxine (15) in the reaction mixture by treatment of acyloxyborohydride (13) with dimethyl sulfate with evolution of methane (Eq. 76). On this mechanistic basis. If a sodium or lithium carboxylate reacts with borane in THF to form an ate complex, which is the same species $\mathbf{1 3}$ as depicted in Eq. 76, the system follows the exactly same reduction pathway until the boroxine $\mathbf{1 5}$ forms. Actually, carboxylate readily reacts with borane in THF and the system exists in equilibrium, which is driven over to the right by the reaction with dimethyl sulfate and hence evolution of methane to yield acyloxyborane 14. Finally, the oxidation of the resultant boroxine 15 with PCC yields aldehydes ${ }^{88}$ as in Eq. (80).

$$
\begin{gathered}
\mathrm{RCOO}^{-} \mathrm{M}^{+}+\mathrm{BH}_{3} \rightleftharpoons \underset{13}{\mathrm{RCOOBH}_{3}{ }^{-} \mathrm{M}^{+}} \frac{\mathrm{Me}_{2} \mathrm{SO}_{4}}{-\mathrm{CH}_{4} \uparrow} \mathrm{RCOOBH}_{\mathbf{1 4}}(80) \\
\longrightarrow \underset{\mathbf{1 5}}{1 / 3\left(\mathrm{RCH}_{2} \mathrm{OBO}\right)_{3}} \stackrel{\mathrm{PCC}}{\longrightarrow} \mathrm{RCHO}
\end{gathered}
$$

Generally, aliphatic carboxylic acid salts convert to aldehydes in essentially quantitative yields. However, the aromatic derivatives bearing a readily reactive group, such as cyano
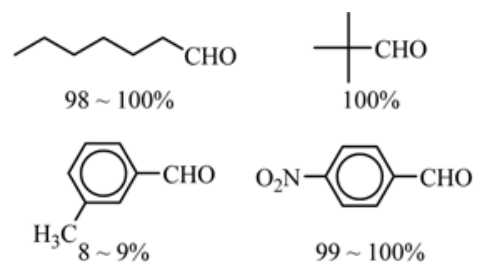

$$
\begin{aligned}
& \mathrm{Ph}^{`} \text { ¿ } \\
& \mathrm{PhCHO}^{\prime} \\
& 98 \sim 99 \%
\end{aligned}
$$

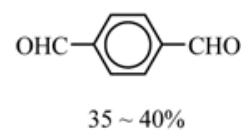

and olefin groups, afford very low yield of aldehyde. Dicarboxylic acid salts also fail to provide satisfactory yield of dialdehyde.

Carboxylic acid metal salts can be converted to aldehydes by treatment with one more equivalent of borane in THF (i.e., two equivalents) in place of dimethyl sulfate. ${ }^{89}$ In this case the second mole of $\mathrm{BH}_{3}$ behaves as a Lewis acid to abstract hydride from acyloxyborohydride (13) to form acyloxyborane (14), which then converts to boroxine (15). The oxidation of the resultant reaction mixture with PCC gives aldehydes, Actually, this system is quite similar to the former method, showing the almost same trend in such conversion (Eq. 81).

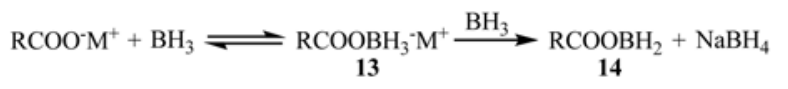

$$
\begin{aligned}
& 1 / 3\left(\mathrm{RCH}_{2} \mathrm{OBO}\right)_{3} \longrightarrow \mathrm{RCHO} \\
& 15 \\
& \overbrace{100 \%}^{\mathrm{CHO}} \mathrm{f}_{100 \%}^{\mathrm{CHO}} \\
& \mathrm{Ph} \curvearrowright \mathrm{CHO} \\
& 7 \sim 8 \% \\
& \longrightarrow \mathrm{CHO} \\
& 50 \sim 56 \%
\end{aligned}
$$
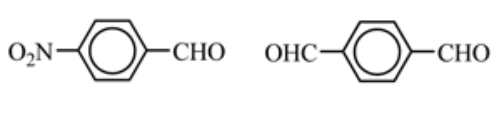

Stepwise Reduction-oxidation Procedure for Conversion of RCOCl to RCHO. Such a stepwise procedure can equally be applied to the conversion of acid chlorides to aldehydes through the complete reduction of the compounds with $\mathrm{AlH}_{3}{ }^{90}$ or $\mathbf{L A H},{ }^{91}$ and followed by oxidation of the resultant alkoxyaluminum with PCC or PDC (Eq. 82). Both procedures afford the same results to give the essentially quantitative yields; no dependence on PCC or PDC is apparent.

$$
\left.\mathrm{RCOCl} \stackrel{\mathrm{AlH}_{3} \text { or } \mathbf{L A H}}{\longrightarrow}\left[\mathrm{RCH}_{2} \mathrm{O}\right]-\mathrm{Al}^{-}\right] \stackrel{\text { PCC or PDC }}{\longrightarrow} \mathrm{RCHO}
$$

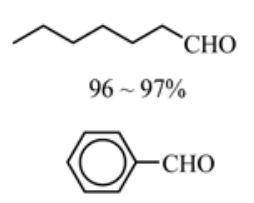

$98 \%$

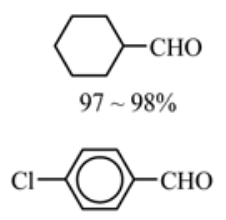

$97 \%$

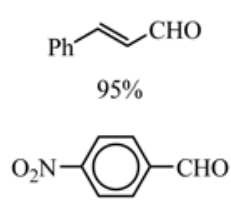

$94 \%$
Sodium borohydride, a very mild and economical reducing agent, seems to be reagents of choice for such a complete reduction of acid chlorides to the corresponding alkoxyboron. But the reaction in THF is very slow because of its very low solubility, requiring $24 \mathrm{~h}$ in refluxing THF for complete reduction. However, the reaction is completed in THF-DMF $(1: 1)$ in $24 \mathrm{~h}$ at $25^{\circ} \mathrm{C}$. The tolerance of sodium borohydride toward a wide variety of functional groups as well as its easy handling and low cost, combined with the mild nature of PCC as an oxidizing agent, makes this method simple, general and practical, ${ }^{92}$ as in Eq. (83). The reaction is broadly applicable to a variety of acid chlorides bearing every organic functional groups to afford the corresponding 
aldehydes in essentially quantitative yields.

$$
\text { RCOCl } \underset{\text { THF-DMF, } 25^{\circ} \mathrm{C}}{\stackrel{\mathrm{NaBH}_{4}}{\longrightarrow}}\left[\mathrm{RCH}_{2} \mathrm{O}_{-1}^{\mathrm{B}-}\right] \mathrm{Na}^{+} \stackrel{\text { PCC }}{\longrightarrow} \text { RCHO }
$$

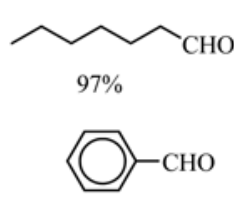

$98 \%$
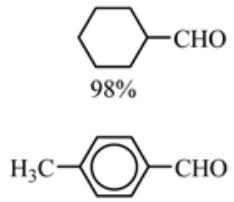

$99 \%$<smiles>O=C/C=C/c1ccccc1</smiles><smiles>O=Cc1ccc([N+](=O)[O-])cc1</smiles>

$97 \%$
Stepwise Reduction-Oxidation Procedure for Conversion of RCOOR' to RCHO. The stepwise procedure involved a complete reduction of esters with aluminum hydride ${ }^{93}$ or $\mathbf{L A H}^{94}$ (a half equivalent) and a partial oxidation of the resultant alkoxyaluminum intermediate with PCC or PDC provides the corresponding aldehydes in essentially quantitative yields: this reaction appears to be equally applicable to both aliphatic and aromatic esters (Eq. 84).

$$
\begin{aligned}
& \mathrm{RCOOR}^{\prime} \stackrel{\mathrm{AlH}_{3} \text { or } \mathrm{LAH}}{\longrightarrow} \mathrm{RH}_{2} \mathrm{CO}-\mathrm{Al}^{\prime}, \stackrel{\mathrm{PCC} \text { or PDC }}{\longrightarrow} \mathrm{RCHO} \\
& \overbrace{95 \sim 97 \%}^{\mathrm{CHO}} \underset{97 \sim 99 \%}{\mathrm{O}}-\mathrm{CHO} \\
& \mathrm{Ph}^{\curvearrowright} \mathrm{CHO} \\
& \mathrm{Cl} \longrightarrow \mathrm{CHO} \mathrm{O}_{2} \mathrm{~N}-\mathrm{CHO} \\
& 97 \sim 98 \% \\
& 94 \sim 98 \%
\end{aligned}
$$

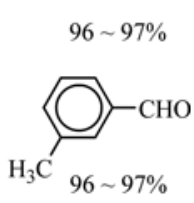

Stepwise Reduction Procedure for Conversion of $\mathrm{RC}(\mathrm{O}) \mathrm{NH}_{2}$ to $\mathrm{RCHO}$. The reaction of primary carboxamides with diisobutylaluminum hydride (DIBAH) at $0{ }^{\circ} \mathrm{C}$ to give an intermediate $\mathbf{1 6}$ with evolution of one equivalent of hydrogen, which is then reduced by excess lithium tri(diethylamino)aluminum hydride (LTDEA) at room temperature to the corresponding aldehydes in yields of $50-82 \%{ }^{95}$ (Eq. 85).

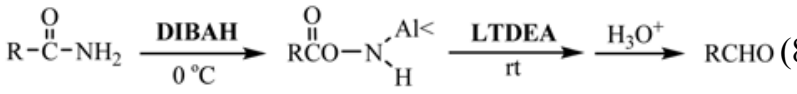

$$
\begin{aligned}
& \mathrm{Cl}_{56 \%} \sim_{\mathrm{CHO}}^{\mathrm{CHO}} \overbrace{61 \%}^{\mathrm{CH} \%} \overbrace{\mathrm{CHO}} \\
& \text { - }
\end{aligned}
$$

\section{Summary of Recommended Procedures for Aldehyde Synthesis by Reduction}

In this section the recommended procedures for synthesis of aldehydes from readily available carboxylic acids and their derivatives by reduction, developed by the author and collaborators, are summarized in item by carboxylic acid derivatives, such as carboxylic acid, carboxylic acid metal salt, acid chloride, ester, amide, and nitrile.

Conversion of Carboxylic Acid to Aldehyde. The recommended procedures for the conversion of carboxylic acid itself to aldehyde are classified as follows: (i) a direct partial reduction, (ii) a partial reduction through a reactive acyloxy-9-BBN, and (iii) a complete reducton to alkoxy moiety, and followed by partial oxidation.

The procedure for direct partial reduction involves the utilizing thexylhalo- or thexylalkoxyboranes-methyl sulfide (ThxBHX-SMe $2, \mathbf{X}=\mathrm{Cl}, \mathrm{Br}, \mathrm{OR}),{ }^{12,13,26}$ as illustrated in Scheme 3 and 4. Especially, the ability for converting only aromatic carboxylic acids to the corresponding aldehydes selectively in the presence of aliphatic acids intact with thexylhalo- and thexylalkoxyboranes is noteworthy.

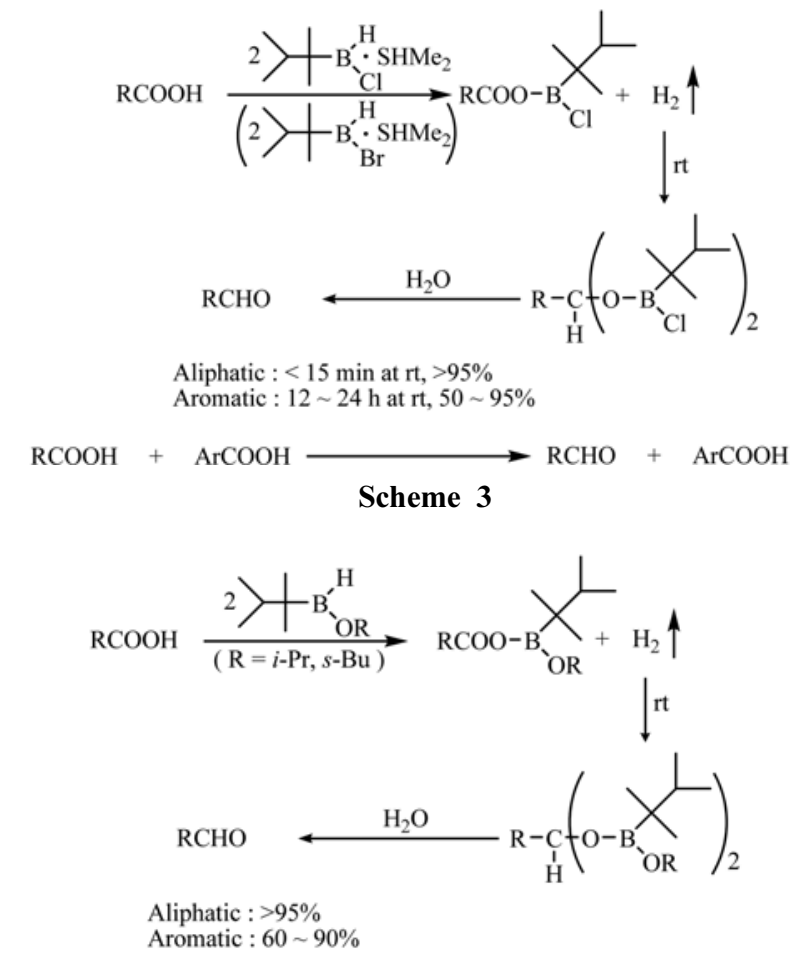

Scheme 4

The recommended procedure for conversion of acyloxy group of acyloxy-9-BBN, a reactive intermediate, to aldehyde involves the partial reduction with lithium tri(diethylamino)aluminum hydride (LTDEA) in the presence of two equivalent of pyridine ${ }^{80}$ In this case, when no pyridine is added, the yields decrease significantly to $60-70 \%$ (Scheme 5 ).

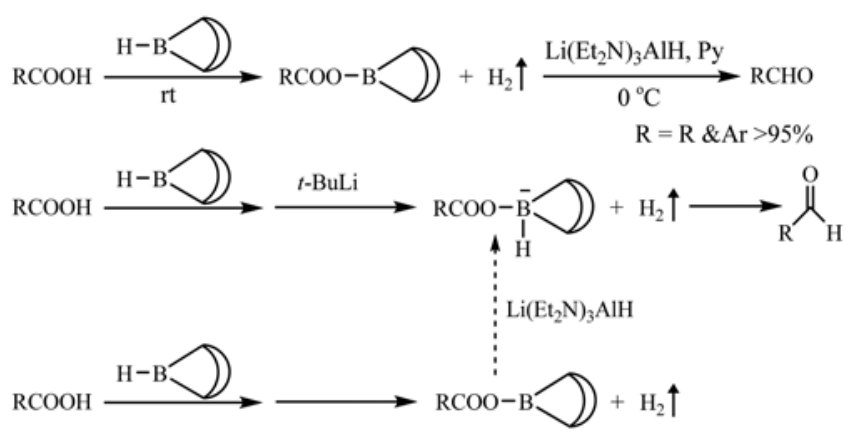

Scheme 5 
The stepwise reduction-oxidation procedure, involved the complete reduction of carboxylic acid to alkoxy moieties utilizing borane-methyl sulfide (BMS), ${ }^{81}$ aluminum hydride ${ }^{82}$ or lithium aluminum hydride (LAH $)^{83}$ and oxidation with PCC or PDC, is also recommended (Scheme 6). Especially, the procedure utilizing sodium borohydride and dimethyl sulfate appears to be the best one, because of its mildness, easy handling and its low cost ${ }^{85}$ (Scheme 7).

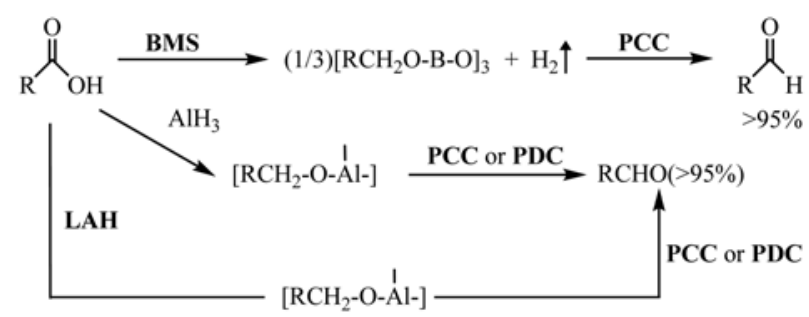

Scheme 6

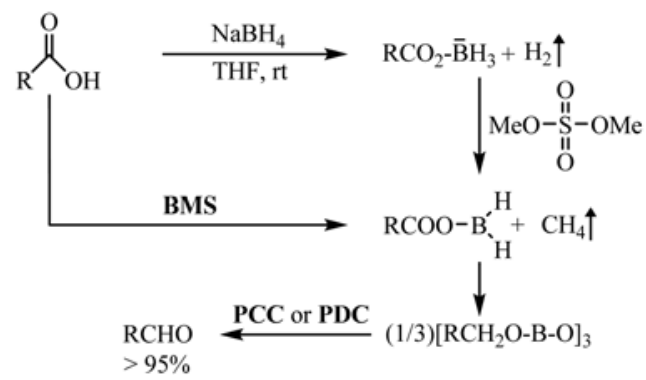

Scheme 7

Conversion of Carboxylic Acid Metal Salts to Aldehyde. Depending on the structure of compounds applied, users can choose any one among the procedures developed: the procedures utilizing thexylbromoborane-methyl sulfide $\left(\text { ThxBHBr } \cdot \mathbf{S M e}_{2}\right)^{17,19}$ (Scheme 8), 9-BBN, ${ }^{86,87}$ (Scheme 9), or $\mathrm{BH}_{3}$ in $\mathbf{T H F}^{89}$ (Scheme 10 and 11). However, the procedure depicted in Scheme 10 seems to be the most practical.

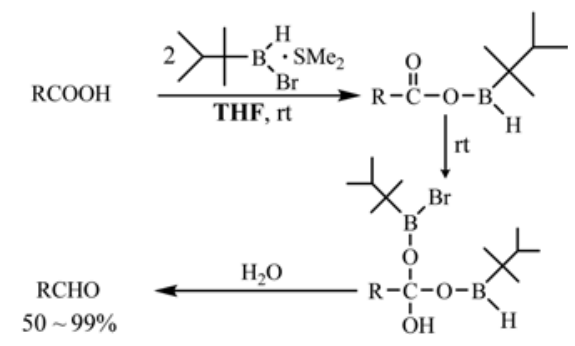

Scheme 8

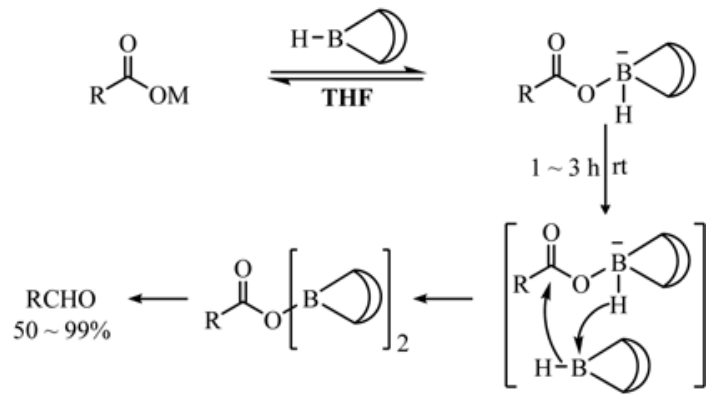

Scheme 9

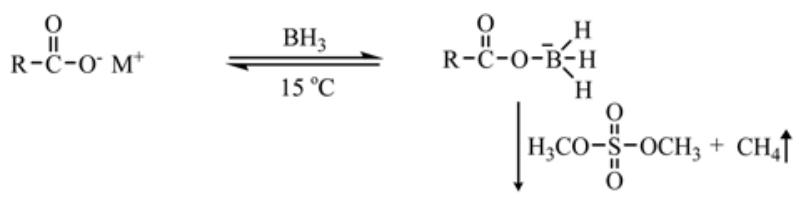

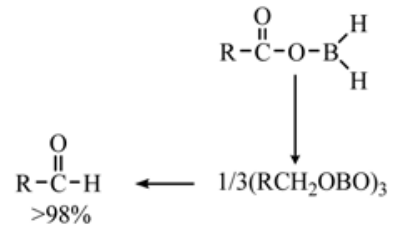

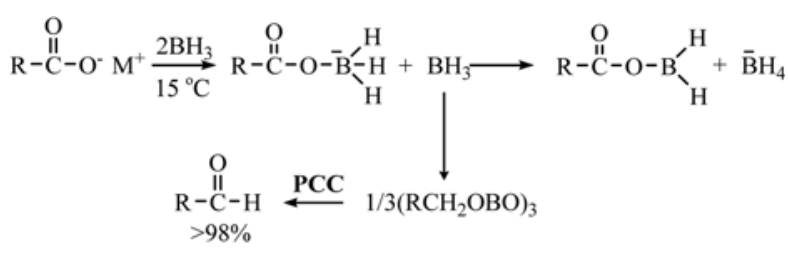

Scheme 11

Conversion of Acid Chloride to Aldehyde. The recommended procedure for conversion of acid chloride to aldehyde is the direct reduction with tri-tert-butoxyaluminohydride (STBA) ${ }^{42}$ and thexylalkoxyborane (ThxBHOR, $\mathbf{R}=\boldsymbol{i}-\mathbf{P r}, \boldsymbol{s}-\mathbf{B u})^{26}$ as depicted in Scheme 12. In addition to these, the stepwise reduction-oxidation procedures ${ }^{90-92}$ (particularly, utilizing sodium borohydride ${ }^{92}$ ) are recommended (Scheme 13).

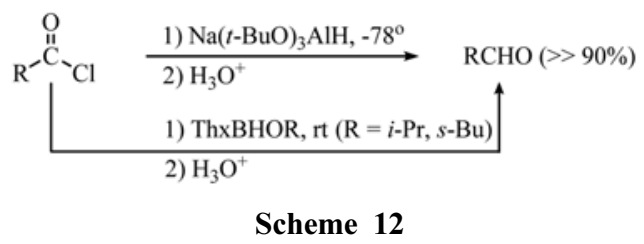

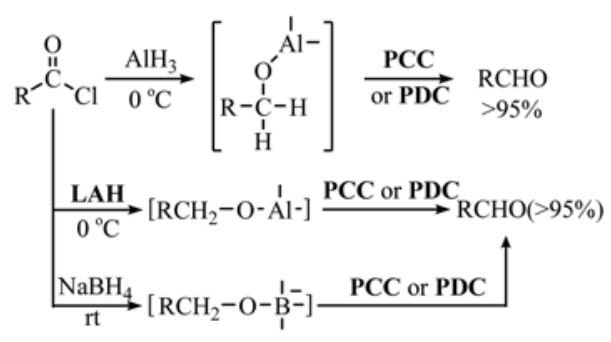

Scheme 13

Conversion of Ester to Aldehyde. The direct reduction of esters with sodium $^{70}$ and lithium ${ }^{71}$ tri(diethylamino)-

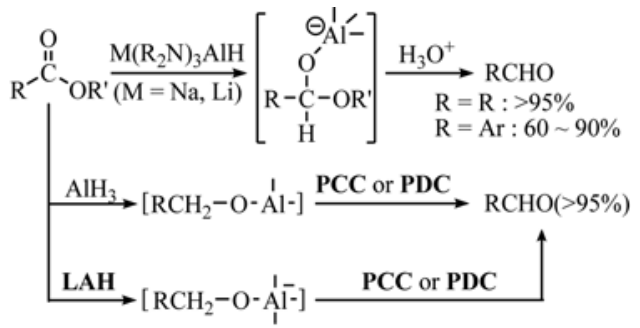

Scheme 14 
aluminum hydride (STDEA and LTDEA) produces aldehydes in good yields. Moreover, the stepwise reductionoxidation procedures afford the corresponding aldehydes in higher than $95 \%{ }^{93,94}$ (Scheme 14).

Conversion of Primary Carboxamide to Aldehyde. There have appeared a number of reduction methods to convert tertiary amides to aldehydes in literature. However, the direct conversion of primary amides to aldehydes by reduction with LTDEA seems to be the first example. ${ }^{95}$ The yields are satisfactory (Scheme 15).

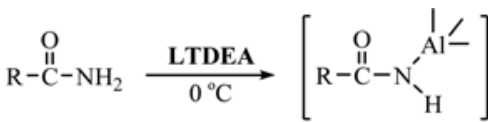

$$
\begin{aligned}
& \underset{\substack{\text { RCHO } \\
50 \sim 82 \%}}{\lfloor\text { rt }}
\end{aligned}
$$

Scheme 15

Conversion of Nitrile to Aldehyde. Diisobutylaluminum hydride -methyl sulfide (DIBAH.SMe $)^{54}$ and catecholalane $(\mathbf{C A})^{55}$ can converts both aliphatic and aromatic nitriles to the corresponding aldehydes in very high yields. However, it is worthwhile to note that potassium 9-sec-amyl-9-BBNH (K9-s-Am-9-BBNH) ${ }^{33}$ sodium $^{72}$ and lithium ${ }^{67}$ tri(diethylamino)aluminum hydrides (STDEA and LTDEA) achieve the selective conversion of aromatic nitriles to aldehydes in the presence of aliphatic nitriles unattacked (Scheme 16).

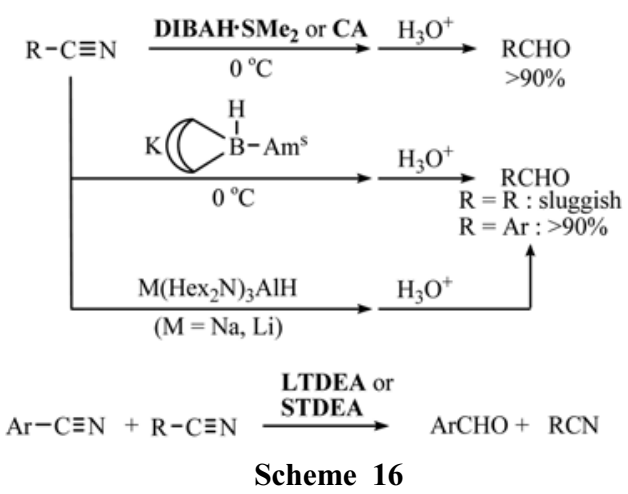

In Scheme 17, all the recommended procedures for conversion of carboxylic acids and their derivatives to aldehydes are summarized.

The general synthetic methodology to obtain aldehydes from carboxylic acids and their derivatives by reduction has been reviewed in $1989 .^{96}$

\section{Evolution of Newly-Devised Meerwein-Ponndorf-Verley Type Reagents and Their Application in Organic Synthesis $^{97,98}$}

The Meerwein-Ponndorf-Verley (MPV) reaction has been known as a mild and specific method of reducing carbonyl compounds since 1925 . However, the discovery of sodium borohydride ${ }^{99}$ in 1942 and of lithium aluminum hydride ${ }^{100}$ in

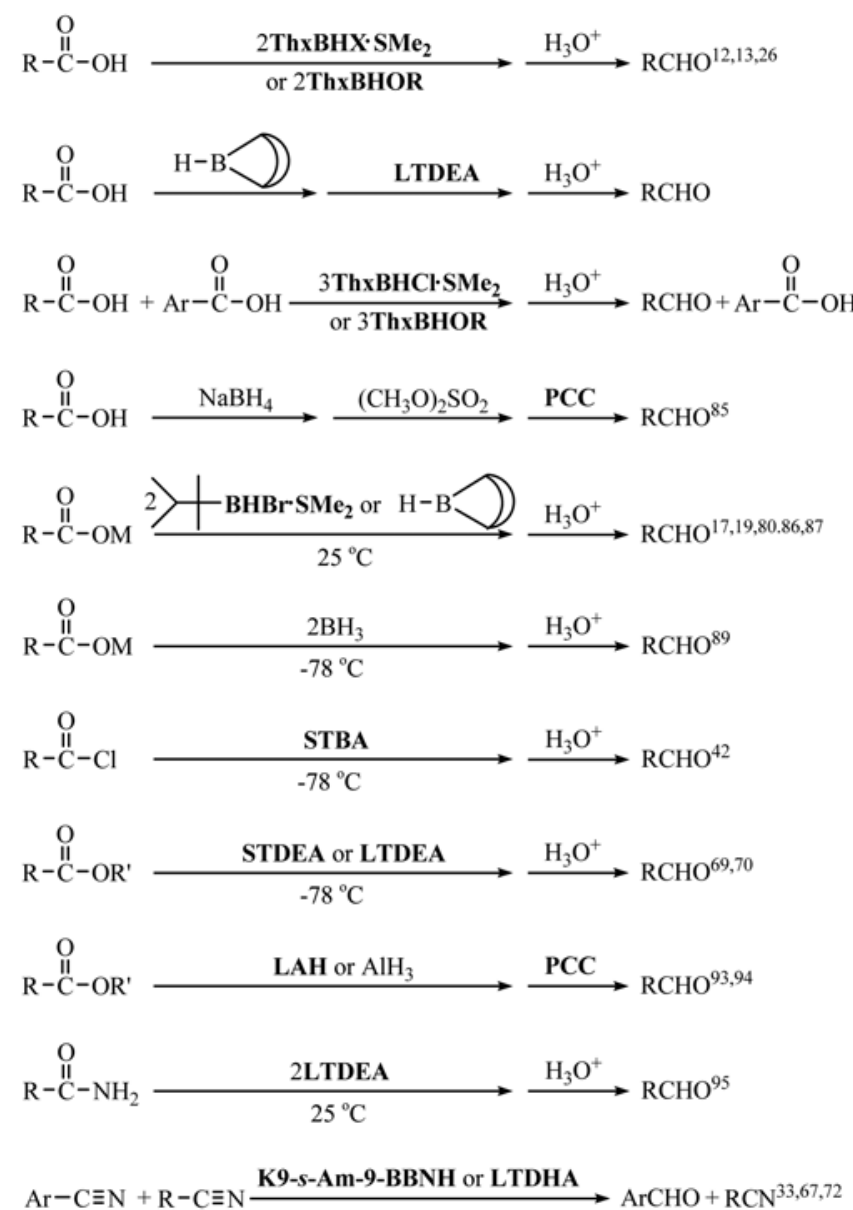

Scheme 17

1945 brought about a revolutionary change in procedures for the reduction of functional groups in organic molecules. Today, for instance, in dealing with the problem of reducing an aldehyde or ketone function, the synthetic organic chemist will rarely undertake to use such a conventional technique. Moreover, the advent of a variety of modified metal hydride reagents possessing a high degree of selectivity has made it possible to have a broad spectrum of reagents for selective reductions. However, recent developments in the design of new type of MPV reagent and in its application for the reduction of organic functional groups such as carbonyl and epoxy compounds led us to reassess its applicability and selectivity in organic synthesis. Consequently, it appears of interest to review recent situation where the newly-developed MPV reactions are possibly the complementary methods of choice for such reductions. This review has attempted to emphasize the distinct contrast in the reducing characteristics existed between metal hydride reagents and MPV reagents. It is the purpose of this review to illustrate the relationship of MPV type reduction to other methods of reduction and then to compare their usefulness in organic synthesis.

Discovery of Aluminum Compounds as MPV Reducing Agent. In the year of 1925 and 1926 it was discovered independently by Verley, ${ }^{101}$ by Meerwein, ${ }^{102}$ and by Ponndorf ${ }^{103}$ that aldehydes and ketones could be reduced satisfactorily. 
In 1937 Lund applied this method to a variety of aldehydes and ketones, and explored the scope and applicability of the MPV reaction ${ }^{104}$ (Eq. 86).

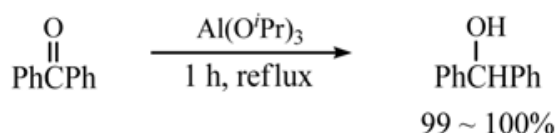

Meerwein also first utilized trialkylaluminum, such as triisobutylaluminum (TIBA) ${ }^{105}$ for the reduction of aldehydes and ketones, which are readily reduced to the corresponding alcohols. ${ }^{106}$

Early Explorations for BORON COMpounds as MPV Type Reducing Agents. The first report on trialkylborane as a reducing agent originated from Meerwein in $1936,{ }^{105}$ in which heating a neat mixture of triethylborane and benzaldehyde eliminates ethylene with formation of diethylboronic ester (Eq. 87). In this reaction benzaldehyde was

$$
\mathrm{Et}_{3} \mathrm{~B}+\mathrm{PhCHO} \underset{\text { neat }}{\stackrel{90 \sim 140{ }^{\circ} \mathrm{C}}{\longrightarrow}} \mathrm{H}_{2} \mathrm{C}=\mathrm{CH}_{2}+\mathrm{Et}_{2} \mathrm{~B}-\mathrm{OCH}_{2} \mathrm{Ph}
$$

reduced to the boronic ester of benzyl alcohol. About thirty years later, Mikhailov et al. ${ }^{107}$ reexamined such a reaction with higher trialkylboranes in the presence of benzaldehyde at elevated temperatures (Eq. 88). They indicate that the rate of the elimination of an olefin (i.e., the reduction of benzaldehyde) from a trialkylborane increases with increase in the number of methyl groups on the $\beta$-carbon atom.

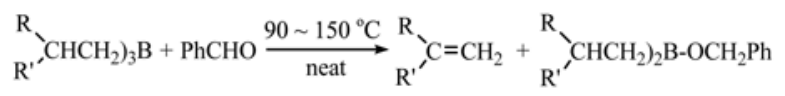

In late 1970 Midland initiated to improve such a sluggish reaction to a useful technique for the selective reduction of aldehydes using $B$-alkyl-9-borabicyclo[3.3.1]nonane (B-R9-BBN). ${ }^{108}$ Especially, $B$-(3-methyl-2-butyl)-9-BBN (B-Sia9-BBN) is an effective reagent for the reduction of a wide variety of aldehydes under mild conditions (i.e., $2 \mathrm{~h}$ in refluxing THF) ${ }^{109}$ (Eq. 89). Such $\boldsymbol{B}$-R-9-BBN reagents show

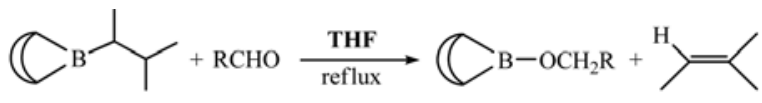

only a reactivity toward aldehydes: aldehydes are reduced rapidly, whereas ketones are reduced only very sluggishly. However, the situation has been changed when Professor Brown et al. developed diisopinocampheylhaloboranes $\left(\mathbf{I p c}_{\mathbf{2}} \mathbf{B X}\right)$ in $1985 .{ }^{110}$ These reagents can react with ketones at convenient rates even at $-25^{\circ} \mathrm{C}$ (Eq. 90).

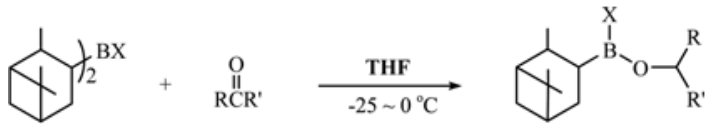

Mechanistic Consideration of the MPV Reactions.

Aluminum Reagents. The MPV reaction with aluminum isoproxide is reversible, but the equilibrium can be shifted to the point of complete reduction by removal of the acetone with a stream of dry nitrogen or by slow distillation. The equilibrium proceeds by an oxidation-reduction reaction of a carbinol-carbonyl pair accelerated by aluminum alkoxide.

The generally accepted mechanism for MPV reactions proceeds via a complex in which both the carbonyl compound and the reducing alcohol are bound to the metal ion as shown in Scheme 18 for the reaction of aluminum isoprop-<smiles>[R]C([R])=O</smiles>

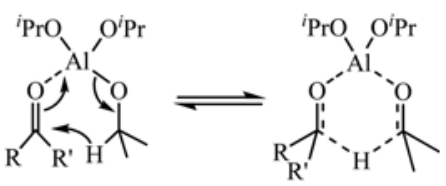<smiles>[R]C([R])(C)O[Al](OC(C)C)(OC(C)C)OC(C)C</smiles>

oxide. The carbonyl is then activated upon coordination to $\mathrm{Al}(\mathrm{III})$, followed by a hydride transfer from the alcoholate to the carbonyl group via a six-membered transition state. Likewise, the mechanism of the reaction of carbonyl compounds with triisobutylaluminum (TIBA) involves hydride shift from the $\beta$-carbon atom and thus proves to be very similar to the MPV reduction process (Scheme 19).

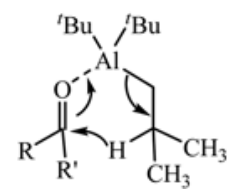

Scheme 2

Boron Reagents. As in the report by Mikhailov ${ }^{107}$ on the reaction of trialkylboranes with benzaldehyde at elevated temperatures, the rate of the elimination of an olefin from a trialkylborane increases with increase in the number of methyl groups on the $\beta$-carbon atom, which indicates reaction with elimination of a hydride ion via a cyclic electron transfer (Scheme 20).

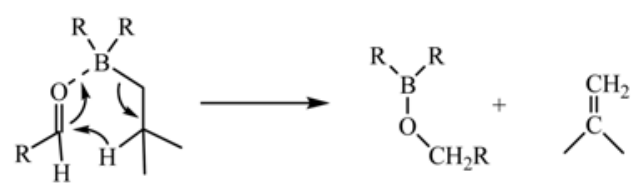

Scheme 20

Consideration on $\boldsymbol{\beta}$-Hydrogen Source of Catalyst. The $\beta$-hydrogen sources in MPV reduction can be divided into two categories. As depicted in Scheme 1 for the classical MPV reduction, the $\beta$-hydrogen comes from isopropoxy group of catalyst that, in turn, leads to the formation of acetone. On the other hand, as shown in Scheme 18 and 19, the $\beta$-hydrogen originates from alkyl group of catalyst that, in turn, leads to the formation of alkene.

The formation of acetone causes the reaction being reversible; therefore we need to remove acetone in order to shift 
the equilibrium in the desired direction. However, the formation of alkene does not interfere in the reduction process.

Appearance of New MPV Type Reagents. We usually say that MPV reduction is performed with aluminum isopropoxide as a catalyst and isopropyl alcohol as a hydride source. From the mechanistic point of view as depicted in Scheme 19, however, there are two points to be considered. One is that the actual reduction takes place by virtue of the $\beta$-hydrogen transfer from isopropoxy group attached to $\mathrm{Al}$ atom of catalyst. This means that isopropyl alcohol does not participate at the key step of reduction: isopropyl alcohol acts as an isopropoxy group source which substantially provides a hydride. The other is that MPV reaction is reversible: acetone formed accelerates the reversible reaction.

Practically, there have encountered some problems in this reaction: the reduction usually proceeds sluggishly even with an excess catalyst and requires the removal of acetone in order to shift the equilibrium in the desired direction. Therefore, efforts to devise new catalysts and reagents to overcome such limitations have been continuously devoted.

Aluminum-Containing Reagents. Recently, there have appeared a series of diisobutylaluminum derivatives, such as diisobutylhaloalanes (17), ${ }^{111-115}$ diisobutylalkoxyalanes (18) ${ }^{115-118}$ diisobutylaminoalanes (19),${ }^{119-121}$ diisobutylacetoxyalanes (20 and 21), ${ }^{122}$ and diisobutylmethanesulfonylalanes (22 and 23), ${ }^{123-126}$ which were prepared by simple reaction of diisobutylaluminum hydride (DIBAH) with the corresponding hydrogen halides, alcohols, amines, acetic acids, and methanesulfonic acids, respectively (Eq. 91-97). These diisobutylaluminum derivatives have achieved a very high chemo-, regio- and stereoselectivity in the reduction of aldehydes and ketones.

\begin{tabular}{|c|c|c|}
\hline $\begin{array}{l}i-\mathrm{Bu}_{2} \mathrm{AlH} \\
(\text { DIBAH) }\end{array}$ & $+\mathrm{HX}$ & $\begin{array}{c}i-\mathrm{Bu}_{2} \mathrm{AlH} \\
17\end{array}$ \\
\hline$i-\mathrm{Bu}_{2} \mathrm{AlH}$ & $+\mathrm{ROH}$ & $\begin{array}{c}i-\mathrm{Bu}_{2} \mathrm{AlH} \\
\mathbf{1 8}\end{array}$ \\
\hline$i-\mathrm{Bu}_{2} \mathrm{AlH}$ & $+\mathrm{R}_{2} \mathrm{NH}$ & $\begin{array}{c}i-\mathrm{Bu}_{2} \mathrm{AlH} \\
19\end{array}$ \\
\hline$i-\mathrm{Bu}_{2} \mathrm{AlH}$ & $+\mathrm{CH}_{3} \mathrm{COOH}$ & $\begin{array}{l}i-\mathrm{Bu}_{2} \mathrm{AlOAc} \\
\mathbf{2 0}\end{array}$ \\
\hline$i-\mathrm{Bu}_{2} \mathrm{AlH}$ & $+\mathrm{CF}_{3} \mathrm{COOH}$ & $\begin{array}{l}i-\mathrm{Bu}_{2} \mathrm{AlO}_{2} \mathrm{CCF}_{3} \\
\mathbf{2 1}\end{array}$ \\
\hline$i-\mathrm{Bu}_{2} \mathrm{AlH}$ & $+\mathrm{CH}_{3} \mathrm{SO}_{3} \mathrm{H}$ & $\begin{array}{l}i-\mathrm{Bu}_{2} \mathrm{AlOSO}_{2} \mathrm{CH}_{3} \\
\mathbf{2 2}\end{array}$ \\
\hline$i-\mathrm{Bu}_{2} \mathrm{AlH}$ & $+\mathrm{CF}_{3} \mathrm{SO}_{3} \mathrm{H}$ & $\begin{array}{l}i-\mathrm{Bu}_{2} \mathrm{AlOSO}_{2} \mathrm{CF}_{3} \\
\mathbf{2 3}\end{array}$ \\
\hline
\end{tabular}

Boron-Containing Reagents. Generally, trialkylboranes are known to be tolerant to a wide variety of functional groups, ${ }^{127}$ but certain $\boldsymbol{B}$-R-9-BBN, especially $\boldsymbol{B}$-Sia-9-BBN (24) is a mild chemoselective reducing agent for aldehydes. ${ }^{108,109}$

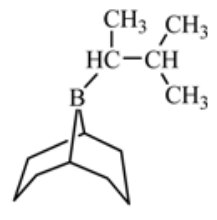

24
However, the first report on trialkylborane being capable of reducing both aldehydes and ketones under mild conditions appeared in 1985. ${ }^{128}$ Professor Brown and his coworkers devised diisopinocampheylchloroborane (Ipc 2 BCl) (25), which is the outcome from a strategic modification of the electronic and steric environments of the boron in trialkylboranes can reduce a variety of ketones as well as aldehydes to the corresponding alcohols even at $-25{ }^{\circ} \mathrm{C}$. Soon other mono- and diisopinocampheylhaloboranes (26 and 27), were

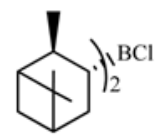

25

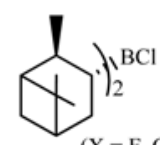

26

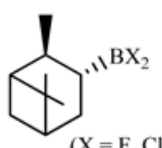

27 also prepared. ${ }^{129-133}$ Furthermore, hydroxy-, alkoxy-, acetoxyand methanesulfonyl-incorporated diisopinocampheylborane derivatives (28-33) were prepared and their applicability in MPV type reduction was explored. ${ }^{134-140}$

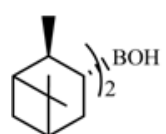

28

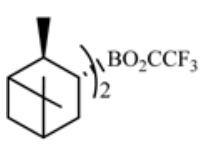

31

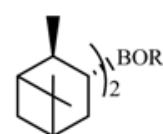

29

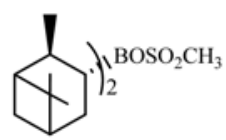

32

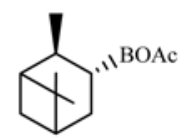

30

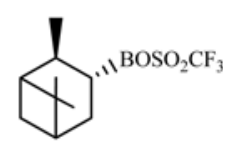

33
Boron isopropoxide, a counterpart of aluminum isopropoxide, and also appears as a mild reducing agent, showing a high chemoselectivity in the reduction of aldehydes and ketones $^{141,142}$ The reducing characteristics of dichloroisopropoxyborane is also examined and compared to those of boron isopropoxide: this reagent is slightly stronger reducing agent than boron isopropoxide, but still shows a high chemoselectivity toward carbonyl compounds. ${ }^{143}$

Application for Organic Synthesis. The MPV reduction is a classical but still widely used method for organic synthesis, because of high selectivity, relatively mild reaction conditions, simple and safe operations, and the low cost. In general, MPV reduction is performed with various catalyst and isopropyl alcohol as a hydride source; the mechanism can be described by the activation of the carbonyl group through its coordination to Lewis acidic metal site followed by reversible hydride transfer from alcoholate to the carbonyl acceptor via six-membered cyclic transition state as shown in Scheme 18 to 20. In this mechanistic point of view, the key step of this reaction must be the coordination of carbonyl oxygen to Lewis acidic metal site: without coordination of the substrate, no reduction takes place. Another characteristic feature of this reaction to be considered is the hydride-transfer pathway in which the reduction proceeds through the six-membered transition state. These combined characteristic features seem to play a major role performing an excellent selectivity in the MPV reductions, such as the following chemo, regio, and stereoselective reductions of carbonyl and epoxy compounds. 
General Reducing Characteristics of Diisobutylaluminum and Diisopinocampheylboron Derivatives Toward Common Organic Functional Groups. Recently, the general reducing characteristics of diisobutylaluminum derivatives, such

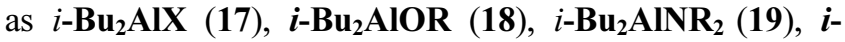
$\mathrm{Bu}_{2} \mathrm{AlOAc}(20), i-\mathrm{Bu}_{2} \mathrm{AlO}_{2} \mathrm{CCF}_{3}(21), i-\mathrm{Bu}_{2} \mathrm{AlOSO}_{2} \mathrm{CH}_{3}$ (22), $i$ - $\mathrm{Bu}_{2} \mathrm{AlOSO}_{2} \mathrm{CF}_{3}$ (23), and diiopinocampheylboron derivatives, such as $\mathbf{I p c}_{2} \mathbf{B X}$ (26), Ipc $\mathbf{I}_{2} \mathbf{B O R}(\mathbf{2 8}$ and 29), $\mathrm{Ipc}_{2} \mathrm{BOAc}(30), \mathrm{Ipc}_{2} \mathrm{BO}_{2} \mathrm{CCF}_{3}(31), \mathrm{Ipc}_{2} \mathrm{AlOSO}_{2} \mathrm{CH}_{3}(32)$, and $\mathbf{I p c}_{2} \mathrm{AlOSO}_{2} \mathbf{C F}_{3}(33)$, have been examined systematically. After a broad examination and comparsion, some conclusions on the general reducing action of these derivatives toward organic functional groups have been drawn as follows:

(i) the relative reactivities of $\mathbf{I} \mathbf{p c}_{2} \mathbf{B X}$ series toward carbonyl compounds are in sequence of $\mathbf{I p c}_{2} \mathbf{B C I}>\mathbf{I p c}_{2} \mathbf{B F}>>$ $\mathrm{Ipc}_{2} \mathrm{BBr}>\mathrm{Ipc}_{2} \mathrm{BI}$,

(ii) the reactivity of $\mathbf{I p c}_{2} \mathbf{B O R}$ (28 and 29) is much weaker than $\operatorname{Ipc}_{2} \mathbf{B X}(\mathbf{2 6})$,

(iii) $\mathbf{I p c}_{2} \mathbf{B O R}$ (28 and 29) can reduce aldehydes, but can not attack ketones,

(iv) the relative reactivities of $\boldsymbol{i}-\mathbf{B} \mathbf{u}_{2} \mathbf{A l}$-series are $\boldsymbol{i}-\mathbf{B} \mathbf{u}_{2} \mathbf{A l X}$

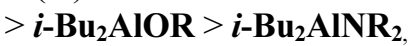

(v) the relative reactivities of $\boldsymbol{i}-\mathbf{B u}_{2} \mathbf{A I O R}(\mathbf{1 8})$ series are $i$ $\mathrm{Bu}_{2} \mathrm{AlOH}>i-\mathrm{Bu}_{2} \mathrm{AlOEt}>i-\mathrm{Bu}_{2} \mathrm{AlO}^{i} \mathrm{Pr}>i-\mathrm{Bu}_{2} \mathrm{AlO}^{t} \mathrm{Bu}$,

(vi) the reactivity of $\mathbf{I p c}_{2} \mathbf{B O}_{2} \mathbf{C C F}_{3}$ (31), a fluorinated acetate derivative, is much higher than that of acetate derivative itself, Ipc $\mathbf{~}_{2} \mathbf{B O A c}$ (30),

(vii) the reactivity of $\operatorname{Ipc}_{2} \mathrm{AlOSO}_{2} \mathbf{C F}_{3}(33)$, a fluorinated sulfonated derivative, is much higher than that of sulfonate derivative itself, $\mathbf{I p c}_{2} \mathrm{AlOSO}_{2} \mathrm{CH}_{3}$ (32).

As a result, the reactivity depends on what kind of moiety being attached to diisobutylaluminum or diisopinocampheylboron. Such reactivity difference may be attributed to the steric and electronic effects of the substituent. A relative reactivity toward organic functional groups is summarized in the Table 1.

Most derivatives are reactive toward aldehydes and ketones, but quite inert to other functional groups including even acid chlorides. Especially noteworthy is that $\mathbf{I p c}_{2} \mathbf{B O H}$ appears the mildest one among the derivatives, exhibiting absolutely no reactivity toward every organic functional groups except
Table 1. Comparison in Reactivity of Diisopinocampheylboron and Diisobutylaluminum Derivatives toward Common Organic Functional Groups ${ }^{a}$

\begin{tabular}{|c|c|c|c|c|c|c|}
\hline \multirow{2}{*}{$\begin{array}{c}\text { Reagent } \\
\text { type }\end{array}$} & \multicolumn{6}{|c|}{ Organic functional groups } \\
\hline & aldehyde & ketone & ester & $\begin{array}{c}\text { acid } \\
\text { chloride }\end{array}$ & nitrile & epoxide \\
\hline $\mathbf{I p c}_{2} \mathrm{BX}$ & +++ & ++ & - & - & + & + \\
\hline $\mathbf{I p c}_{2} \mathrm{BOR}$ & ++ & - & - & - & - & - \\
\hline$i-\mathrm{Bu}_{2} \mathrm{AlX}$ & +++ & +++ & - & - & + & ++ \\
\hline$i-\mathrm{Bu}_{2} \mathrm{AlOR}$ & ++ & + & - & - & - & - \\
\hline$i-\mathrm{Bu}_{2} \mathrm{AlNR}_{2}$ & ++ & + & - & - & - & - \\
\hline
\end{tabular}

${ }^{a}+$ Designates 'reactive', whereas designates 'inert'.

aldehyde.

Conversion of $\alpha, \beta$-Unsaturated Carbonyl Compounds to the Corresponding Allylic Alcohols. Reduction of $\alpha, \beta-$ unsaturated aldehydes and ketones with conventional reducing agents produces the three possible products in a different ratio. Thus, reduction in a 1,2-addition fashion gives the corresponding unsaturated alcohol (allylic alcohol) (34). A conjugative addition (1,4-addition) affords the corresponding saturated carbonyl compound (35). And if the reduction proceeds in a 1,4-addition followed by 1,2-addition, a saturated carbinol (36) is produced (Scheme 21).

In particular, the selective conversion of $\alpha, \beta$-unsaturated carbonyl compounds to the corresponding allylic alcohols (34) is the focus of special interest since this is often a key step in the preparation of various fine chemicals. Therefore, endless efforts have been undertaken to develop reducing systems which effect such a regioselective conversion.

As mentioned earlier, diisobutylaluminum derivatives (1723) $)^{114,122,124,125,126,140,144-148}$ and diisopinocampheylboron derivatives $(\mathbf{2 5 - 3 3})^{132,135-137,140,149-153}$ have been applied to the regioselective reduction of $\alpha, \beta$-unsaturated aldehydes and ketones. All the derivatives examined can reduce a variety of $\alpha, \beta$-unsaturated aldehydes and ketones to the corresponding allylic alcohols, except $\mathbf{I p c}_{2} \mathbf{B} \mathbf{O R}{ }^{135-138}$, which can only reduce aldehydes but not attack ketones at all. Even though the reaction rate is different each other, the selectivity appears to be an essentially $100 \%$, as in Eq. (98).
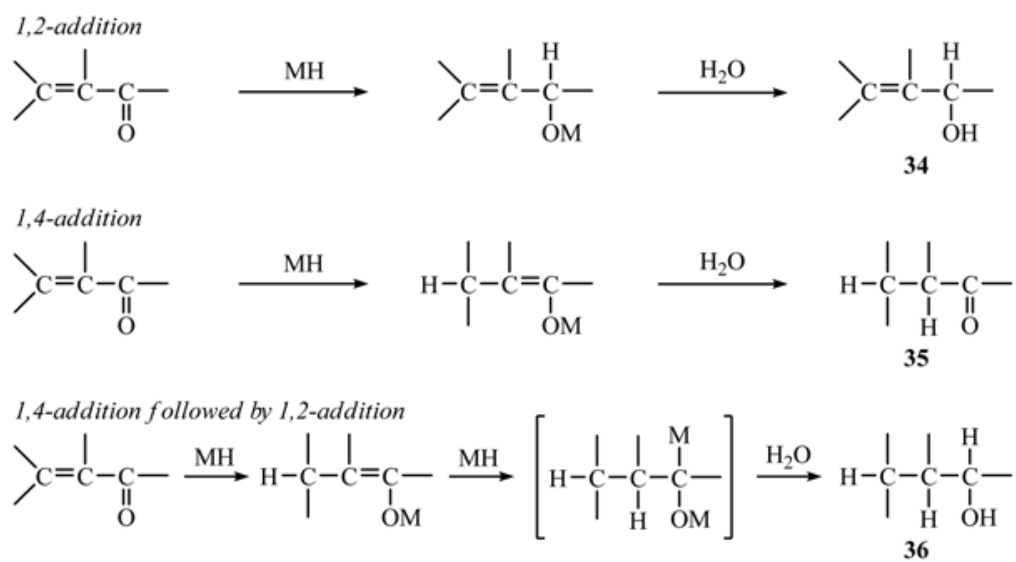


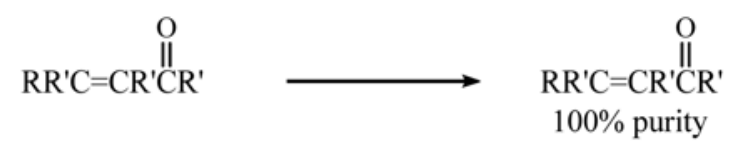

Some examples for the 1,2-reduction of representative $\alpha$, $\beta$-unsaturated carbonyl compounds achieved by the new MPV reagents are summarized in Table 3.

Table 3. Regioselective Reduction of Representative $\alpha, \beta$-Unsaturated Carbonyl Compounds with MPV Type Reagents ${ }^{a}$

\begin{tabular}{|c|c|c|c|c|c|c|}
\hline Compound & Reagent $^{b}$ & $\mathrm{Rgt} / \mathrm{Cpd}$ & $\begin{array}{l}\text { Reaction } \\
\text { temp. }\left({ }^{\circ} \mathrm{C}\right)\end{array}$ & $\begin{array}{l}\text { Reaction } \\
\text { time (h) }\end{array}$ & $\begin{array}{l}\text { Yield } \\
(\%)\end{array}$ & Ref \\
\hline \multirow[t]{21}{*}{$\mathrm{Ch}_{3} \mathrm{CH}=\mathrm{CHCHO}$} & Ipc $_{2} \mathrm{BF}$ & 1.1 & 0 & 24 & 100 & 144 \\
\hline & $\mathbf{I p c}_{2} \mathrm{BCl}$ & 1.1 & 0 & 3 & $>99.9$ & 132,150 \\
\hline & $\mathbf{I p c}_{2} \mathrm{BBr}$ & 2.0 & 0 & 48 & 95 & 132 \\
\hline & $\mathbf{I p c}_{2} \mathrm{BI}$ & 2.0 & 25 & 24 & 98 & 132 \\
\hline & $\mathbf{I p c}_{2} \mathrm{BOH}$ & 2.0 & 25 & 1 & $>99.9$ & 136 \\
\hline & $\mathbf{I p c}_{2} \mathrm{BOEt}$ & 2.0 & 25 & 1 & 100 & 136 \\
\hline & $\mathbf{I p c}_{2} \mathrm{BO}^{i} \mathrm{Pr}$ & 2.0 & 25 & 1 & 100 & 136 \\
\hline & $\mathbf{I p c}_{2} \mathrm{BO}^{t} \mathrm{Bu}$ & 2.0 & 25 & 1 & 100 & 135,136 \\
\hline & $\mathbf{I p c}_{2} \mathrm{BOC}_{\text {hex }}$ & 1.1 & 25 & 12 & 99 & 137,138 \\
\hline & $\mathbf{I p c}_{2} \mathrm{BOPh}$ & 1.1 & 25 & 6 & 100 & 138 \\
\hline & $\mathbf{I p c}_{2} \mathrm{BOAc}$ & 1.1 & 25 & 6 & 99 & 152 \\
\hline & $\mathbf{I p c}_{2} \mathrm{BO}_{2} \mathrm{CCF}_{3}$ & 1.1 & 25 & 3 & 99.9 & 152 \\
\hline & $i-\mathrm{Bu}_{2} \mathrm{AlF}$ & 1.1 & 25 & 3 & 99.9 & 149 \\
\hline & $i-\mathrm{Bu}_{2} \mathrm{AlCl}$ & 1.1 & 25 & 3 & $>99.9$ & 145 \\
\hline & $i-\mathrm{Bu}_{2} \mathrm{AlOH}$ & 2.0 & 25 & 3 & $>99.9$ & 146 \\
\hline & $i-\mathrm{Bu}_{2} \mathrm{AlOEt}$ & 2.0 & 25 & 6 & 100 & 146 \\
\hline & $i-\mathrm{Bu}_{2} \mathrm{AlO}^{i} \mathrm{Pr}$ & 2.0 & 25 & 6 & 99 & 146 \\
\hline & $i-\mathrm{Bu}_{2} \mathrm{AlO}^{t} \mathrm{Bu}$ & 2.0 & 25 & 24 & 100 & 146,147 \\
\hline & $i-\mathrm{Bu}_{2} \mathrm{AlNEt}_{2}$ & 2.0 & 25 & 12 & $>99.9$ & 148 \\
\hline & $i-\mathrm{Bu}_{2} \mathrm{AlN}^{i} \mathrm{Bu}_{2}$ & 2.0 & 25 & 12 & 100 & 148 \\
\hline & $i-\mathrm{Bu}_{2} \mathrm{AlNPh}_{2}$ & 2.0 & 25 & 24 & 100 & 148 \\
\hline \multirow[t]{21}{*}{$\mathrm{PhCH}=\mathrm{CHCHO}$} & $\mathbf{I p c}_{2} \mathrm{BF}$ & 1.1 & 0 & 3 & 100 & 144 \\
\hline & $\mathbf{I p c}_{2} \mathrm{BCl}$ & 1.1 & 0 & 12 & 100 & 132,150 \\
\hline & $\mathbf{I p c _ { 2 }} \mathrm{BBr}$ & 1.1 & 0 & 48 & 95 & 132 \\
\hline & $\mathbf{I p c}_{2} \mathrm{BI}$ & 1.1 & 25 & 144 & 100 & 132 \\
\hline & $\mathbf{I p c}_{2} \mathrm{BOH}$ & 2.0 & 25 & 12 & 100 & 136 \\
\hline & $\mathbf{I p c}_{2} \mathrm{BOEt}$ & 2.0 & 25 & 6 & 100 & 136 \\
\hline & $\mathbf{I p c}_{2} \mathrm{BO}^{i} \mathrm{Pr}$ & 2.0 & 25 & 24 & 96 & 136 \\
\hline & $\mathbf{I p c}_{2} \mathrm{BO}^{t} \mathrm{Bu}$ & 2.0 & 25 & 12 & 100 & 136 \\
\hline & $\mathbf{I p c}_{2} \mathrm{BOC}_{\text {hex }}$ & 1.1 & 25 & 6 & 99 & 136 \\
\hline & $\mathbf{I p c}_{2} \mathrm{BOPh}$ & 1.1 & 25 & 1 & 99 & 135,136 \\
\hline & $\mathbf{I p c}_{2} \mathrm{BOAc}$ & 1.1 & 25 & 3 & 99 & 152 \\
\hline & $\mathbf{I p c}_{2} \mathrm{BO}_{2} \mathrm{CCF}_{3}$ & 1.1 & 25 & 1 & 99.9 & 152 \\
\hline & $i-\mathrm{Bu}_{2} \mathrm{AlF}$ & 1.1 & 25 & 24 & 91 & 149 \\
\hline & $i-\mathrm{Bu}_{2} \mathrm{AlCl}$ & 1.1 & 25 & 24 & 100 & 145 \\
\hline & $i-\mathrm{Bu}_{2} \mathrm{AlOH}$ & 2.0 & 25 & 6 & 100 & 146 \\
\hline & $i-\mathrm{Bu}_{2} \mathrm{AlOEt}$ & 2.0 & 25 & 12 & 100 & 146 \\
\hline & $i-\mathrm{Bu}_{2} \mathrm{AlO}^{i} \mathrm{Pr}$ & 2.0 & 25 & 12 & 100 & 146 \\
\hline & $i-\mathrm{Bu}_{2} \mathrm{AlO}^{t} \mathrm{Bu}$ & 2.0 & 25 & 48 & 100 & 146,147 \\
\hline & $i-\mathrm{Bu}_{2} \mathrm{AlNEt}_{2}$ & 2.0 & 25 & 24 & 100 & 148 \\
\hline & $i-\mathrm{Bu}_{2} \mathrm{AlN}^{i} \mathrm{Bu}_{2}$ & 2.0 & 25 & 24 & 99 & 148 \\
\hline & $i-\mathrm{Bu}_{2} \mathrm{AlNPh}_{2}$ & 2.0 & 25 & 72 & 97 & 148 \\
\hline \multirow{8}{*}{$\stackrel{\mathrm{O}}{\mathrm{O}} \mathrm{CH}_{3} \mathrm{CH}=\mathrm{CHCCH}_{3}$} & $\mathbf{I p c}_{2} \mathrm{BCl}$ & 1.1 & 0 & 24 & 100 & 132,150 \\
\hline & $\mathbf{I p c}_{2} \mathrm{BBr}$ & 1.1 & 0 & 24 & 70 & 132 \\
\hline & $\mathbf{I p c}_{2} \mathrm{BI}$ & 1.1 & 25 & 24 & 25 & 132 \\
\hline & $\mathbf{I p c}_{2} \mathrm{BOH}$ & 2.0 & 25 & 24 & 0 & 136 \\
\hline & $\mathbf{I p c}_{2} \mathrm{BOEt}$ & 2.0 & 25 & 24 & 0 & 136 \\
\hline & $\mathbf{I p c}_{2} \mathrm{BOPh}$ & 2.0 & 25 & 24 & 0 & 136 \\
\hline & $\mathbf{I p c}_{2} \mathrm{BOAc}$ & 1.1 & 25 & 24 & 5 & 152 \\
\hline & $\mathbf{I p c}_{2} \mathrm{BO}_{2} \mathrm{CCF}_{3}$ & 1.1 & 25 & 24 & 40 & 152 \\
\hline
\end{tabular}


Table 3. Continued

\begin{tabular}{|c|c|c|c|c|c|c|}
\hline Compound & Reagent $^{b}$ & $\mathrm{Rgt} / \mathrm{Cpd}$ & $\begin{array}{l}\text { Reaction } \\
\text { temp. }\left({ }^{\circ} \mathrm{C}\right)\end{array}$ & $\begin{array}{l}\text { Reaction } \\
\text { time (h) }\end{array}$ & $\begin{array}{l}\text { Yield } \\
(\%)\end{array}$ & Ref \\
\hline \multirow{9}{*}{$\stackrel{\stackrel{\mathrm{I}}{\mathrm{C}}}{\mathrm{CH}_{3} \mathrm{CH}=\mathrm{CH} C \mathrm{CH}}$} & $i-\mathrm{Bu}_{2} \mathrm{AlF}$ & 1.1 & 25 & 24 & 30 & 149 \\
\hline & $i-\mathrm{Bu}_{2} \mathrm{AlCl}$ & 1.1 & 25 & 6 & 100 & 145 \\
\hline & $i-\mathrm{Bu}_{2} \mathrm{AlOH}$ & 2.0 & 25 & 6 & 100 & 146 \\
\hline & $i$ - $\mathrm{Bu}_{2} \mathrm{AlOEt}$ & 2.0 & 25 & 6 & 98 & 146 \\
\hline & $i-\mathrm{Bu}_{2} \mathrm{AlO}^{i} \mathrm{Pr}$ & 2.0 & 25 & 24 & 100 & 146 \\
\hline & $i-\mathrm{Bu}_{2} \mathrm{AlO}^{t} \mathrm{Bu}$ & 2.0 & 25 & 24 & 97 & 146,147 \\
\hline & $i-\mathrm{Bu}_{2} \mathrm{AlNEt}_{2}$ & 2.0 & 25 & 12 & 100 & 148 \\
\hline & $i-\mathrm{Bu}_{2} \mathrm{AlN}^{i} \mathrm{Bu}_{2}$ & 2.0 & 25 & 12 & 100 & 148 \\
\hline & $i-\mathrm{Bu}_{2} \mathrm{AlNPh}_{2}$ & 2.0 & 25 & 24 & 100 & 148 \\
\hline \multirow{44}{*}{$\stackrel{\mathrm{O}}{\mathrm{II}} \mathrm{PhCH}=\mathrm{CHC} \mathrm{Ph}$} & $\mathbf{I p c}_{2} \mathrm{BCl}$ & 2.0 & 25 & 24 & 100 & 132,150 \\
\hline & Ipc $\mathbf{c}_{2} \mathrm{BBr}$ & 2.0 & 25 & 48 & 70 & 132 \\
\hline & $\mathbf{I p c}_{2} \mathrm{BI}$ & 2.0 & 25 & 48 & 65 & 132 \\
\hline & Ipc $\mathbf{c}_{2} \mathrm{BOH}$ & 2.0 & 25 & 24 & 0 & 136 \\
\hline & $\mathbf{I p c}_{2} \mathrm{BOEt}$ & 2.0 & 25 & 24 & 0 & 136 \\
\hline & $\mathbf{I p c}_{2} \mathrm{BOPh}$ & 2.0 & 25 & 24 & 0 & 136 \\
\hline & $\mathbf{I p c}_{2} \mathrm{BOAc}$ & 1.1 & 25 & 6 & 11 & 152 \\
\hline & $\mathbf{I p c}_{2} \mathrm{BO}_{2} \mathrm{CCF}_{3}$ & 1.1 & 25 & 6 & 99 & 152 \\
\hline & $i-\mathrm{Bu}_{2} \mathrm{AlF}$ & 2.0 & 25 & 24 & 10 & 149 \\
\hline & $i-\mathrm{Bu}_{2} \mathrm{AlCl}$ & 2.0 & 25 & 72 & 99.9 & 145 \\
\hline & $i-\mathrm{Bu}_{2} \mathrm{AlOH}$ & 2.0 & 25 & 120 & 100 & 146 \\
\hline & $i$-Bu2 $\mathrm{AlOEt}$ & 2.0 & 25 & 168 & 100 & 146 \\
\hline & $i-\mathrm{Bu}_{2} \mathrm{AlO}^{i} \mathrm{Pr}$ & 2.0 & 25 & 240 & 100 & 146 \\
\hline & $i-\mathrm{Bu}_{2} \mathrm{AlO}^{t} \mathrm{Bu}$ & 2.0 & 25 & 240 & 100 & 146 \\
\hline & $i-\mathrm{Bu}_{2} \mathrm{AlNEt}_{2}$ & 4.0 & 25 & 240 & 100 & 148 \\
\hline & $i-\mathrm{Bu}_{2} \mathrm{AlN}^{i} \mathrm{Bu}_{2}$ & 4.0 & 25 & 240 & 98 & 148 \\
\hline & $i-\mathrm{Bu}_{2} \mathrm{AlNPh}_{2}$ & 4.0 & 25 & 240 & 98 & 148 \\
\hline & $\mathbf{I p c}_{2} \mathrm{BF}$ & 1.1 & 25 & 0.25 & 100 & 144 \\
\hline & $\mathbf{I p c _ { 2 }} \mathrm{BCl}$ & 1.1 & 0 & 3 & $>99.9$ & 132,150 \\
\hline & $\mathbf{I p c _ { 2 }} \mathrm{BBr}$ & 1.1 & 0 & 48 & 100 & 132 \\
\hline & $\mathbf{I p c _ { 2 }} \mathrm{BBr}$ & 1.1 & 25 & 72 & 100 & 132 \\
\hline & $\mathbf{I p c}_{2} \mathrm{BI}$ & 1.1 & 25 & 3 & 0 & 136 \\
\hline & $\mathbf{I p c}_{2} \mathrm{BOH}$ & 1.1 & 25 & 48 & 0 & 136 \\
\hline & $\mathbf{I p c}_{2} \mathrm{BO}^{t} \mathrm{Bu}$ & 1.1 & 25 & 3 & $>99.9$ & 145 \\
\hline & $i-\mathrm{Bu}_{2} \mathrm{AlCl}$ & 2.0 & 25 & 24 & 100 & 146 \\
\hline & $i-\mathrm{Bu}_{2} \mathrm{AlOH}$ & 2.0 & 25 & 24 & $>99.9$ & 146 \\
\hline & $i$ - $\mathrm{Bu}_{2} \mathrm{AlOEt}$ & 2.0 & 25 & 72 & 100 & 146 \\
\hline & $i-\mathrm{Bu}_{2} \mathrm{AlO}^{i} \mathrm{Pr}$ & 2.0 & 25 & 72 & 96 & 146 \\
\hline & $i-\mathrm{Bu}_{2} \mathrm{AlO}^{t} \mathrm{Bu}$ & 2.0 & 25 & 24 & 100 & 148 \\
\hline & $i-\mathrm{Bu}_{2} \mathrm{AlNEt}_{2}$ & 2.0 & 25 & 24 & 100 & 148 \\
\hline & $i-\mathrm{Bu}_{2} \mathrm{AlN}^{i} \mathrm{Bu}_{2}$ & 2.0 & 25 & 24 & 100 & 148 \\
\hline & $\mathbf{I p c}_{2} \mathrm{BCl}$ & 1.1 & 0 & 3 & $>99.9$ & 132,150 \\
\hline & $\mathbf{I p c _ { 2 }} \mathrm{BBr}$ & 1.1 & 0 & 48 & 100 & 132 \\
\hline & $\mathbf{I p c}_{2} \mathrm{BI}$ & 1.1 & 25 & 72 & 100 & 132 \\
\hline & Ipc $_{2} \mathrm{BOH}$ & 1.1 & 25 & 6 & 0 & 136 \\
\hline & $\mathbf{I p c}_{2} \mathrm{BO}^{t} \mathrm{Bu}$ & 1.1 & 25 & 6 & 0 & 136 \\
\hline & $i-\mathrm{Bu}_{2} \mathrm{AlCl}$ & 1.1 & 25 & 12 & 100 & 145 \\
\hline & $i-\mathrm{Bu}_{2} \mathrm{AlOH}$ & 2.0 & 25 & 24 & 100 & 146 \\
\hline & $i-\mathrm{Bu}_{2} \mathrm{AlOEt}$ & 2.0 & 25 & 72 & 100 & 146 \\
\hline & $i-\mathrm{Bu}_{2} \mathrm{AlO}^{i} \mathrm{Pr}$ & 2.0 & 25 & 120 & 100 & 146 \\
\hline & $i-\mathrm{Bu}_{2} \mathrm{AlO}^{t} \mathrm{Bu}$ & 2.0 & 25 & 240 & 100 & 146 \\
\hline & $i-\mathrm{Bu}_{2} \mathrm{AlNEt}_{2}$ & 2.0 & 25 & 24 & 100 & 148 \\
\hline & $i-\mathrm{Bu}_{2} \mathrm{AlN}^{i} \mathrm{Bu}_{2}$ & 2.0 & 25 & 24 & 100 & 148 \\
\hline & $i-\mathrm{Bu}_{2} \mathrm{AlNPh}_{2}$ & 2.0 & 25 & 72 & 100 & 148 \\
\hline
\end{tabular}

${ }^{a}$ Reaction mixtures contained reagent and compound in THF, $\mathrm{Et}_{2} \mathrm{O}$ or hexane. ${ }^{b} \mathbf{I p c}=$ isopinocampheyl. ${ }^{c} \mathrm{GC}$ yields. ${ }^{d}$ Purity of all alcohols obtained is essentially $100 \%$. 
We can envision such a selectivity may be attributed to the reaction mechanism as proposed in the MPV type reactions (Scheme 22). As in the mechanism, 'a-attack' via a sixmembered hydrogen transfer must be in a lower energy level than that of ' $b$-attack' via an eight-membered hydrogen transfer.
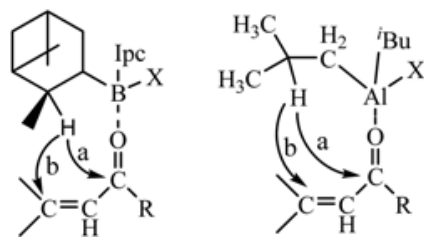

Scheme 22

In addition, it should be pointed out that the conversion yield to the corresponding alcohols reaches essentially $100 \%$ as well. It is usual that the classical MPV reaction using aluminum isopropoxide and the related MPV type reaction using other catalysts have been performed in the presence of isopropyl alcohol as a hydrogen donor, which, in turn, leads to the reaction mixture being lied in equilibrium. Further, the resultant acetone formed in due reaction seems to make the reaction mixture more complicated. However, in such reactions with diisobutylaluminum or diisopinocampheylboron derivatives, no hydrogen donor has been added, and hence no equilibrium exists. The olefins formed such as isobutylene or $\alpha$-pinene seem not to interfere with these reactions.

Chemoselective Reduction between Structurally Different Carbonyl Compounds. As growing the complexity of molecules which chemists are concerning, new methods and new reagents which offer a very clean and selective reduction of one carbonyl group in the presence of another or in the presence of other functional groups have been constantly being sought.

Recently, diisobutylaluminum derivatives $(\mathbf{1 7 - 2 3})^{111,114,118 \text {, }}$ $119,122,126,132$ and diisopinocampheylboron derivatives (2533) ${ }^{132,134-138,152}$ have also been applied to the competitive reduction between structurally different carbonyl compounds with a standard list consisting of representative pairs of an aldehyde - an aldehyde, an aldehyde - a ketone, a ketone - a ketone, and a carbonyl compound-another reducible organic compound. Some excellent results achieved by such MPV reagents are summarized in Table 4.

Table 4. Chemoselective Reduction between Structurally Different Carbonyl Compounds with Various MPV Type Reducing Agent ${ }^{a}$

\begin{tabular}{|c|c|c|c|c|c|}
\hline Starting mixture & Reagent & Temp. $\left({ }^{\circ} \mathrm{C}\right)$ & Time (h) & $\begin{array}{l}\text { Ratio of reduction } \\
\text { products }^{b}\end{array}$ & Ref \\
\hline Butanal + hexanal & $i-\mathrm{Bu}_{2} \mathrm{AlCl}$ & 25 & 1 & $95: 5$ & 111 \\
\hline \multirow{3}{*}{ Butanal + benzaldeheyde } & $i-\mathrm{Bu}_{2} \mathrm{AlCl}$ & 25 & 0.5 & $95: 5$ & 111 \\
\hline & $i-\mathrm{Bu}_{2} \mathrm{AlO}^{i} \mathrm{Pr}$ & 25 & 6 & $4: 96$ & 118 \\
\hline & $i-\mathrm{Bu}_{2} \mathrm{AlO}^{t} \mathrm{Bu}$ & 25 & 12 & $3: 97$ & 118 \\
\hline \multirow[t]{2}{*}{ Hexanal + benzaldehyde } & $i-\mathrm{Bu}_{2} \mathrm{AlO}^{i} \mathrm{Pr}$ & 25 & 3 & $1: 99$ & 118 \\
\hline & $i-\mathrm{Bu}_{2} \mathrm{AlO}^{t} \mathrm{Bu}$ & 25 & 6 & $0.5: 99.5$ & 118 \\
\hline Hexanal $+p$-anisaldehyde & $i-\mathrm{Bu}_{2} \mathrm{AlO}^{t} \mathrm{Bu}$ & 25 & 12 & $99: 1$ & 118 \\
\hline \multirow[t]{3}{*}{ Benzaldehyde $+p$-anisaldehyde } & $i-\mathrm{Bu}_{2} \mathrm{AlOEt}$ & 25 & 3 & $99.5: 0.5$ & 118 \\
\hline & $i-\mathrm{Bu}_{2} \mathrm{AlO}^{i} \mathrm{Pr}$ & 25 & 3 & $99.5: 0.5$ & 118 \\
\hline & $i-\mathrm{Bu}_{2} \mathrm{AlO}^{t} \mathrm{Bu}$ & 25 & 6 & $>99.9: \operatorname{tr}$ & 118 \\
\hline \multirow[t]{7}{*}{ Hexanal + cyclohexanone } & $\mathbf{I p c}_{2} \mathrm{BCl}$ & 0 & 3 & $70: 30$ & 132 \\
\hline & & -30 & 3 & 100:0 & 132 \\
\hline & $\mathbf{I p c}_{2} \mathrm{BOH}$ & 25 & 12 & 100:0 & 134,136 \\
\hline & $\mathbf{I p c}_{2} \mathrm{BOEt}$ & 25 & 12 & 100:0 & 136 \\
\hline & $\mathbf{I p c}_{2} \mathrm{BO}^{i} \mathrm{Pr}$ & 25 & 12 & 100:0 & 136 \\
\hline & $\mathbf{I p c}_{2} \mathrm{BO}{ }^{t} \mathrm{Bu}$ & 25 & 6 & 100:0 & 135,136 \\
\hline & $i-\mathrm{Bu}_{2} \mathrm{AlO}^{t} \mathrm{Bu}$ & 25 & 12 & $>99.9: \operatorname{tr}$ & 118 \\
\hline \multirow[t]{13}{*}{ Hexanal + 2-heptanone } & $\mathbf{I p c}_{2} \mathrm{BCl}$ & 0 & 3 & 100:0 & 132 \\
\hline & $\mathbf{I p c}_{2} \mathrm{BOH}$ & 25 & 12 & 100:0 & 134,136 \\
\hline & $\mathbf{I p c}_{2} \mathrm{BO}^{t} \mathrm{Bu}$ & 25 & 6 & 100:0 & 135,136 \\
\hline & $\mathbf{I p c}_{2} \mathrm{BOC}_{\text {hex }}$ & 25 & 24 & 100:0 & 137,138 \\
\hline & $\mathbf{I p c}_{2} \mathrm{BOPh}$ & 25 & 12 & 100:0 & 138 \\
\hline & Ipc $\mathbf{c}_{2} \mathrm{BOAc}$ & 0 & 3 & 100:0 & 152 \\
\hline & & 25 & 1 & 100:0 & 152 \\
\hline & $\mathbf{I p c}_{2} \mathrm{BO}_{2} \mathrm{CCF}_{3}$ & 0 & 3 & 100:0 & 152 \\
\hline & & 25 & 1 & $99: 1$ & 152 \\
\hline & $i-\mathrm{Bu}_{2} \mathrm{AlCl}$ & 25 & 1 & 100:0 & 111 \\
\hline & $i-\mathrm{Bu}_{2} \mathrm{AlOEt}$ & 25 & 6 & 100:0 & 118 \\
\hline & $i-\mathrm{Bu}_{2} \mathrm{AlO}^{i} \mathrm{Pr}$ & 25 & 6 & 100:0 & 118 \\
\hline & $i-\mathrm{Bu}_{2} \mathrm{AlO}^{t} \mathrm{Bu}$ & 25 & 12 & 100:0 & 118 \\
\hline
\end{tabular}


Table 4. Continued

\begin{tabular}{|c|c|c|c|c|c|}
\hline Starting mixture & Reagent & Temp. $\left({ }^{\circ} \mathrm{C}\right)$ & Time (h) & $\begin{array}{l}\text { Ratio of reduction } \\
\text { products }^{b}\end{array}$ & Ref \\
\hline \multirow[t]{12}{*}{ Hexanal + acetaophenone } & $\mathbf{I p c}_{2} \mathrm{BCl}$ & 0 & 3 & 100:0 & 132 \\
\hline & $\mathbf{I p c}_{2} \mathrm{BOH}$ & 25 & 24 & 100:0 & 134,136 \\
\hline & Ipc $_{2}$ BOEt & 25 & 6 & $>99.9: 0$ & 136 \\
\hline & $\mathbf{I p c}_{2} \mathrm{BO}^{i} \mathrm{Pr}$ & 25 & 6 & $>99.9: 0$ & 136 \\
\hline & $\mathbf{I p c}_{2} \mathrm{BO}^{t} \mathrm{Bu}$ & 25 & 24 & 100:0 & 135,136 \\
\hline & $\mathbf{I p c}_{2} \mathrm{BOC}_{\text {hex }}$ & 25 & 24 & 100:0 & 137,138 \\
\hline & $\mathbf{I p c}_{2} \mathrm{BOPh}$ & 25 & 12 & 100:0 & 138 \\
\hline & $\mathbf{I p c}_{2} \mathrm{BOAc}$ & 25 & 3 & 100:0 & 152 \\
\hline & $\mathbf{I p c}_{2} \mathrm{BO}_{2} \mathrm{CCF}_{3}$ & 25 & 3 & 100:0 & 152 \\
\hline & $i-\mathrm{Bu}_{2} \mathrm{AlCl}$ & 25 & 1 & 100:0 & 111 \\
\hline & $i-\mathrm{Bu}_{2} \mathrm{AlOEt}$ & 25 & 6 & 100:0 & 118 \\
\hline & $i-\mathrm{Bu}_{2} \mathrm{AlO}^{t} \mathrm{Bu}$ & 25 & 12 & $99.5: 0.5$ & 118 \\
\hline \multirow[t]{13}{*}{ Hexanal + benzophenone } & $\mathbf{I p c}_{2} \mathrm{BCl}$ & 0 & 3 & 100:0 & 132 \\
\hline & $\mathbf{I p c}_{2} \mathrm{BOH}$ & 25 & 24 & $100: 0$ & 134,136 \\
\hline & $\mathbf{I p c}_{2} \mathrm{BOEt}$ & 25 & 24 & 100:0 & 136 \\
\hline & $\mathbf{I p c}_{2} \mathrm{BO} \mathrm{O}^{i} \mathrm{Pr}$ & 25 & 6 & $>99.9: 0$ & 136 \\
\hline & $\mathbf{I p c}_{2} \mathrm{BO}{ }^{t} \mathrm{Bu}$ & 25 & 6 & $100: 0$ & 135,136 \\
\hline & $\mathbf{I p c}_{2} \mathrm{BOC}_{\text {hex }}$ & 25 & 24 & 100:0 & 137,138 \\
\hline & $\mathbf{I p c}_{2} \mathrm{BOPh}$ & 25 & 12 & 100:0 & 138 \\
\hline & $\mathbf{I p c}_{2} \mathrm{BOAc}$ & 0 & 3 & 100:0 & 152 \\
\hline & $\mathbf{I p c}_{2} \mathrm{BO}_{2} \mathrm{CCF}_{3}$ & 0 & 3 & 100:0 & 152 \\
\hline & $i-\mathrm{Bu}_{2} \mathrm{AlCl}$ & 25 & 1 & 100:0 & 111 \\
\hline & $i-\mathrm{Bu}_{2} \mathrm{AlOEt}$ & 25 & 6 & 100:0 & 118 \\
\hline & $i-\mathrm{Bu}_{2} \mathrm{AlO}^{i} \mathrm{Pr}$ & 25 & 6 & 100:0 & 118 \\
\hline & $i-\mathrm{Bu}_{2} \mathrm{AlO}^{t} \mathrm{Bu}$ & 25 & 12 & 100:0 & 118 \\
\hline \multirow{2}{*}{ Cyclohexanone + cyclopentanone } & $i-\mathrm{Bu}_{2} \mathrm{AlO}^{i} \mathrm{Pr}$ & 25 & 24 & $92: 8$ & 118 \\
\hline & $i-\mathrm{Bu}_{2} \mathrm{AlO}^{t} \mathrm{Bu}$ & 25 & 48 & $95: 5$ & 118 \\
\hline \multirow[t]{5}{*}{ Cyclohexnone +2 -heptanone } & $\mathbf{I p c}_{2} \mathrm{BCl}$ & 0 & 3 & $99.5: 0.5$ & 132 \\
\hline & $i-\mathrm{Bu}_{2} \mathrm{AlCl}$ & 25 & 3 & 99.9:0.1 & 111 \\
\hline & $i-\mathrm{Bu}_{2} \mathrm{AlOEt}$ & 25 & 24 & $100: 0$ & 118 \\
\hline & $i-\mathrm{Bu}_{2} \mathrm{AlO}^{i} \mathrm{Pr}$ & 25 & 24 & $100: 0$ & 118 \\
\hline & $i-\mathrm{Bu}_{2} \mathrm{AlO}^{t} \mathrm{Bu}$ & 25 & 48 & 100:0 & 118 \\
\hline \multirow[t]{4}{*}{ Cyclohexanone + acetophenone } & $\mathbf{I p c}_{2} \mathrm{BCl}$ & 0 & 3 & $95: 5$ & 132 \\
\hline & & -30 & 12 & 100:0 & 132 \\
\hline & $i-\mathrm{Bu}_{2} \mathrm{AlCl}$ & 25 & 3 & $98: 2$ & 111 \\
\hline & $i-\mathrm{Bu}_{2} \mathrm{AlOEt}$ & 25 & 24 & $95: 5$ & 118 \\
\hline \multirow[t]{4}{*}{ Cyclohexanone + benzophenone } & $i-\mathrm{Bu}_{2} \mathrm{AlCl}$ & 25 & 3 & 99.9:0.1 & 111 \\
\hline & $i-\mathrm{Bu}_{2} \mathrm{AlOEt}$ & 25 & 24 & 100:0 & 118 \\
\hline & $i-\mathrm{Bu}_{2} \mathrm{AlO}^{i} \mathrm{Pr}$ & 25 & 24 & 100:0 & 118 \\
\hline & $i-\mathrm{Bu}_{2} \mathrm{AlO}^{t} \mathrm{Bu}$ & 25 & 48 & 100:0 & 118 \\
\hline \multirow[t]{3}{*}{ Acetophenone +2 -heptanone } & $i-\mathrm{Bu}_{2} \mathrm{AlCl}$ & 25 & 3 & 100:0 & 111 \\
\hline & $i-\mathrm{Bu}_{2} \mathrm{AlOEt}$ & 25 & 48 & 100:0 & 118 \\
\hline & $i-\mathrm{Bu}_{2} \mathrm{AlO}^{i} \mathrm{Pr}$ & 25 & 48 & $>99.9: \operatorname{tr}$ & 118 \\
\hline \multirow[t]{3}{*}{ 2-Heptanone + bezophenone } & $i-\mathrm{Bu}_{2} \mathrm{AlOEt}$ & 25 & 96 & $95: 5$ & 118 \\
\hline & $i-\mathrm{Bu}_{2} \mathrm{AlO}^{i} \mathrm{Pr}$ & 25 & 96 & $94: 6$ & 118 \\
\hline & $i-\mathrm{Bu}_{2} \mathrm{AlO}^{t} \mathrm{Bu}$ & 25 & 120 & $94: 6$ & 118 \\
\hline \multirow[t]{4}{*}{ Acetophenone + benzophenone } & $\mathbf{I p c}_{2} \mathrm{BCl}$ & 0 & 3 & 99.9:0.1 & 132 \\
\hline & $i-\mathrm{Bu}_{2} \mathrm{AlCl}$ & 25 & 3 & 100:0 & 111 \\
\hline & $i-\mathrm{Bu}_{2} \mathrm{AlOEt}$ & 25 & 48 & 100:0 & 118 \\
\hline & $i-\mathrm{Bu}_{2} \mathrm{AlO}^{i} \mathrm{Pr}$ & 25 & 48 & 100:0 & 118 \\
\hline \multirow[t]{5}{*}{ Hexanal + hexanoyl chloride } & $\mathbf{I p c}_{2} \mathrm{BCl}$ & 0 & 3 & 100:0 & 132 \\
\hline & $\mathbf{I p c}_{2} \mathrm{BOH}$ & 25 & 12 & 100:0 & 134,136 \\
\hline & $\mathbf{I p c}_{2} \mathrm{BOEt}$ & 25 & 12 & 100:0 & 136 \\
\hline & $i-\mathrm{Bu}_{2} \mathrm{AlO}^{i} \mathrm{Pr}$ & 25 & 24 & 100:0 & 118 \\
\hline & $i-\mathrm{Bu}_{2} \mathrm{AlO}^{t} \mathrm{Bu}$ & 25 & 48 & 100:0 & 118 \\
\hline
\end{tabular}


Table 4. Continued

\begin{tabular}{|c|c|c|c|c|c|}
\hline Starting mixture & Reagent & Temp. $\left({ }^{\circ} \mathrm{C}\right)$ & Time (h) & $\begin{array}{l}\text { Ratio of reduction } \\
\text { products }^{b}\end{array}$ & Ref \\
\hline \multirow[t]{2}{*}{ Cyclohexanone + cyclopentanone } & $i-\mathrm{Bu}_{2} \mathrm{AlO}^{i} \mathrm{Pr}$ & 25 & 24 & $92: 8$ & 118 \\
\hline & $i-\mathrm{Bu}_{2} \mathrm{AlO}^{t} \mathrm{Bu}$ & 25 & 48 & $95: 5$ & 118 \\
\hline \multirow[t]{5}{*}{ Cyclohexnone + 2-heptanone } & $\mathbf{I p c}_{2} \mathrm{BCl}$ & 0 & 3 & $99.5: 0.5$ & 132 \\
\hline & $i-\mathrm{Bu}_{2} \mathrm{AlCl}$ & 25 & 3 & 99.9:0.1 & 111 \\
\hline & $i-\mathrm{Bu}_{2} \mathrm{AlOEt}$ & 25 & 24 & $100: 0$ & 118 \\
\hline & $i-\mathrm{Bu}_{2} \mathrm{AlO}^{i} \mathrm{Pr}$ & 25 & 24 & 100:0 & 118 \\
\hline & $i-\mathrm{Bu}_{2} \mathrm{AlO}^{t} \mathrm{Bu}$ & 25 & 48 & 100:0 & 118 \\
\hline \multirow[t]{4}{*}{ Cyclohexanone + acetophenone } & $\mathbf{I p c}_{2} \mathrm{BCl}$ & 0 & 3 & $95: 5$ & 132 \\
\hline & & -30 & 12 & 100:0 & 132 \\
\hline & $i-\mathrm{Bu}_{2} \mathrm{AlCl}$ & 25 & 3 & $98: 2$ & 111 \\
\hline & $i-\mathrm{Bu}_{2} \mathrm{AlOEt}$ & 25 & 24 & $95: 5$ & 118 \\
\hline \multirow[t]{4}{*}{ Cyclohexanone + benzophenone } & $i-\mathrm{Bu}_{2} \mathrm{AlCl}$ & 25 & 3 & 99.9:0.1 & 111 \\
\hline & $i-\mathrm{Bu}_{2} \mathrm{AlOEt}$ & 25 & 24 & $100: 0$ & 118 \\
\hline & $i-\mathrm{Bu}_{2} \mathrm{AlO}^{i} \mathrm{Pr}$ & 25 & 24 & 100:0 & 118 \\
\hline & $i-\mathrm{Bu}_{2} \mathrm{AlO}^{t} \mathrm{Bu}$ & 25 & 48 & 100:0 & 118 \\
\hline \multirow[t]{3}{*}{ Acetophenone +2 -heptanone } & $i-\mathrm{Bu}_{2} \mathrm{AlCl}$ & 25 & 3 & 100:0 & 111 \\
\hline & $i-\mathrm{Bu}_{2} \mathrm{AlOEt}$ & 25 & 48 & $100: 0$ & 118 \\
\hline & $i-\mathrm{Bu}_{2} \mathrm{AlO}^{i} \mathrm{Pr}$ & 25 & 48 & $>99.9: \operatorname{tr}$ & 118 \\
\hline \multirow[t]{3}{*}{ 2-Heptanone + bezophenone } & $i-\mathrm{Bu}_{2} \mathrm{AlOEt}$ & 25 & 96 & $95: 5$ & 118 \\
\hline & $i-\mathrm{Bu}_{2} \mathrm{AlO}^{i} \mathrm{Pr}$ & 25 & 96 & $94: 6$ & 118 \\
\hline & $i-\mathrm{Bu}_{2} \mathrm{AlO}^{t} \mathrm{Bu}$ & 25 & 120 & $94: 6$ & 118 \\
\hline \multirow[t]{4}{*}{ Acetophenone + benzophenone } & $\mathbf{I p c}_{2} \mathrm{BCl}$ & 0 & 3 & 99.9:0.1 & 132 \\
\hline & $i-\mathrm{Bu}_{2} \mathrm{AlCl}$ & 25 & 3 & 100:0 & 111 \\
\hline & $i-\mathrm{Bu}_{2} \mathrm{AlOEt}$ & 25 & 48 & 100:0 & 118 \\
\hline & $i-\mathrm{Bu}_{2} \mathrm{AlO}^{i} \mathrm{Pr}$ & 25 & 48 & 100:0 & 118 \\
\hline \multirow{14}{*}{ Hexanal + hexanoyl chloride } & $\mathbf{I p c}_{2} \mathrm{BCl}$ & 0 & 3 & 100:0 & 132 \\
\hline & $\mathbf{I p c}_{2} \mathrm{BOH}$ & 25 & 12 & 100:0 & 134,136 \\
\hline & $\mathbf{I p c}_{2} \mathrm{BOEt}$ & 25 & 12 & $100: 0$ & 136 \\
\hline & $\mathbf{I p c}_{2} \mathrm{BO}^{i} \mathrm{Pr}$ & 25 & 6 & 100:0 & 136 \\
\hline & $\mathbf{I p c}_{2} \mathrm{BO}{ }^{t} \mathrm{Bu}$ & 25 & 6 & 100:0 & 135,136 \\
\hline & Ipc $_{2} \mathrm{BOC}_{\text {hex }}$ & 25 & 24 & $100: 0$ & 137,138 \\
\hline & Ipc $_{2} \mathrm{BOPh}$ & 25 & 12 & $100: 0$ & 138 \\
\hline & $\mathbf{I p c}_{2} \mathrm{BOAc}$ & 25 & 1 & 100:0 & 152 \\
\hline & $\mathbf{I p c}_{2} \mathrm{BO}_{2} \mathrm{CCF}_{3}$ & 25 & 1 & 100:0 & 152 \\
\hline & $i-\mathrm{Bu}_{2} \mathrm{AlCl}$ & 25 & 1 & $100: 0$ & 111 \\
\hline & $i-\mathrm{Bu}_{2} \mathrm{AlOH}$ & 25 & 3 & 100:0 & 118 \\
\hline & $i-\mathrm{Bu}_{2} \mathrm{AlOEt}$ & 25 & 6 & $100: 0$ & 118 \\
\hline & $i-\mathrm{Bu}_{2} \mathrm{AlO}^{i} \mathrm{Pr}$ & 25 & 6 & 100:0 & 118 \\
\hline & $i-\mathrm{Bu}_{2} \mathrm{AlO}^{t} \mathrm{Bu}$ & 25 & 12 & 100:0 & 118 \\
\hline \multirow[t]{8}{*}{ Hexanal + benzoyl chloride } & $\mathbf{I p c}_{2} \mathrm{BOH}$ & 25 & 12 & 100:0 & 134,136 \\
\hline & $\mathbf{I p c}_{2} \mathrm{BOEt}$ & 25 & 6 & 100:0 & 136 \\
\hline & $\mathbf{I p c _ { 2 }} \mathrm{BO}^{i} \mathrm{Pr}$ & 25 & 6 & 100:0 & 136 \\
\hline & $\mathbf{I p c}_{2} \mathrm{BO}^{t} \mathrm{Bu}$ & 25 & 12 & 100:0 & 135,136 \\
\hline & $i-\mathrm{Bu}_{2} \mathrm{AlOH}$ & 25 & 3 & 100:0 & 118 \\
\hline & $i-\mathrm{Bu}_{2} \mathrm{AlOEt}$ & 25 & 6 & 100:0 & 118 \\
\hline & $i-\mathrm{Bu}_{2} \mathrm{AlO}^{i} \mathrm{Pr}$ & 25 & 6 & 100:0 & 118 \\
\hline & $i-\mathrm{Bu}_{2} \mathrm{AlO}^{t} \mathrm{Bu}$ & 25 & 12 & 100:0 & 118 \\
\hline \multirow[t]{6}{*}{ 2-Heptanone + benzoyl chloride } & $\mathbf{I p c}_{2} \mathrm{BCl}$ & 0 & 6 & 100:0 & 132 \\
\hline & $i-\mathrm{Bu}_{2} \mathrm{AlCl}$ & 25 & 12 & 100:0 & 111 \\
\hline & $i-\mathrm{Bu}_{2} \mathrm{AlOH}$ & 25 & 24 & $98: 2$ & 118 \\
\hline & $i-\mathrm{Bu}_{2} \mathrm{AlOEt}$ & 25 & 96 & $99: 1$ & 118 \\
\hline & $i-\mathrm{Bu}_{2} \mathrm{AlO}^{i} \mathrm{Pr}$ & 25 & 96 & 100:0 & 118 \\
\hline & $i-\mathrm{Bu}_{2} \mathrm{AlO}^{t} \mathrm{Bu}$ & 25 & 120 & 100:0 & 118 \\
\hline
\end{tabular}

${ }^{a}$ One equivalent of reagent added to an equimolar mixture of starting compounds. ${ }^{b}$ Total yields of product alcohols were $\geq 99 \%$. 

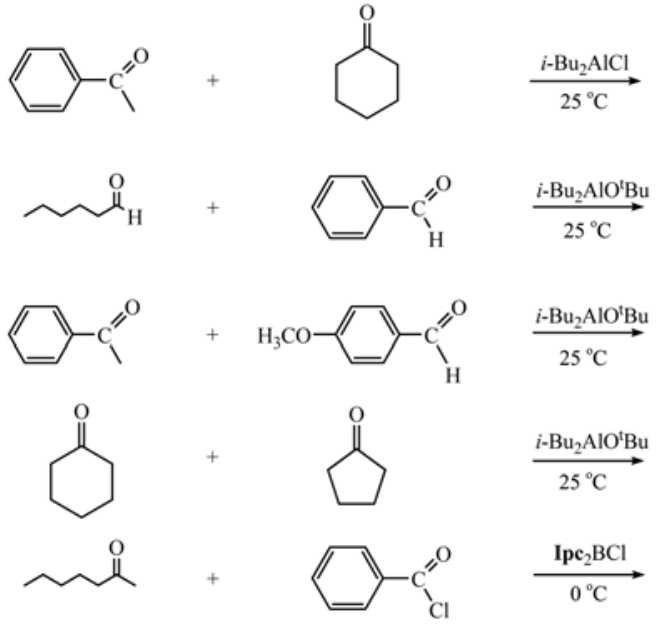

As a result, all these reagents examined can reduce one of aliphatic and aromatic aldehydes selectively in the presence of quite a number of different ketones (Eq. 99). Even more remarkable is the chemoselective discrimination between aldehydes. Thus, benzaldehye can be selectively reduced in the presence of hexanal with $\boldsymbol{i}$-Bu $\mathbf{B} \mathbf{A I O R}$ (Eq. 100). Butanal and hexanal are much more reactive than $p$-anisaldehyde toward $\boldsymbol{i}$-Bu $\mathbf{u}_{2} \mathbf{A l O R}$ (Eq. 101). Furthermore, various reagents can discriminate between structurally different ketones. Even cyclohexanone can be selectively reduced in the presence of cyclopentanone in a up to 95:5 selectivity with $\boldsymbol{i}$ $\mathbf{B u}_{2} \mathbf{A l O}^{t} \mathbf{B u}$ (Eq. 102). In addition, various functional groups, such as esters, nitriles, amides and alkenes, are not affected by these reagents. Even acid chlorides are inert to the reagents (Eq. 103).

Stereoselective Reduction of Cycloalkanones. It has been desirable to have reagents that could reduce substituted cycloalkanones to the corresponding one of two possible epimeric alcohols in $99 \%$ or better stereoselectivity. For example, in the reduction of 4-methylcyclohexanone one might expect to obtain cis-4-methylcyclohexanol, the thermodynamically less stable epimer, or trans-4-methylcyclohexanol, the thermodynamically more stable one (Eq. 104).

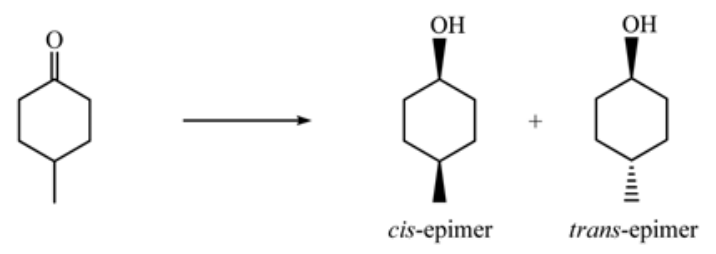

One of the exceptionally promising developments in the area of stereoselective reduction of cyclic ketones must be the advent of hindered trisubstituted borohydrides, such as lithium trisiamylborohydride $\left(\mathrm{LiSia}_{3} \mathrm{BH}\right),{ }^{153}$ lithium tri- $S$ butylborohydride $\left(\mathrm{Li}^{\mathrm{s}} \mathrm{Bu} 3 \mathrm{BH}\right){ }^{154}$ potassium 9-t-butyl-9-boratbicyclo[3.3.1] nonane (K9- $\left.{ }^{t} \mathrm{Bu}-9-\mathbf{B B N H}\right), 32$ lithium (2,3dimethyl-2-butyl)-t-butoxy borohydride $\left(\mathrm{Thx}^{t} \mathrm{BuOBH}_{2}\right),{ }^{38 \mathrm{~b}}$ potassium 9-(2,3-dimethyl-2-butoxy)-9-BBNH ${ }^{31 \mathrm{~b}}$ and so on. ${ }^{155}$ These reagents reduce cyclic ketones with super stereoselectivity to produce the corresponding thermodynamically

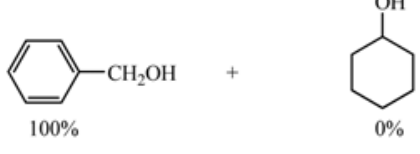

$100 \%$

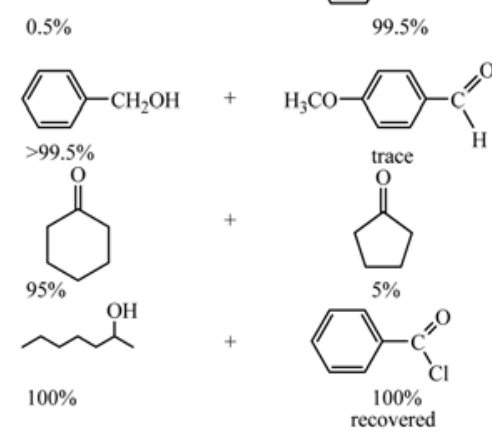

less stable alcohol epimer (Eq. 105 and 106). These reagents reduce cyclic ketones with super stereoselectivity to produce the corresponding thermodynamically less stable alcohol epimer (Eq. 105 and 106) as summarized in Table 5.

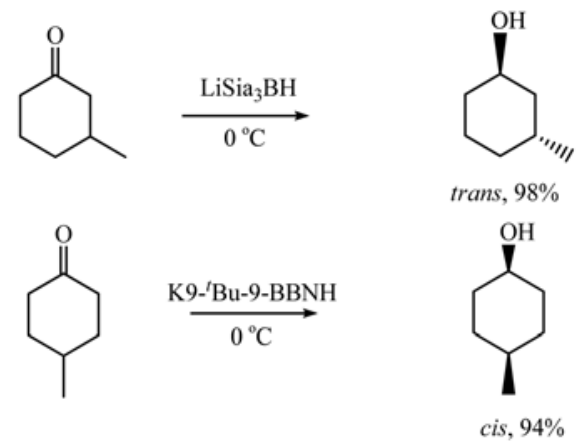

Very recently, diisopinocampheylhaloboranes such as $\mathbf{I p c}_{2} \mathbf{B C F}, \mathbf{I p c _ { 2 }} \mathbf{B C I}, \mathbf{I p c _ { 2 }} \mathbf{B B r}$ and $\mathrm{Ipc}_{2} \mathrm{BI}$ have been examined for their stereoselectivities in the reduction of typical cyclic ketones. The stereoselectivity for producing the thermodynamically less stable isomer increases dramatically with increasing steric size of the halogen substituent. Especially the iodo derivative appears to be a really ideal stereoselective reducing agent, showing an essentially $100 \%$ selectivity in the reduction of representative cyclic ketones at $-30{ }^{\circ} \mathrm{C}$. However, $\mathbf{I p c}_{2} \mathbf{B I}$ possesses a drawback in producing alcohols, showing significantly low conversion yields ${ }^{135}$ (Eq. 107).

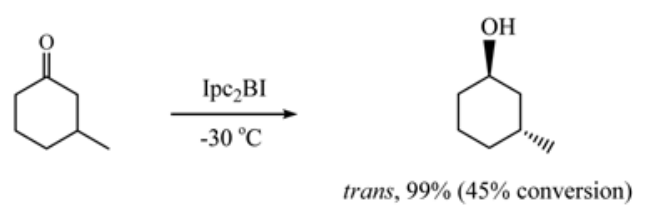

Similarly, the newly-devised actoxy- and methanesulfonylsubstituted diisobutylalane derivatives, such as $\mathrm{Al}$-acetoxydiisobutylalane (DIBAOAc, 20), $A$-trifluoroacetoxydiisobutylalane (DIBAO $\left.\mathbf{C C F}_{3}, \mathbf{2 1}\right), A l$-methanesulfonyldiisobutylalane (DIBAOSO $2 \mathrm{CH}_{3}, 22$ ), and $\mathrm{Al}$-trifluoromethanesulfonyldiisobutylalane (DIBAOSO $\left.2 \mathbf{C F}_{3}, 23\right)$, achieve the stereoselective reduction of representative cyclic ketones to produce the thermodynamically more stable alcohols exclu- 
Table 5. Stereoselectivity in the Reduction of Cyclic Ketones with Representative Reagents at $0{ }^{\circ} \mathrm{C}$

\begin{tabular}{|c|c|c|}
\hline Ketone & Reagent & $\begin{array}{c}\text { Selectivity in less stable } \\
\text { epimer }(\%)\end{array}$ \\
\hline & $\mathrm{LiThx}^{t} \mathrm{BuOBH}_{2}$ & $>99.5$ \\
\hline & K9-OThx-9-BBNH & 98.5 \\
\hline & $\mathrm{Li}^{\mathrm{s}} \mathrm{Bu}_{3} \mathrm{BH}$ & 99.3 \\
\hline & $\mathrm{LiSia}_{3} \mathrm{BH}$ & 99.4 \\
\hline & K9- ${ }^{t} \mathrm{Bu}-9-\mathbf{B B N H}$ & 99.5 \\
\hline & $\mathrm{LiThx}^{t} \mathrm{BuOBH}_{2}$ & 96 \\
\hline & K9-OThx-9-BBNH & 90 \\
\hline & $\mathrm{Li}^{\mathrm{s}} \mathrm{Bu}_{3} \mathrm{BH}$ & 85 \\
\hline & $\mathrm{LiSia}_{3} \mathrm{BH}$ & 98 \\
\hline & K9- ${ }^{t} \mathrm{Bu}-9-\mathbf{B B N H}$ & 96 \\
\hline & $\mathrm{LiThx}^{t} \mathrm{BuOBH}_{2}$ & 92 \\
\hline & K9-OThx-9-BBNH & 85.5 \\
\hline & $\mathrm{Li}^{\mathrm{s}} \mathrm{Bu}_{3} \mathrm{BH}$ & 80.5 \\
\hline & $\mathrm{LiSia}_{3} \mathrm{BH}$ & 93 \\
\hline & K9- ${ }^{t} \mathrm{Bu}-9-\mathbf{B B N H}$ & 94 \\
\hline & $\mathrm{LiThx}^{t} \mathrm{BuOBH}_{2}$ & 95 \\
\hline & K9-OThx-9-BBNH & 87 \\
\hline & $\mathrm{Li}^{\mathrm{s}} \mathrm{Bu}_{3} \mathrm{BH}$ & 87.5 \\
\hline & $\mathrm{LiSia}_{3} \mathrm{BH}$ & 96.5 \\
\hline & K9- ${ }^{t} \mathrm{Bu}-9-\mathbf{B B N H}$ & 98.5 \\
\hline & $\mathrm{LiThx}^{t} \mathrm{BuOBH}_{2}$ & $>99.5$ \\
\hline & K9-OThx-9-BBNH & $>99.9$ \\
\hline & $\mathrm{Li}^{\mathrm{s}} \mathrm{Bu}_{3} \mathrm{BH}$ & 99.8 \\
\hline & $\mathrm{LiSia}_{3} \mathrm{BH}$ & 99 \\
\hline & K9- ${ }^{t} \mathrm{Bu}-9-\mathbf{B B N H}$ & 99 \\
\hline & $\mathrm{LiThx}^{t} \mathrm{BuOBH}_{2}$ & 98 \\
\hline & K9-OThx-9-BBNH & 95 \\
\hline & $\mathrm{Li}^{\mathrm{s}} \mathrm{Bu}_{3} \mathrm{BH}$ & 99.6 \\
\hline & $\mathrm{LiSia}_{3} \mathrm{BH}$ & 99 \\
\hline & K9- ${ }^{t} \mathrm{Bu}-9-\mathbf{B B N H}$ & 95.5 \\
\hline & $\mathrm{LiThx}^{t} \mathrm{BuOBH}_{2}$ & $>99.5$ \\
\hline & K9-OThx-9-BBNH & 97.5 \\
\hline & $\mathrm{Li}^{\mathrm{s}} \mathrm{Bu}_{3} \mathrm{BH}$ & 99.6 \\
\hline & $\mathrm{LiSia}_{3} \mathrm{BH}$ & $>99.9$ \\
\hline & K9- ${ }^{t} \mathrm{Bu}-9-\mathbf{B B N H}$ & 99.9 \\
\hline & $\mathrm{LiThx}^{t} \mathrm{BuOBH}$ & $>99.5$ \\
\hline
\end{tabular}

sively. $^{122,126}$

Recently, $\boldsymbol{i}-\mathbf{B u}_{2} \mathbf{A l O}{ }^{i} \mathbf{P r}$ has been applied to the stereoselective reduction of representative monocyclic and bicyclic ketones. ${ }^{136}$ Experiments were carried out under two different conditions: a mixture of ketone and reagent (1:1) at $25^{\circ} \mathrm{C}$ in $\mathrm{Et}_{2} \mathrm{O}$ or a mixture of ketone and reagent $(2: 1)$ in refluxing $\mathrm{Et}_{2} \mathrm{O},{ }^{157,158}$ and the results are summarized in Table 6 . In the experiment on an equimolar mixture of reagent and ketone at $25{ }^{\circ} \mathrm{C}$, the stereochemistry of reduction appears apprarently dependent on the reaction time. The stereoselectivity increases consistently with increase of reaction time to afford the thermodynamically more stable isomer alcohols exclusively (Eq. 108), with exception of camphor which is resistant to reduction under the reaction conditions. Furthermore, like triisobutylaluminum (TIBA), it has been

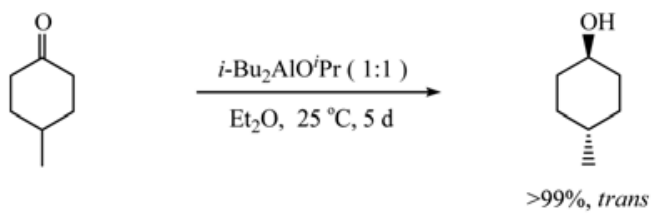

found that the isobutyl group of $\boldsymbol{i}-\mathbf{B} \mathbf{u}_{2} \mathbf{A l O}^{i} \mathbf{P r}$ is involved in this reduction. ${ }^{158}$ Therefore, two equivalents of ketone are reduced with one equivalent of the reagent in refluxing $\mathrm{Et}_{2} \mathrm{O}$,

Table 6. Stereoselective Reduction of Cyclic Ketones with $i$ $\mathrm{Bu}_{2} \mathrm{AlO}^{i} \mathrm{Pr}$ in $\mathrm{Et}_{2} \mathrm{O}$

\begin{tabular}{|c|c|c|c|c|c|}
\hline \multirow[t]{2}{*}{ Ketone } & \multirow{2}{*}{$\begin{array}{c}\text { reaction } \\
\text { Time } \\
\text { (h) }\end{array}$} & \multicolumn{4}{|c|}{$\begin{array}{c}\text { Ketone:reagent }=1: 1 \text { Ketone:reagent }=2: 1 \\
\left(25^{\circ} \mathrm{C}\right)\end{array}$} \\
\hline & & $\begin{array}{c}\text { Ratio of } \\
\text { more stable } \\
\text { isomer }\end{array}$ & $\begin{array}{c}\text { Yield of } \\
\text { alcohol } \\
(\%)\end{array}$ & $\begin{array}{l}\text { Ratio of } \\
\text { more stable } \\
\text { isomer }\end{array}$ & $\begin{array}{c}\text { Yield of } \\
\text { alcohol } \\
(\%)\end{array}$ \\
\hline & 3 & 49 & 51 & & \\
\hline & 6 & 67 & 71 & & \\
\hline & 24 & 85 & 92 & 87 & 76 \\
\hline & 72 & 91 & 98 & 89.5 & 87 \\
\hline & 120 & 95 & $>99.9$ & 90 & 92 \\
\hline & 168 & 96 & 100 & & \\
\hline & 360 & & & 93.5 & 99 \\
\hline & 6 & 91 & 98 & & \\
\hline & 24 & 93 & 99 & 91 & 81 \\
\hline & 72 & 93 & $>99.9$ & 92 & 92 \\
\hline & 96 & 94 & 100 & & \\
\hline & 120 & 95 & 100 & 92 & 97 \\
\hline & 240 & & & 94 & $>99.9$ \\
\hline & 3 & 89 & 94 & & \\
\hline & 24 & 92 & 99 & 92 & 87 \\
\hline & 72 & 94 & $>99.9$ & 93.5 & 94 \\
\hline & 96 & 97 & 100 & & \\
\hline & 120 & $>99.9$ & 100 & 94 & 97 \\
\hline & 240 & & & 97 & 100 \\
\hline & 6 & 91 & 98 & & \\
\hline & 24 & 95 & $>99.9$ & 91 & 82 \\
\hline & 72 & 97 & 100 & 94.5 & 94 \\
\hline & 96 & 98 & 100 & & \\
\hline & 120 & & & 97 & 97 \\
\hline & 240 & & & 98 & 100 \\
\hline & 12 & 97 & 89 & & \\
\hline & 24 & 98 & 94 & 93 & 78.5 \\
\hline & 72 & $>99.9$ & 99 & 94 & 89 \\
\hline & 120 & & & 94.5 & 90 \\
\hline & 240 & & & 96 & 97 \\
\hline & 6 & 85 & 43 & & \\
\hline & 24 & 90 & 76 & 68 & 58 \\
\hline & 72 & 93 & 96 & 81 & 73 \\
\hline & 120 & 97 & 100 & 86 & 80 \\
\hline & 240 & & & 91.5 & 98 \\
\hline & 24 & 31 & 7 & 35 & 2.5 \\
\hline & 120 & 36 & 14 & 49 & 6 \\
\hline & 168 & 37 & 23 & & \\
\hline & 360 & & & 69 & 20 \\
\hline
\end{tabular}


although the second ketone is reduced in a relatively slow rate (Eq. 109). This seems to be a phenomenon that must rise<smiles>CC(C)(C)C1CCC(=O)CC1</smiles>
$\underset{\text { reflux, } 7 \mathrm{~d}}{\stackrel{0.5 \text { equiv } i-\mathrm{Bu}_{2} \mathrm{AlO}^{i} \mathrm{Pr}, \mathrm{Et}_{2} \mathrm{O}}{\longrightarrow}}$<smiles>CC(C)(C)[C@H]1CC[C@@H](O)CC1</smiles>

$98 \%$, trans

where the thermodynamically less stable alcohol isomer, one of the two isomer produced by reduction with $\boldsymbol{i}-\mathbf{B u}_{2} \mathbf{A l O}{ }^{i} \mathbf{P r}$, is converted to the more stable one by thermodynamically controlled isomer equilibration via a MPV type reduction. ${ }^{157}$ Such a time dependence on the stereochemistry has also been found in the reduction of cyclic ketones with other aluminum derivatives such as TIBA $^{159,160}$ and 1-pyrrolyldiisobutylalane. ${ }^{161}$

Such a mechanism involving thermodynamically controlled isomer equilibration can be extended to utilization of diisobutylaluminum hydride (DIBAH) itself. When the reduction of excess cyclic ketone with DIBAH is carried out at $0{ }^{\circ} \mathrm{C}$, only the free hydride is involved and hence only one equivalent of ketone is reduced to show a low stereoselectivity. However, when the reduction is repeated at $25^{\circ} \mathrm{C}$ or under reflux, one isobutyl group as well as the free hydride of DIBAH is also involved. ${ }^{162}$ And the system just follows the thermodynamically controlled isomer equilibration in similar to the case of $\boldsymbol{i}-\mathbf{B u}_{2} \mathbf{A l O} \mathbf{O}^{i} \mathbf{P r}$ (Scheme 23).
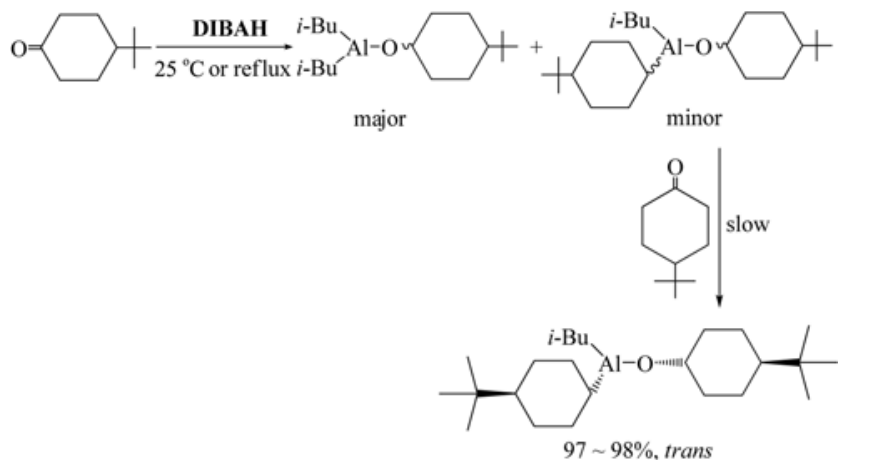

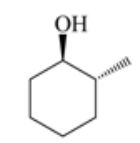

$92 \sim 93 \%$, trans

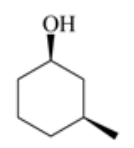

$95 \sim 96 \%$, cis
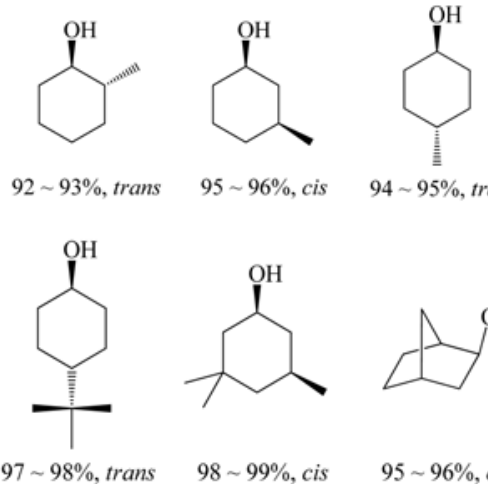

$94 \sim 95 \%$, trans

$97 \sim 98 \%$, trans

$98 \sim 99 \%$, cis

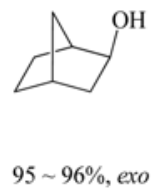

Scheme 23

A similar trend has also been observed in the reduction of cyclic ketones with $\mathrm{AlH}_{3}{ }^{163}$ In this case 3.3 equiv of ketone is needed. However, the stereoselectivity accomplished in this reduction appears somewhat lower than that achieved by diisobutylaluminum derivatives (Eq. 110).

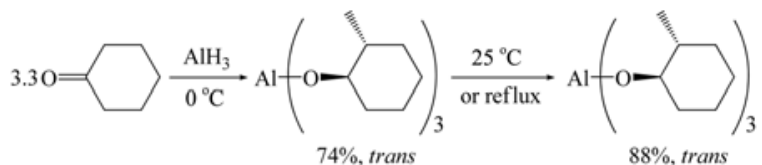

A solution of $\mathrm{BH}_{3}$ THF can also be applied to such stereoselective reductions. ${ }^{164}$ Because of the relatively smaller size of boron atom than that of aluminum atom, the stereochemistry of reduction is dependent on the reaction time only under reflux, while the reactions at $0{ }^{\circ} \mathrm{C}$ and $25^{\circ} \mathrm{C}$ show no such a time dependence.
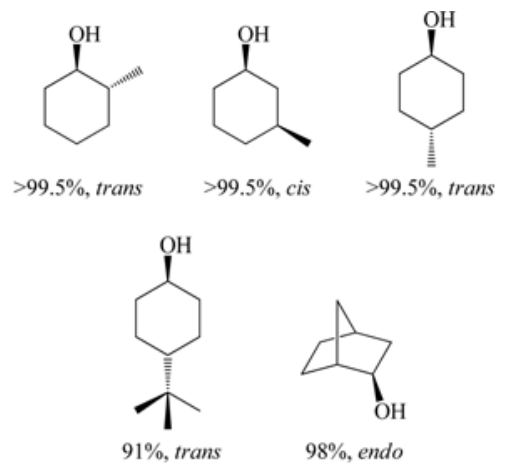

Regioselective Ring-Opening of Epoxide. As expected for $\mathbf{S}_{\mathrm{N}} \mathbf{2}$ processes, nucleophilic hydride transferring reagents, such as $\mathrm{LiAlH}_{4}{ }^{165}$ and $\mathbf{L i E t}_{3} \mathbf{B H}{ }^{166}$ attack epoxides at the less substituted site to afford the more highly substituted alcohol (Eq. 111-113).

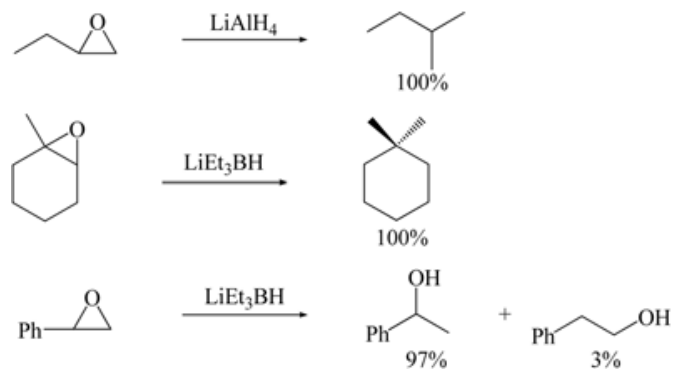

On the other hand, with electrophilic hydride reagents such as $\mathrm{BH}_{3}{ }^{167}$ and $\mathrm{AlH}_{3}{ }^{168}$ reverse opening is often observed to produce the less substituted alcohol, but mixtures usually result (Eq. 114 and 115).

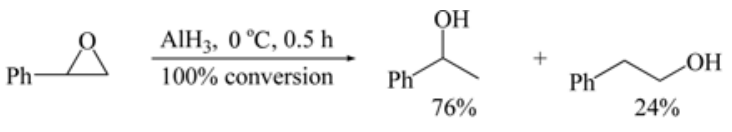

$$
\begin{aligned}
& \curvearrowright \frac{\mathrm{BH}_{3}, 25^{\circ} \mathrm{C}, 2 \mathrm{~d}}{48 \% \text { conversion }} \overbrace{96 \%}^{\mathrm{OH}}+\overbrace{4 \%}^{\mathrm{OH}}
\end{aligned}
$$

However, activation of epoxide by complexation with a Lewis acid, and followed by nucleophilic attack with conventional mild metal hydrides has been demonstrated to be 
the most convenient and reliable process for producing predominately the less substituted alcohols. ${ }^{169,170}$ The addition of a Lewis acid not only accelerates the rate but also changes the products drastically. $\mathrm{BF}_{3}$ and $\mathrm{Ph}_{3} \mathrm{~B}$ are utilized as an efficient Lewis acid for such activation (Eq. 116 and 117).

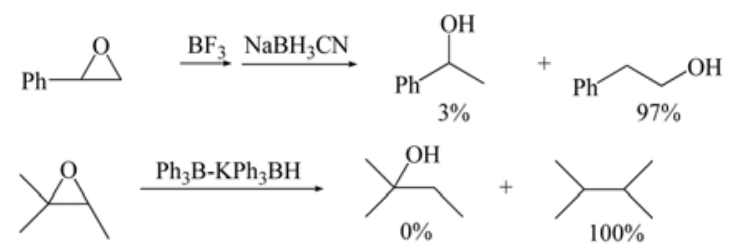

The $\mathrm{BF}_{3}$ effect on the rate enhancement and hence the clean product formation has also been observed in the reduction of epoxides with $\mathrm{BH}_{3} .{ }^{171}$ Thus, the reduction of styrene oxide with $\mathrm{BH}_{3}$ alone provides only $28 \%$ of the expected 2-phenylethanol at $0{ }^{\circ} \mathrm{C}$ in 6 h. ${ }^{167}$ However, the presence of $\mathrm{BF}_{3}$ completely reduces styrene oxide at $0{ }^{\circ} \mathrm{C}$ in less than $0.5 \mathrm{~h}$ to give a clean product (Eq. 118 and 119).

$$
\stackrel{\mathrm{O}}{\frac{\mathrm{BH}_{3}}{0^{\circ} \mathrm{C}, 6 \mathrm{~h}}} \underset{\frac{\mathrm{BH}_{3}-\mathrm{BF}_{3}}{0^{\circ} \mathrm{C}, 0.5 \mathrm{~h}}}{\mathrm{OH}}
$$

The first report on the MPV type reduction of epoxides seems to be the communication which describes the reaction of epoxides with boron isopropoxide. ${ }^{172}$ The reagent is absolutely inert toward aliphatic epoxides such as 1,2epoxybutane, 1,2-epoxyoctane and 1,2-epoxycyclohexane even in refluxing THF for 7 days. On the other hand, the reaction of aromatic epoxides proceeds slowly in refluxing THF to produce exclusively the less substituted alcohols (Eq. 120). In general, the reactivity of boron triisopropoxide

$$
\stackrel{\mathrm{B}\left(\mathrm{O}^{i} \mathrm{Pr}\right)_{3}}{\text { reflux, THF, 7d }}
$$

is much milder than that of aluminum triisopropoxide: the reagent can reduce only aliphatic aldehydes and ketones. However, dichloroisopropoxyborane, a chlorine-incorporated boron alkoxide, shows a higher reactivity than that of boron triisopropoxide. ${ }^{173}$

The fluorine-incorporated diisobutylalane (DIBAF), one of the diisobutylhaloalane derivatives (17), exhibits a high reactivity toward various epoxides to complete the reduction in less than $24 \mathrm{~h}$ at $25^{\circ} \mathrm{C}$. Furthermore, DIBAF achieves the regioselective cleavage of phenyl- or alkyl-substituted epoxides to the less substituted alcohols resulting from anti ring opening. Especially, the reagent attacks only at the phenyl-substituted site where both phenyl and alkyl groups are attached separately at each carbon site of epoxy ring. ${ }^{114}$ (Eq. 121).

$$
\underset{24 \mathrm{~h}}{\frac{\mathrm{DIBAF}}{25^{\circ} \mathrm{C}, 6 \mathrm{~h}}}
$$

Similarly, the newly-devised acetoxy- and methanesulfonylsubstituted diisobutylalane derivatives, such as $A l$-acetoxydiisobutylalane (DIBAOAc, 20), Al-trifluoroacetoxydisiobutylalane (DIBAO $\left.\mathbf{C C F}_{3}, \mathbf{2 1}\right), A l$-methanesulfonyldiisobutylalane (DIBAOSO $\mathbf{C H}_{3}, \mathbf{2 2}$ ), and $\mathrm{Al}$-trifluoromethanesulfonyldiisobutylalane (DIBAOSO $\mathbf{C F}_{3}, \mathbf{2 3}$ ), achieve the regioselective ring opening of epoxides. In general, the reactivity of fluorine-substituted derivatives are much higher than that of the parent unsubstituted derivatives. For example, DIBAOSO $\mathbf{C F}_{3}(\mathbf{2 3})$ can reduce a variety of aliphatic and aromatic epoxides readily at $25^{\circ} \mathrm{C}$ to the ring-opened alcohol products. ${ }^{125,126}$ In this reaction, the less substituted alcohols are produced as a sole product (Eq. 122).

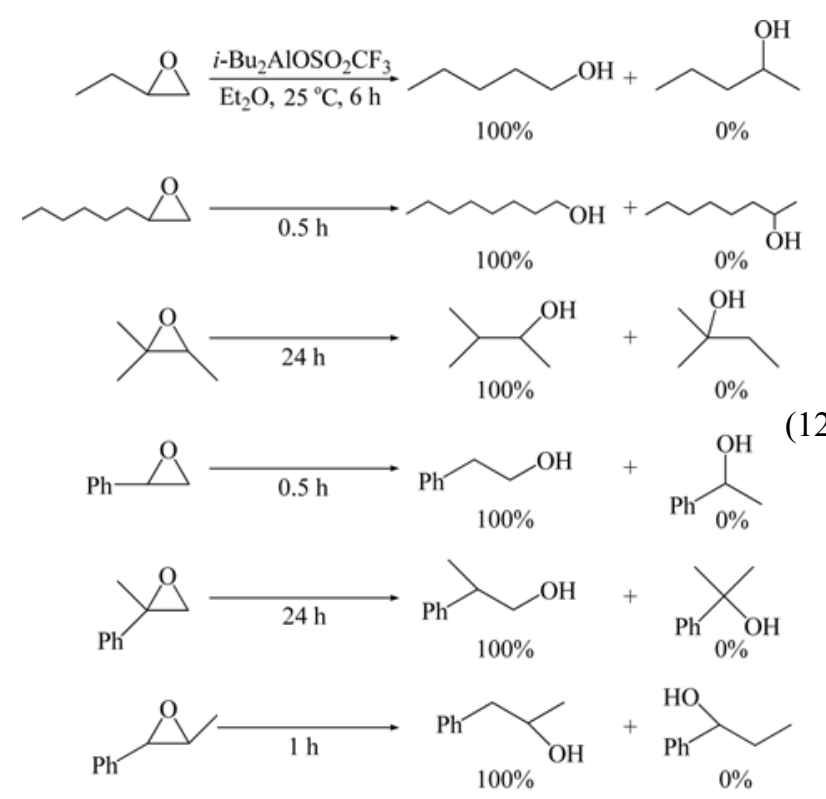

Especially noteworthy is that the results achieved by $\operatorname{DIBAO}_{2} \mathbf{C C F}_{3}(\mathbf{2 1})^{122}$ : the ring-opening reaction is com- 
pleted in less than $1 \mathrm{~h}$ at $0{ }^{\circ} \mathrm{C}$ as in Eq. (123).

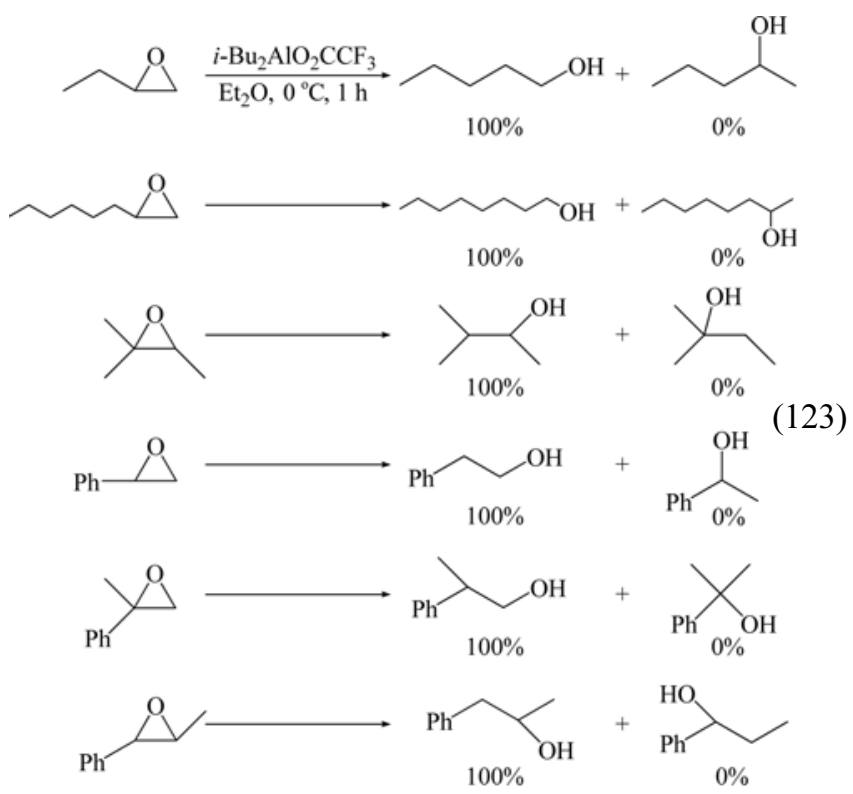

It must be concluded that such a perfect regioselective ring-opening arises from the $\beta$-hydrogen transfer from the reagent only to the more positive carbon of the coordinated epoxy ring (Scheme 24).<smiles>[R]C1CC1(CC(C)(C)C)O[Al](Br)(Cc1ccccc1)OC(F)(F)F</smiles>

Scheme 24

\section{Asymmetric Reactions}

Asymmetric Reduction. The asymmetric reduction of prochiral ketones is carried out with chiral limonylborane ${ }^{174}$ (37) and potassium 9-O-isopinocampheloxy-9-boratabicyclo[3.3.1] nonane ${ }^{175}$ (K9-O-Ipc-9-BBNH, 38) toward several prochiral ketones. The chiral $\mathbf{3 7}$ is prepared by hydroboration of (+)-limonene with $\mathrm{BH}_{3}$ in THF, and the chiral 38 is prepared by reaction of (-)-isopinocampheol with 9-BBN followed by addition of $\mathrm{KH}$ as in Eq. (124) and (125).

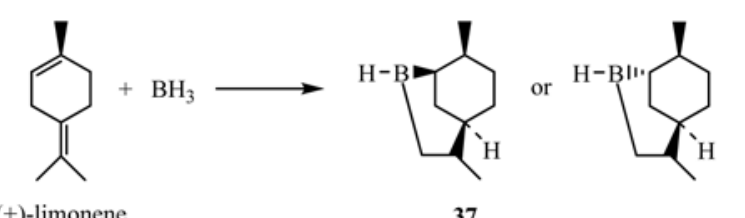

(+)-limonene

$$
37
$$

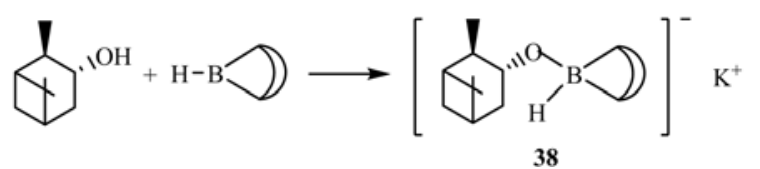

The asymmetric inductions by $\mathbf{3 5}$ are between $4-9 \%$ ee, but all the alcohols obtained from (+)-limonene are consistently enriched in the enantiomer with the $\mathrm{S}$ configuration. However, the reagent $\mathbf{3 6}$ provides good optical induction (30-60\% ee) (Eq. 126).<smiles>[R]C([R])=O</smiles>

Resolution of Racemic Epoxide and Episulfide. The presence of small amount of lithium chloride shows a tremendous rate enhancement in the borane ${ }^{7}$ or alkylborane ${ }^{176}$ reduction of three membered heterocyclic compounds, such as epoxide and episulfide. Such a rate enhancement can be explained by the phenomenon that this system is in equilibrium with lithium chloroborohydrides (basic hydrides) as in Eq. (127) (ref the Eq. 1). The initial coordination of borane species on the oxygen or sulfur atom of the heterocyclic compounds, and followed by the rapid attack of the adduct by the basic hydrides, provides the ring-opened products readily.

$\mathrm{BH}_{3}\left(\mathrm{RBH}_{2}\right.$ or $\left.\mathrm{R}_{2} \mathrm{BH}\right)+\mathrm{LiCl} \rightleftharpoons \mathrm{LiBH}_{3} \mathrm{Cl}\left(\mathrm{LiBH}_{2} \mathrm{Cl}\right.$ or $\left.\mathrm{LiR}_{2} \mathrm{BHCl}\right)$

The chiral diisopinocampheylborane, (-)-Ipc $\mathbf{2} \mathbf{B H}$, is applied to this system. If (-)-Ipc $\mathbf{B H}$ coordinates exclusively on $R$ or $S$-enantiomer in the reaction of racemic mixture, the resolution could be achieved. In fact, the chiral borane coordinates on $R$-1,2-butylene oxide (and on $R$-1-butene

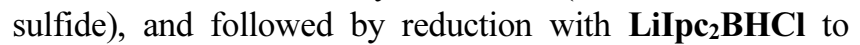
afford the corresponding $R$-2-butanol and $R$-2-butanethiol in $22 \%$ ee and $18 \%$ ee, respectively.

\section{Development of New Hydroborating Agents and Their Application in Organic Synthesis}

Thexylhaloborane-methyl Sulfide. Thexylhaloboranesmethyl sulfide (ThxBHX·SMe $2, \mathbf{X}=\mathrm{Cl}$, Br, I; refer Eq. (7) for preparation)) is an exceptionally valuable reagent for the selective hydroboration of alkenes and alkynes of different
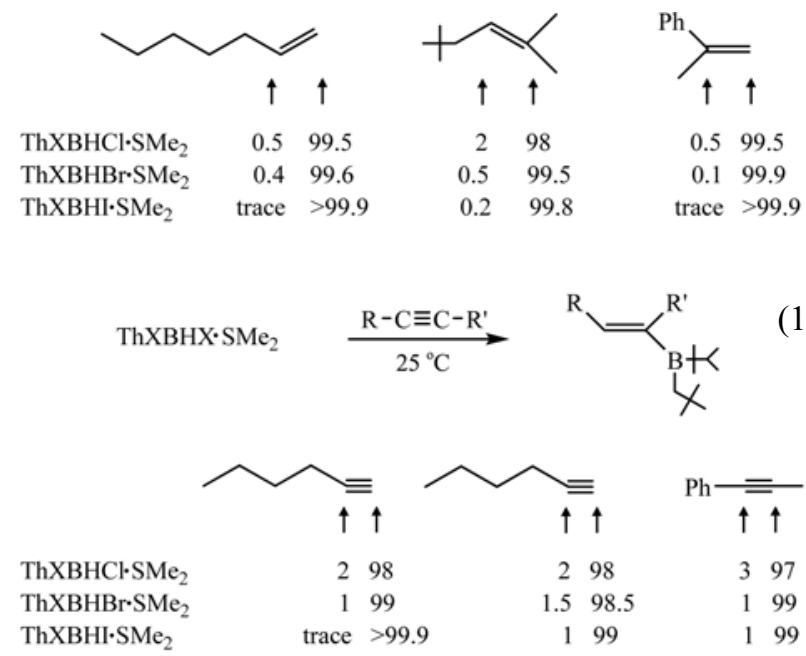
structural types. ${ }^{21,177}$ Especially noteworthy is the hydroboration of alkynes with excess $\mathbf{T h x B H X} \cdot \mathbf{S M e}_{2}$. All the reagents in an excess amount undergo a clean monohydroboration with either internal or terminal alkynes at $25{ }^{\circ} \mathrm{C}$ (Eq. 128).

The relative rate of hydroboration with $\mathbf{T h x B H X} \cdot \mathbf{S M e}_{2}$ toward alkynes depends on the steric and electronic nature of the reagents, as anticipated: ThxBHX $\cdot \mathbf{S M e}_{2}>\mathbf{T h x B H X} \cdot$ $\mathbf{S M e}_{2}>>$ ThxBHX.SMe 2 . The regiospecific hydroboration of $\mathbf{T h x B H X} \cdot \mathrm{SMe}_{2}$ provides a valuable synthetic route to isomerically pure aldehydes and ketones from alkynes as in Eq. (129) and (130).

$$
\begin{aligned}
& \mathrm{HC} \equiv \mathrm{C}\left(\mathrm{CH}_{2}\right)_{4} \mathrm{CH}_{3} \underset{2{ }^{\circ} \mathrm{C}, 12 \mathrm{~h}}{\stackrel{\text { ThXBHI.SMe }}{\longrightarrow}} \stackrel{1 . \mathrm{NaOH}}{2 \text {. buffer }(\mathrm{pH} 7)} \underset{\mathrm{H}_{2} \mathrm{O}}{\longrightarrow} \mathrm{CH}_{3}\left(\mathrm{CH}_{2}\right)_{4} \mathrm{CH}_{2} \mathrm{CHO} \\
& \mathrm{HC} \equiv \mathrm{CPh} \longrightarrow \stackrel{\text { II }}{\longrightarrow} \longrightarrow \stackrel{\text { PhCH}}{\text { IC }-\mathrm{CH}_{3}}
\end{aligned}
$$

Isopinocampheylhaloborane-methyl Sulfide. Quite similarly, isopinocampheylhaloboranes-methyl sulfide (IpcBHX·SMe $, \mathbf{X}=\mathrm{Cl}, \mathrm{Br}$, I; refer Eq. (17) for preparation) also achieves an excellent regioselective hydroboration to alkenes and alkynes. ${ }^{23,178}$ Especially, the iodo derivative monohydrroborates to alkynes in essentially $100 \%$ regioselectivity.

Thexylalkoxyborane. Thexylalkoxyboranes (ThxBHOR) also show a high regioselectivity in the hydroboraton of alkenes and alkynes. ${ }^{179}$ The selectivity appears to be less than that of $\mathbf{T h x B H X} \cdot \mathbf{S M e}_{2}$ and IpcBHX.SMe 2 , but still satisfactory.

Comparison of Directive Effect. Results in the hydroboration of 2-hexyne and 1-phenyl-1-propyne, represen-

Table 7. Directive Effects (\% Substitution) in 1-Substituted Propynes with Various Hydroborating Agents $^{a}$

\begin{tabular}{|c|c|c|c|c|}
\hline \multirow{3}{*}{ Hydroborating reagent } & \multicolumn{4}{|c|}{$\mathrm{R}$} \\
\hline & \multicolumn{2}{|c|}{$n-\operatorname{Pr}$} & \multicolumn{2}{|c|}{$\mathrm{Ph}$} \\
\hline & $\mathrm{b}$ & $\mathrm{a}$ & $\mathrm{b}$ & $\mathrm{a}$ \\
\hline $\mathrm{B}_{2} \mathrm{H}_{6}$ in diglyme ${ }^{b}$ & 40 & 60 & 74 & 26 \\
\hline $\mathrm{ThxBH}_{2}{ }^{b}$ & 39 & 61 & 43 & 57 \\
\hline $\mathrm{HBBr}_{2} \cdot \mathrm{SMe}_{2}^{d}$ & 25 & 75 & 64 & 36 \\
\hline Catecholborane $^{e}$ & 40 & 60 & 27 & 73 \\
\hline 2,2'-biphenoxyborane & 39 & 61 & 16 & 84 \\
\hline 9-BBN & 22 & 78 & 65 & 35 \\
\hline $\mathrm{CHex}_{2} \mathrm{BH}$ & 33 & 67 & 29 & 71 \\
\hline $\mathrm{Sia}_{2} \mathrm{BH}$ & 39 & 61 & 19 & 81 \\
\hline ThxBHCl-SMe 2 & 2 & 98 & 3 & 97 \\
\hline ThxBHBr$\cdot \mathrm{SMe}_{2}$ & 1.5 & 98.5 & 1 & 99 \\
\hline ThxBHI·SMe 2 & 1 & 99 & 1 & 99 \\
\hline $\mathrm{ThxBHO}^{i} \mathrm{Pr}$ & 32 & 68 & 16 & 84 \\
\hline $\mathrm{ThxBHO}^{s} \mathrm{Bu}$ & 11 & 89 & 14 & 86 \\
\hline $\mathrm{IpcBHCl} \cdot \mathrm{SMe}_{2}$ & 8 & 92 & 1 & 99 \\
\hline $\mathrm{IpcBHBr} \cdot \mathrm{SMe}_{2}$ & 4 & 96 & 0.5 & 99.5 \\
\hline $\mathrm{IpcBHI} \cdot \mathrm{SMe}_{2}$ & 2 & 98 & trace & $>99.9$ \\
\hline
\end{tabular}

$$
\mathrm{RC}^{b} \equiv \mathrm{C}^{a} \mathrm{CH}_{3}
$$

${ }^{a}$ At $25{ }^{\circ} \mathrm{C}$, except where otherwise indicated. ${ }^{b}$ At $0{ }^{\circ} \mathrm{C} .{ }^{e} \mathrm{At} 70{ }^{\circ} \mathrm{C}$. tative 1-substituted propyne derivatives, achieved by several common hydroborating agents are listed in Table 7 for comparison. It is clear that the selectivity achieved by both thexy- and isopinocampheylhaloboranes are far superior than that of other common reagents.

\section{Concluding Remarks}

It is evident that the most desirable goal of the chemists working in the field of conversion of organic functional groups is to develop a full scope of selective reducing or/and hydroborating agents which can transform selectively a particular functional group of concern while other functional groups being intact in a polyfunctionalized complex molecule.

There have appeared a variety of reducing systems, including reagents of 'direct' and 'indirect' hydride sources, which can possibly achieve a selective reduction of any organic functional group. However, it should be pointed out that in spite of their abundant choice in literature one should consider carefully which reagent satisfies one's purpose, because each reagent possesses its own limitation.

Besides, as growing the complexity of molecules which chemists are concerning, continuous efforts to develop new methods and new reagents providing a very clean and selective conversion of particular organic functional group are demanding.

Although most chemists seem to pay much less attention to utilize the MPV type reagents than metal complex hydrides apparently due to their narrow diversity in reduction toward organic functional groups, the MPV reagents possess unique reducing characteristics. Because the MPV reduction takes place only after coordination of the reagent to oxygen atom of the compound, the reagents exhibit an exceptional selectivity.

Such a situation also occurs in the synthetic approach utilizing hydroboration procedures. A number of hydroborating agents are now available, but each reagent possesses its own limitation. Therefore, users must consider the selectivity of the reagent in the hydroboration process, because most hydroborating agents operate as a reducing agent as well.

Therefore, this account has attempted to provide some useful informations to chemists who are concerning about the selective reduction of organic functional groups or/and the selective hydroboration of carbon-carbon multiple bonds.

Finally, the author sincerely hopes that this account will meet the goals he has set for it and users find it to be effective in finding efficient and convenient reducing or/and hydroborating agents for their purpose.

Acknowledgments. First of all, the author sincerely thanks the students, who have paid every efforts to accomplish all the publications under the inferior research conditions. They were really diligent and productive. He also acknowledges that most publications were made possible by the financial support of Korea Government and Yeungnam University 
research foundations. Lastly, this account is dedicated to his wife, Sun Young, who has always screwed up his courage with love.

\section{References}

1. Yoon, N. M.; Cha, J. S. J. Korean Chem. Soc. 1977, 21, 108.

2. Brown, H. C.; Krishnamurthy, S. Tetrahedron 1979, 35, 567.

3. Brown, H. C.; Schlesinger, H. I.; Burg, A. B. J. Am. Chem. Soc. 1939, 61, 673 .

4. Kim, J. D.; Park, B. S.; Cha, J. S. J. Natural Sciences 1981, 1, 101.

5. Yoon, N. M.; Oh, I. H.; Choi, K. I.; Lee, H. J. Heterocycles 1984, 22,39 .

6. Yoon, N. M.; Cha, J. S.; Park, W. S. Bull. Korean Chem. Soc. $1983,4,14$

7. Yoon, N. M.; Cha, J. S. J. Korean Chem. Soc. 1978, 22, 37.

8. Yoon, N. M.; Cha, J. S. J. Korean Chem. Soc. 1978, 22, 259.

9. Cha, J. S.; Lee, J. C.; Kim, J. E.; Lee, K. W.; Yoon, M. S. Bull. Korean Chem. Soc. 1987, 8, 304.

10. Cha, J. S.; Kim, J. M.; Lee, J. C.; Lee, H. S. Bull. Korean Chem. Soc. 1991, 12, 612.

11. Brown, H. C.; Cha, J. S.; Nazer, B.; Yoon, N. M. J. Am. Chem. Soc. 1984, 106, 8001.

12. Brown, H. C.; Cha, J. S.; Yoon, N. M.; Nazer, B. J. Org. Chem. 1987, 52,5400 .

13. Brown, H. C.; Nazer, B.; Cha, J. S.; Sikorski, J. A. J. Org. Chem. 1986, $51,5264$.

14. Cha, J. S.; Kim, J. E.; Kim, J. D. Tetrahedron Lett. 1985, 26, 6453.

15. Cha, J. S.; Kim, J. E.; Oh, S. Y. Bull. Korean Chem. Soc. 1987, 8, 313.

16. Cha, J. S.; Kim J. E.; Oh, S. Y.; Lee, J. C.; Lee, K. W. Tetrahedron Lett. 1987, 28, 2389.

17. Cha, J. S.; Kim, J. E.; Lee, K. W. J. Org. Chem. 1987, 52, 5030.

18. Cha, J. S.; Oh, S. Y.; Kim, J. E. Bull. Korean Chem. Soc. 1987, 8, 301.

19. Cha, J. S.; Lee, K. W.; Yoon, M. S.; Lee, J. C. Bull. Korean Chem. Soc. 1988, 9, 384.

20. Cha, J. S.; Brown, H. C. Bull. Korean Chem. Soc. 2005, 26, 292.

21. Cha, J. S.; Min, S. J.; Kim, J. M. Bull. Korean Chem. Soc. 1994, $15,478$.

22. Cha, J. S.; Min S. J.; Kim, J. M.; Kwon, O. O.; Jeoung, M. K. Org. Prep. Proced. Int. 1993, 25, 466.

23. Cha, J. S.; Min, S. J.; Kim, J. M.; Kwon, O. O.; Kim, E. J. Bull. Korean Chem. Soc. 1995, 16. 37.

24. Cha, J. S.; Chang, S. W.; Kim, J. M.; Kwon, O. O.; Chun, J. H.; Cho, S. D.; Lee, H. S. Org. Prep. Proced. Int. 1998, 30, 63.

25. Cha, J. S.; Chang, S. W.; Kim, J. M.; Kwon, O. O.; Chun, J. H.; Cho, S. D. Bull. Korean Chem. Soc. 1998, 19, 243.

26. Cha, J. S.; Chang, S. W.; Kim, J. M.; Know, O. O.; Lee, J. C. Org. Prep. Proced. Int. 1997, 29, 665.

27. Brown, H. C.; Cha, J. S.; Nazer, B. Inorg. Chem. 1984, 23, 2929.

28. Brown, H. C.; Cha, J. S.; Nazer, B.; Kim, S.-J.; Krishnamurthy, S. J. Org. Chem. 1984, 49, 885.

29. Brown, H. C.; Nazer, B.; Cha, J. S. Synthesis 1984, 498.

30. Cha, J. S.; Kim, J. E.; Lee, J. C.; Yoon, M. S. Bull. Korean Chem. Soc. 1986, 7, 66.

31. (a) Brown, H. C.; Cha, J. S.; Nazer, B. J. Org. Chem. 1985, 50, 549. (b) Brown, H. C.; Cha, J. S.; Nazer, B. J. Org. Chem. 1984, 49, 2073.

32. Cha, J. S.; Yoon, M. S.; Lee, K. W.; Lee, J. C. Heterocycles 1988 , 27, 1455.

33. Cha, J. S.; Yoon, M. S.; Kim, Y. S.; Lee, K. W. Tetrahedron Lett. 1988, 29, 1069.

34. Cha, J. S.; Yoon, M. S.; Lee, K. W.; Lee, J. C. Bull. Korean Chem. Soc. 1989, 10, 75.
35. Cha, J. S.; Yoon, M. S. Tetrahedron Lett. 1989, 30, 3677.

36. Brown, H. C.; Park, W. S.; Cha, J. S.; Cho, B. T. J. Org. Chem. 1986, $51,337$.

37. Cha, J. S.; Lee, S. E. Bull. Korean Chem. Soc. 1992, 13, 531.

38. (a) Cha, J. S.; Lee, D. Y. Bull. Korean Chem. Soc. 2002, 23, 856 (b) Cha, J. S.; Lee, D. Y.; Moon, S. J. Bull. Korean Chem. Soc. 2001, 22, 661.

39. Cho, S. D.; Lim, H. J.; Kim, H. J.; Cha, J. S. Bull. Korean Chem. Soc. 2002, 23, 1695.

40. Cha, J. S.; Brown, H. C. J. Org. Chem. 1993, 58, 4727.

41. Cha, J. S.; Brown, H. C. Org. Prep. Proced. Int. 1994, 26, 459.

42. Cha, J. S.; Brown, H. C. J. Org. Chem. 1993, 58, 4732.

43. Cha, J. S.; Kwon, S. Y.; Kim, J. M.; Kwon, O. O.; Lee, K. W. Bull. Korean Chem. Soc. 1999, 20, 737.

44. Cha, J. S.; Yu, S. J.; Roh, M. Y.; Yi, J. E.; Park, S. J.; Kwon, O. O Bull. Korean Chem. Soc. 2008, 29, 2379.

45. Cha, J. S.; Yu, S. J. Bull. Korean Chem. Soc. 2009, 30, 1588.

46. (a) Brown, H. C.; Yoon, N. M. J. Am. Chem. Soc. 1966, 88, 1484. (b) Yoon, N. M.; Brown, H. C. Ibid. 1968, 90, 2927.

47. Cha, J. S.; Brown, H. C. J. Org. Chem. 1993, 58, 3974.

48. Cha, J. S.; Kwon, O. O.; Kim, J. M. Bull. Korean Chem. Soc. 1994, 15, 132.

49. Cha, J. F.; Kwon, O. O.; Lee, J. C.; Kim, J. M. Bull. Korean Chem. Soc. 1994, 15, 644.

50. Cha, J. S.; Lee, K. D.; Kwon, O. O.; Kim, J. M.; Lee, H. S. Bull. Korean Chem. Soc. 1995, 16, 561.

51. Cha, J. S.; Moon, S. J. Bull. Korean Chem. Soc. 2002, 23, 1340.

52. Yoon, N. M.; Gyoung, Y. S. J. Org. Chem. 1985, 50, 2443.

53. Cha, J. S.; Jeong, M. K.; Kwon, O. O.; Lee, K. D.; Lee, H. S. Bull. Korean Chem. Soc. 1994, 15, 873.

54. Cha, J. S.; Kwon, O. O.; Jeoung, M. K.; Kim, E. J. Bull. Korean Chem. Soc. 1994, 15, 1021.

55. Cha, J. S.; Chang, S. W.; Kwon, O. O.; Kim, J. M. Synlett 1996, 165.

56. Cha, J. S.; Chang, S. W.; Lee, J. E.; Kim, J. M.; Kwon, O. O.; Lee, H. S.; Song, H. C. Bull. Korean Chem. Soc. 1996, 17, 720.

57. Cha, J. S.; Lee, J. C.; Kim, J. M.; Jeong, S. W.; Park, K. S.; Lee, S. E.; Lee, H. S. Bull. Korean Chem. Soc. 1992, 13, 581.

58. Cha, J. S.; Lee, J. C. Bull. Korean Chem. Soc. 1993, 14, 469.

59. Cha, J. S.; Lee, S. E.; Lee, H. S. Bull. Korean Chem. Soc. 1991, $12,644$.

60. Cha, J. S.; Kwon, O. O.; Lee, J. C. Bull. Korean Chem. Soc. $1993,14,743$.

61. Cha, J. S.; Lee, J. C.; Ju, Y. C. Bull. Korean Chem. Soc. 1997, 18 , 890.

62. Cha, J. S.; Min, S. J.; Lee, J. C.; Lee, H. S.; Lee, S. E. Org. Prep. Proced. Int. 1992, 24, 335.

63. Cha, J. S. Bull. Korean Chem. Soc. 1992, 13, 670.

64. Cha, J. S.; Lee, J. C.; Lee, J. C.; Lee, H. S.; Lee, S. E.; Kim, J. M.; Kwon, O. O.; Min, S. J. Tetrahedron Lett. 1991, 32, 6903.

65. Cha, J. S.; Lee, J. C.; Lee, H. S.; Lee, S. E. Bull. Korean Chem. Soc. 1991, 12, 598 .

66. Cha, J. S.; Lee, S. E. Bull. Korean Chem. Soc. 1992, 13, 451,

67. Cha, J. S.; Lee, S. E.; Lee, H. S. Org. Prep. Proced. Int. 1992, 24, 331.

68. Cha, J. S.; Kim, J. M.; Jeoung, M. K; Lee, K. D. Bull. Korean Chem. Soc. 1992, 13, 702.

69. Cha, J. S.; Jeoung, M. K.; Kim, J. M.; Kwon, O. O.; Lee, K. D.; Kim, E. J. Bull. Korean Chem. Soc. 1994, 15, 881.

70. Cha, J. S.; Kim, J. M.; Jeoung, M. K.; Kwon, O. O.; Kim, E. J. Org. Prep. Proced. Int. 1995, $27,95$.

71. Cha, J. S.; Kim, J. M.; Jeoung, M. K. Bull. Korean Chem. Soc. 1994, 15, 708 .

72. Cha, J. S.; Jeoung, M. K.; Kim, J. M.; Kwon, O. O.; Lee, J. C. Org. Prep. Proced. Int. 1994, 26, 583.

73. Cha, J. S.; Jang, S. H.; Kwon, S. Y. Bull. Korean Chem. Soc. 2002, 23, 1695.

74. Cha, J. S.; Jang, S. H.; Park, J. H.; Kim, S. K.; Lee, C. S.; Lee, Y. 
R. Bull. Korean Chem. Soc. 2003, 24, 9.

75. Cha, J. S.; Yu, S. J. J. Incl. Phenom. Macrocycl. Chem. 2009, 65, 7.

76. Cha, J. S.; Kim, J. E.; Yoon, M. S.; Kim, Y. S. Tetrahedron Lett. 1987, 28, 6231 .

77. Cha, J. S.; Kim, J. E.; Oh, S. Y.; Kim, J. D. Tetrahedron Lett. 1987, 28, 4575.

78. Cha, J. S.; Oh, S. Y.; Lee, K. W.; Yoon, M. S.; Lee, J. C.; Kim, J. E. Bull. Korean Chem. Soc. 1988, 9, 48.

79. Cha, J. S.; Lee, J. C.; Yoon, M. S.; Seo, J. B.; Kim, J. M. Bull. Korean Chem. Soc. 1987, 11, 76.

80. Cha, J. S.; Lee, J. C.; Lee, H. S.; Lee, S. E. Org. Prep. Proced. Int. 1992, 24, 285.

81. Brown, H. C.; Kulkarni, S. V.; Rao, C. G. Synthesis 1979, 702.

82. Cha, J. S.; Kim, M.-G.; Kim, J. M.; Kwon, O. O.; Chun, J. H.; Cho, S. D. Bull. Korean Chem. Soc. 1998, 19, 724.

83. Cha, J. S.; Kim, J. M.; Chun, J. H.; Kwon, O. O.; Lee, J. C. Bull. Korean Chem. Soc. 1998, 19, 730.

84. Cha, J. S.; Chun, J. H.; Kim, J. M.; Kwon, O. O.; Kwon, S. Y.; Lee, J. C. Bull. Korean Chem. Soc. 1999, 20, 400.

85. Cha, J. S.; Lee, D. Y.; Kim, J. M. Org. Prep. Proced. Int. 1999, 31,694 .

86. Cha, J. S.; Oh, S. Y.; Lee, K. W.; Yoon, M. S.; Lee, J. C. Heterocycles 1988, 27, 1595.

87. Cha, J. S.; Lee, K. W.; Yoon, M. S.; Lee, J. C. Bull. Korean Chem. Soc. 1988, 9, 384.

88. Cha, J. S.; Park, J. H.; Lee, D. Y. Bull. Korean Chem. Soc. 2001, $22,325$.

89. Cha, J. S.; Park, J. H.; Moon, S. J. Bull. Korean Chem. Soc. 2001, $22,1089$.

90. Cha, J. S.; Kim, J. M.; Chun, J. H.; Kwon, O. O.; Kwon, S. Y.; Han, S. W. Org. Prep. Proced. Int. 1999, 31, 204.

91. Cha, J. S.; Chun, J. H. Bull. Korean Chem. Soc. 1999, 20, 375.

92. Cha, J. S.; Lee, D. Y. Bull. Korean Chem. Soc. 2000, 21,1260

93. Cha, J. S.; Kim, J. M.; Chun, J. H.; Kwon, O. O.; Kwon, S. Y.; Cho, S. D. Bull. Korean Chem. Soc. 1998, 19, 1301.

94. Cha, J. S.; Chun, J. H.; Kim, J. M.; Lee, D. Y.; Cho, S. D. Bull. Korean Chem. Soc. 1999, 20, 1373.

95. Cha, J. S.; Lee, S. E.; Lee, H. S.; Lee, J. C.; Kim, J. M.; Kwon, O. O.; Min, S. J. Bull. Korean Chem. Soc. 1992, 13, 338.

96. Cha, J. S. Org. Prep. Proced. Int. 1989, $21,451$.

97. Cha, J. S. Org. Proc. Res. Devel. 2006, 10, 1032.

98. Cha, J. S. Bull. Korean Chem. Soc. 2007, 28, 2162.

99. Schlesinger, H. I.; Brown, H. C.; Hoekstra, H. R.; Rapp, L. R. J. Am. Chem. Soc. 1953, 75, 199.

100. Finholt, A. E.; Bond, A. C., Jr.; Schlesinger, H. I. J. Am. Chem. Soc. 1947, 69, 1199.

101. (a) Verley, A. Bull. Soc. Chim. Fr. 1925, 37, 537, 871. (b) Verley, A. Bull. Soc. Chim. Fr. 1927, 41, 788.

102. Meerwein, H.; Schmidt, R. Liebigs Ann. 1925, 444, 221.

103. Ponndorf, W. Z. Angew. Chem. 1926, 39, 138.

104. Lund, H. Dtsch. Chem. Ges. 1937, 70, 1520.

105. Meerwein, H.; Hinz, G.; Majert, H.; Sönke, H. J. Prakt. Chem. 1936, 147, 226.

106. (a) Ziegler, K.; Schneider, K. Justus Liebigs Ann. Chem. 1959, 623, 9. (b) Ziegler, K.; Schneider, K.; Schneider, J. Angew. Chem. 1955, 67, 425. (c) Haeck, H. H.; Kralt, T. Rec. Trav. Chim. PaysBas 1966, 85, 343.

107. (a) Mikhailov, B. M.; Kiselev, V. G.; Bubnov, Y. N. Izv. AN SSSR, Ser. Khim. 1965, 898. (b) Mikhailov, B. M.; Bubnov, Y. N.; Kiselev, V. G. Zh. Obsh. Khim. 1965, 36, 62; translated into, J. Gen. Chem. USSR 1966, 36, 65.

108. (a) Midland, M. M.; Tramontano, A.; Zderic, S. A. J. Organometal. Chem. 1977, 134, C17. (b) Midland, M. M.; Tramontano, A.; Zderic, S. A. 1978, 156, 203.

109. Midland, M. M.; Tramontano, A. J. Org. Chem. 1978, 43, 1470.

110. (a) Chandrasekharan, J.; Ramachandran, P. V.; Brown, H. C. J. Org. Chem. 1985, 50, 5446. (b) Brown, H. C.; Ramachandran, P.
V.; Chandrasekharan, Heteroatom Chem. 1995, 6, 117.

111. Cha, J. S.; Kwon, O. O.; Kwon, S. Y.; Kim, J. M.; Seo, W. W.; Chang, S. W. Synlett 1995, 1055.

112. Cha, J. S.; Kwon, O. O.; Kwon, S. Y. Bull. Korean Chem. Soc. 1995, 16, 1009.

113. Cha, J. S.; Park, S. J.; Yu, S. J.; Kim, S. K.; Kwon, O. O. Bull. Korean Chem. Soc. 2008, 29, 301.

114. (a) Cha, J. S.; Park, S. J; Yu, S. J.; Kim, S. K.; Kwon, O. O. Bull. Korean Chem. Soc. 2008, 29, 301. (b) Cha, J. S.; Park, S. J. J. Chosun Natural Science 2009, 2, 185.

115. Cha, J. S.; Kwon, O. O.; Kwon, S. Y. Org. Prep. Proced. Int. 1996, 28,355 .

116. Cha, J. S.; Kwon, O. O. J. Org. Chem. 1997, 62, 3019.

117. Cha, J. S.; Kwon, O. O. Bull. Korean Chem. Soc. 1997, 18, 689.

118. Cha, J. S.; Kwon, O. O.; Kim, J. M.; Chun J. H.; Lee, Y. S.; Lee, H. S.; Cho, S. D. Bull. Korean Chem. Soc. 1998, 19, 236.

119. Cha, J. S.; Kwon, S. Y.; Kwon, O. O.; Kim, J. M.; Song, H. C Bull. Korean Chem. Soc. 1996, 17, 900.

120. Kwon, O. O.; Cha, J. S. Bull. Korean Chem. Soc. 2000, 21, 659.

121. Cha, J. S.; Lee, K. W. J. Natural Sciences 2002, 22, 53.

122. Cha, J. S.; Yi, J. E. J. Incl. Phenom. Macrocycl. Chem. 2009, 65, 15 .

123. Cha, J. S.; Park, S. J. Bull. Korean Chem. Soc. 2009, 30, 2823.

124. Cha, J. S.; No, M. Bull. Korean Chem. Soc. 2010, 31, 840.

125. Cha, J. S.; Park, S. J. Bull. Korean Chem. Soc. 2010, 31, 2135.

126. Cha, J. S.; Bull. Korean Chem. Soc. 2011, 32, 219.

127. Brown, H. C.; Kramer, G. W.; Levy, A. B.; Midland, M. M. Organic Synthesis via Boranes; Wiley-Interscience: New York, 1975.

128. (a) Chandrasekharan, J.; Ramachandran, P. V.; Brown, H. C. J. Org. Chem. 1985, 50, 5446. (b) Brown, H. C.; Park, W. S.; Cho, B. T.; Ramachandran, P. V. J. Org. Chem. 1987, 52, 5406.

129. Brown, H. C.; Srebnik, M.; Ramachandran, P. V. J. Org. Chem. 1989, 54, 1577.

130. Brown, H. C.; Ramachandran, P. V. J. Org. Chem. 1989, 54, 4504.

131. Brown, H. C.; Ramachandran, P. V.; Chandrasekharan, J. Heteroatom Chem. 1995, 6, 117.

132. Cha, J. S.; Kim, E. J.; Kwon, O. O.; Kim, J. M. Bull. Korean Chem. Soc. 1996, 17, 50.

133. Cha, J. S.; Kwon, O. O.; Lee, K. W.; Kim, J. M. Bull. Korean Chem. Soc. 2005, 26, 652.

134. Cha, J. S.; Kim, E. J.; Kwon, O. O.; Kwon, S. Y.; Seo, W. W.; Chang, S. W. Org. Prep. Proced. Int. 1995, 27, 541.

135. Cha, J. S.; Kim, E. J.; Kwon, O. O.; Kim, J. M. Bull. Korean Chem. Soc. 1995, 16, 691.

136. Cha, J. S.; Kwon, O. O.; Kim, J. M. Bull. Korean Chem. Soc. 1996, 17,725 .

137. Cha, J. S.; Jang, S. H.; Kwon, S. Y.; Kwon, O. O. Bull. Korean Chem. Soc. 2004, 25, 603.

138. Cha, J. S.; Nam, H. T.; Kwon, S. Y.; Park, S. J.; Kwon, O. O. Bull. Korean Chem. Soc. 2004, 25, 1948.

139. Cha, J. S.; Nam, H. T.; Park, S. J.; Kwon, S. Y.; Kwon, O. O. Bull. Korean Chem. Soc. 2006, 27, 667.

140. Cha, J. S. Bull. Korean Chem. Soc. 2009, 30, 1658.

141. Cha, J. S.; Park, J. H. Bull. Korean Chem. Soc. 2002, 23, 1051.

142. Cha, J. S.; Park, J. H. Bull. Korean Chem. Soc. 2002, 23, 1377.

143. Cha, J. S.; Yu, S. J.; Roh, M. Y.; Park, S. J.; Yi, J. E.; Kwon, O. O. Bull. Korean Chem. Soc. 2008, 29, 885.

144. Cha, J. S.; Park, S. J.; Kwon, O. O. Unpublished results.

145. Cha, J. S.; Kwon, O. O.; Kwon, S. Y. Bull. Korean Chem. Soc. 1995, 16, 1009.

146. Cha, J. S.; Kwon, O. O.; Kwon, S. Y. Org. Prep. Proced. Int. 1996, 28, 355.

147. Cha, J. S.; Kwon, O. O.; Kim, J. M.; Chun, J. H.; Lee, Y. S.; Lee, H. S.; Cho, S. D. Bull. Korean Chem. Soc. 1998, 19, 236.

148. Cha, J. S.; Kwon, S. Y; Kwon, O. O.; Kim, J. M.; Song, H. Bull. Korean Chem. Soc. 1996, 17, 900.

149. Cha, J. S.; Nam, H. T.; Kwon, O. O. Unpublished results. 
150. Cha, J. S.; Kim, E. J.; Kwon, O. O.; Kim, J. M. Bull. Korean Chem. Soc. 1994, 15, 1033.

151. Cha, J. S.; Nam, H. T.; Jang S. H.; Kwon, S. Y.; Park, S. J.; Kwon, O. O. Bull. Korean Chem. Soc. 2004, 25, 1948.

152. Cha, J. S.; Nam, H. T.; Park, S. J.; Kwon, S. Y.; Kwon, O. O. Bull. Korean Chem. Soc. 2006, 27, 667.

153. (a) Krishnamurthy, S.; Brown, H. C. J. Am. Chem. Soc. 1976, 98 , 3383. (b) Brown, H. C.; Cha, J. S.; Nazer, B. J. Org. Chem. 1984, 49, 2073.

154. Brown, H. C.; Krishnamurthy, S. J. Am. Chem. Soc. 1972, 94, 7159.

155. For other stereoselective reducing agents to produce the less stable alcohols and related reviews, see: (a) Corey, E. J.; Becker, K. B.; Varma, R. K. J. Am. Chem. Soc. 1972, 94, 8616. (b) Corey, E. J.; Albonico, S. M.; Koelliker, U.; Schaaf, T. K.; Varma, R. K. J. Am. Chem. Soc. 1971, 93, 1491. (c) Corey, E. J.; Varma, R. K. J. Am. Chem. Soc. 1971, 93, 7319. (d) Brown, H. C.; Kramer, G. W.; Hubbard, J. L.; Krishnamurthy, S. J. Organomet. Chem. 1980, 188, 1. (f) Cha, J. S.; Min, S. J.; Kim, J. M.; Kwon, O. O.; Jeoung, M. K. Org. Prep. Proced. Int. 1993, 25, 444. (g) Krishnamurthy, S. Aldrichimica Acta 1974, 7, 55. (h) Brown, C. A.; Krishnamurthy, S. J. Organomet. Chem. 1978, 156, 111. (i) Brown, H. C.; Krishnamurthy, S. Tetrahedron 1979, 35, 567.

156. Cha, J. S.; Kwon, O. O.; Lee, K. W.; Kim, J. M. Bull. Korean Chem. Soc. 2005, 26, 652.

157. Cha, J. S.; Kwon, O. O. J. Org. Chem. 1997, 62, 3019.

158. Cha, J. S.; Kwon, O. O. Bull. Korean Chem. Soc. 1997, 18, 689.

159. Ashby, E. C.; Yu, S. H. J. Org. Chem. 1970, 35, 1034.

160. (a) Heinsohn, G. E.; Ashby, E. C. J. Org. Chem. 1973, 38, 4232. (b)Winterfeldt, E. Synthesis 1975, 617.

161. Kwon, O. O.; Cha, J. S. Bull. Korean Chem. Soc. 2000, 21, 659.

162. Cha, J. S.; Kwon, O. O.; Kim, J. M.; Cha, S. D. Synlett 1997,
1465

163. Cha, J. S.; Moon, S. J.; Kwon, O. O.; Lee, Y. R. Bull. Korean Chem. Soc. 2000, 21, 128.

164. Cha, J. S.; Moon, S. J.; Park, J. H. J. Org. Chem. 2001, 66, 7514.

165. Brown, H. C.; Weissman, P. M.; Yoon, N. M. J. Am. Chem. Soc. 1966, 88, 1458.

166. Krishnamurthy, S.; Schubert, R. M.; Brown, H. C. J. Am. Chem. Soc. 1973, 95, 8486.

167. Brown, H. C.; Heim, P.; Yoon, N. M. J. Am. Chem. Soc. 1970, 92 , 1637.

168. (a) Brown, H. C.; Yoon, N. M. J. Am. Chem. Soc. 1966, 88, 1464. (b) Yoon, N. M.; Brown, H. C. J. Am. Chem. Soc. 1968, 90, 2927. 147. (c) Hutchins, R. O.; Taffer, I. M.; Burgoyne, W. J. Org. Chem. 1981, 46, 5214.

169. Hutchins, R. O.; Taffer, I. M.; Burgoyne, W. J. Org. Chem. 1981, 46, 5214.

170. Yoon, N. M.; Kim, K. E. J. Org. Chem. 1987, 52, 5564.

171. Brown, H. C.; Yoon, N. M. Chem. Commun. 1968, 1549.

172. Cha, J. S.; Park, J. H. Bull. Korean Chem. Soc. 2002, 23, 1377.

173. Cha, J. S.; Yu, S. J.; Roh, M. Y.; Park, S. J.; Yi, E. J.; Kwon, O. O. Bull Korean Chem. Soc. 2009, 29, 885.

174. Kim, J. D.; Kim, J. E.; Cha, J. S. Bull. Korean Chem. Soc. 1982, $3,130$.

175. Park, W. S.; Cho, B. T.; Cha, J. S. Bull. Korean Chem. Soc. 1987, 8,10 .

176. Yoon, M. N.; Cha, J. S. Unpublished results.

177. Cha, J. S.; Min, S. J.; Kim, J. M.; Kwon, O. O. Tetrahedron Lett. $1993,34,5113$.

178. Cha, J. S.; Min, S. J.; Kim, J. M.; Kwon, O. O.; Kim, E. J. Bull. Korean Chem. Soc. 1994, 15, 687.

179. Cha, J. S.; Seo, W. W.; Kim, J. M.; Kwon, O. O. Bull. Korean Chem. Soc. 1996, 17, 892. 